\title{
Invisible lives
}

Citation for published version (APA):

Gupta, S. (2021). Invisible lives: Tales of people with severe disabilities living in rural India. [Doctoral Thesis, Maastricht University]. Global Academic Press. https://doi.org/10.26481/dis.20210112sg

Document status and date:

Published: 01/01/2021

DOI:

10.26481/dis.20210112sg

Document Version:

Publisher's PDF, also known as Version of record

\section{Please check the document version of this publication:}

- A submitted manuscript is the version of the article upon submission and before peer-review. There can be important differences between the submitted version and the official published version of record.

People interested in the research are advised to contact the author for the final version of the publication, or visit the DOI to the publisher's website.

- The final author version and the galley proof are versions of the publication after peer review.

- The final published version features the final layout of the paper including the volume, issue and page numbers.

Link to publication

\footnotetext{
General rights rights.

- You may freely distribute the URL identifying the publication in the public portal. please follow below link for the End User Agreement:

www.umlib.nl/taverne-license

Take down policy

If you believe that this document breaches copyright please contact us at:

repository@maastrichtuniversity.nl

providing details and we will investigate your claim.
}

Copyright and moral rights for the publications made accessible in the public portal are retained by the authors and/or other copyright owners and it is a condition of accessing publications that users recognise and abide by the legal requirements associated with these

- Users may download and print one copy of any publication from the public portal for the purpose of private study or research.

- You may not further distribute the material or use it for any profit-making activity or commercial gain

If the publication is distributed under the terms of Article $25 \mathrm{fa}$ of the Dutch Copyright Act, indicated by the "Taverne" license above, 


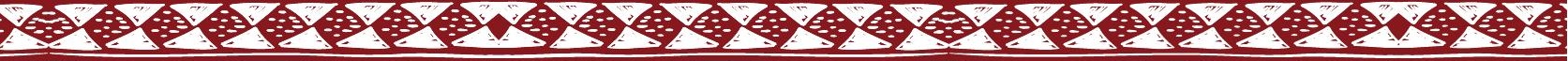

S

\section{INVISIBLE LIVES}

Tales of people with severe disabilities

living in rural India

Shivani Gupta

enenenenenenenenen

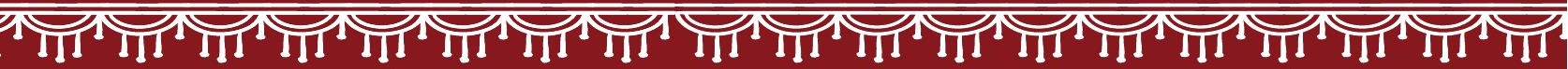

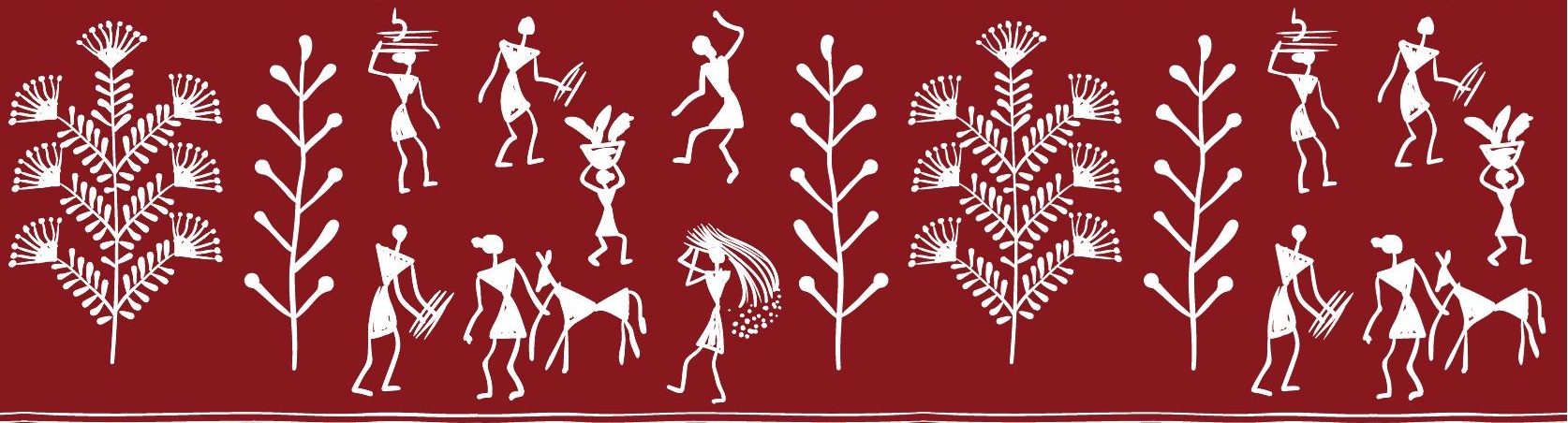

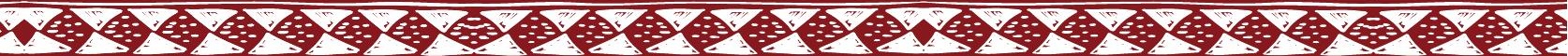





\section{Invisible lives}

\section{Tales of people with severe disabilities living in rural India}

Shivani Gupta 
Invisible lives: Tales of people with severe disabilities living in rural India

\section{Shivani Gupta}

ISBN: 978-94-6423-066-6

Publisher: Global Academic Press

Format: Paperback / softback

The book cover is inspired by Warli Art, a tribal art form, from India. Warli paintings are mostly made on the hut walls and they depict the day-to-day activities of the village people.

(a)copyright Shivani Gupta, Maastricht, 2020

All rights are reserved. No part of this book may be reproduced or transmitted in any form or by any means, without the written permission from the author or, where appropriate, the publisher of the article. 


\section{Invisible lives}

\section{Tales of people with severe disabilities living in rural India}

\section{DISSERTATION}

to obtain the degree of Doctor at the Maastricht University, on the authority of the Rector Magnificus,

Prof.dr. Rianne M. Letschert

in accordance with the decision of the Board of Deans, to be defended in public on Tuesday 12 January 2021, at 13.00 hours

by

Shivani Gupta 


\section{Promotors}

Dr. A. Meershoek

Prof.dr. L.P. de Witte

\section{Members of the Assessment Committee}

Prof.dr. J.S.M. Krumeich (Chair)

Prof.dr. A.E. de Rijk

Prof.dr. A. Ghai (School of Human Studies, Ambedkar University Delhi, India)

Dr. E.A.A. Rameckers

Dr. W. Zhang (GATE, Geneva, Switzerland)

The research presented in this thesis was conducted at the Department of health, ethics $\&$ society Faculty of health, Research school CAPHRI at the University of Maastricht.

This research is undertaken under the NUFFIC Fellowship Award awarded to Shivani Gupta (2016 - 2020) to carry out PhD studies at the University of Maastricht. 
This book is dedicated

to my parents 
Table of Contents

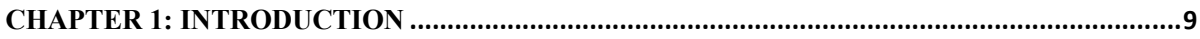

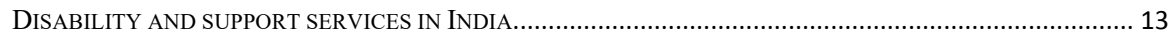

PROBLEMATISING SUPPORT SERVICES IN THE CONTEXT OF INDIA ..................................................... 15

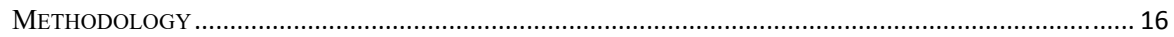

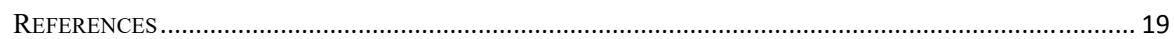

CHAPTER 2: USING THE CAPABILITY APPROACH TO STUDY THE SUCCESSES AND

CHALLENGES IN OPERATIONALISING THE UN CRPD .................................................23

ABSTRACT

CHAPTER 3: DIMENSIONS OF INVISIBILITY: INSIGHTS INTO THE DAILY REALITIES OF PERSONS WITH DISABILITIES LIVING IN RURAL COMMUNITIES IN INDIA ............59

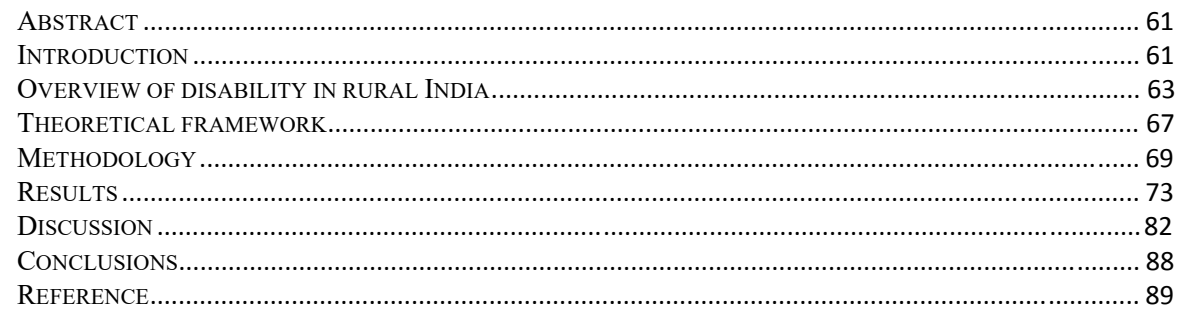

CHAPTER 4: WOMEN'S CAPABILITIES AND THE CHALLENGES OF CARING FOR PERSONS WITH DISABILITIES: EXPERIENCES FROM RURAL AREAS OF ANDHRA

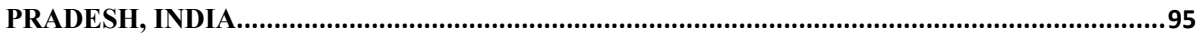

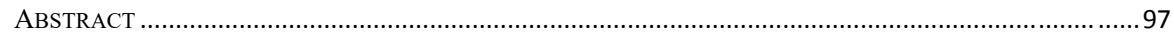

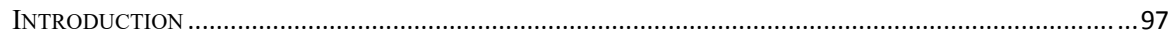

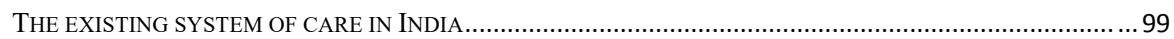

THEORIZING CARE WORK THROUGH THE CAPABILITY APPROACH ...................................................... 102

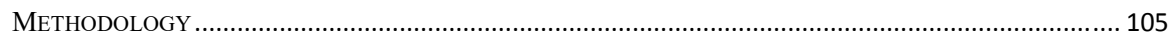

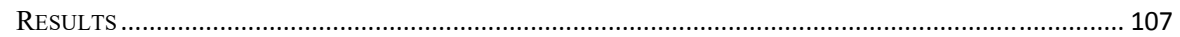

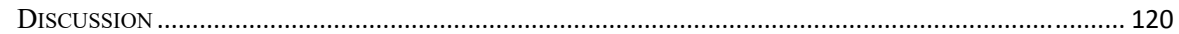

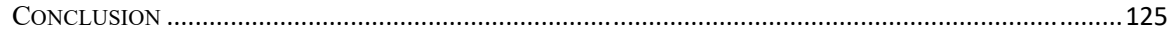

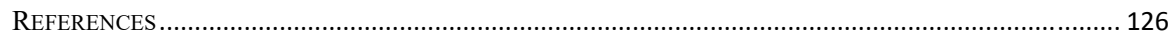

CHAPTER 5: BARRIERS TO USING MOBILITY DEVICES IN RURAL HOMES IN LOW RESOURCE SETTINGS: DEVELOPMENT OF A PRACTICAL ASSESSMENT TOOL FOR

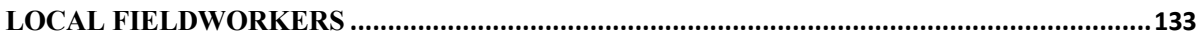

ABSTRACT 
CHAPTER 6: DISCUSSION \& CONCLUSION

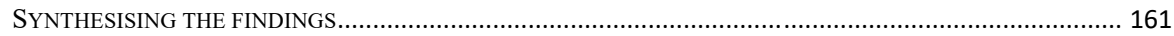

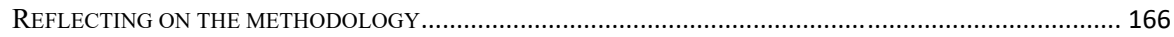

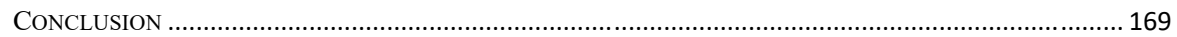

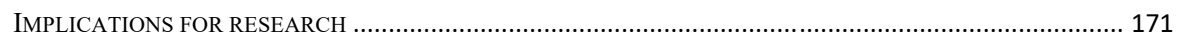

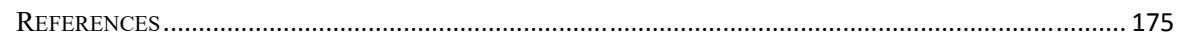

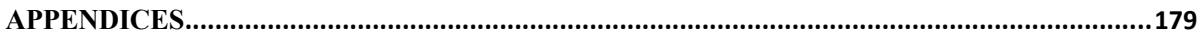

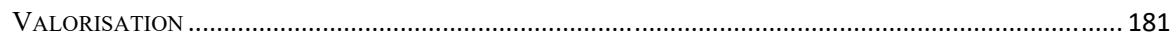

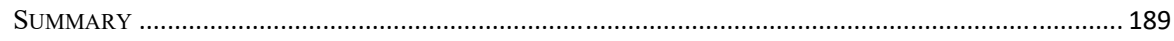

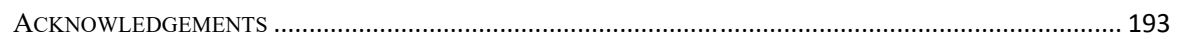

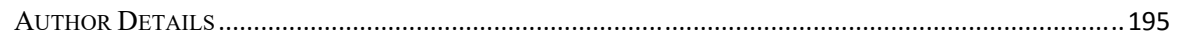




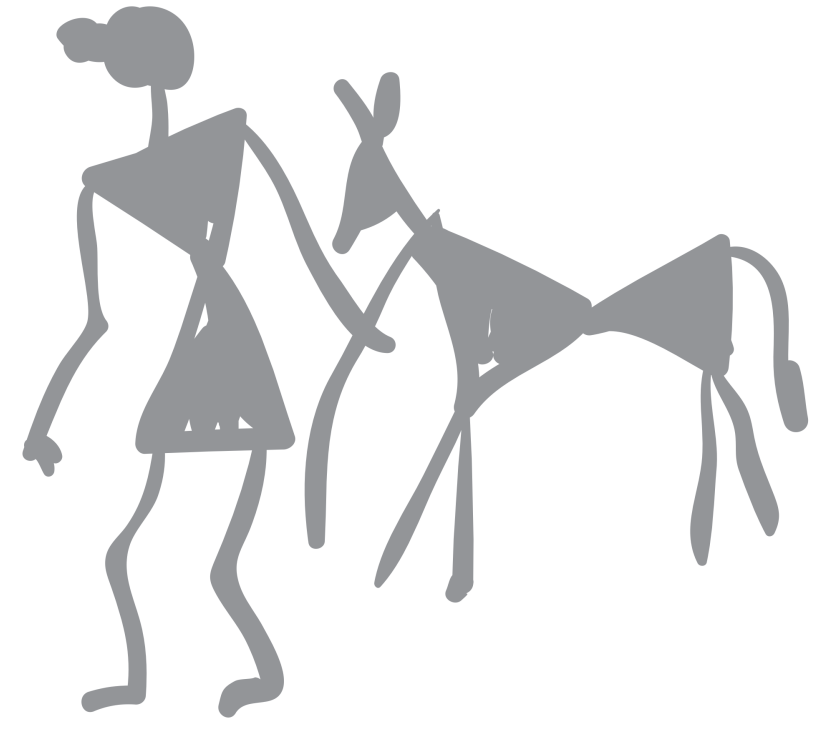


Chapter 1

Introduction 

This thesis is about the choices and control persons with disabilities have when undertaking their daily living activities in rural India. It particularly considers persons with disabilities who require support to undertake activities of daily living such as grooming, feeding, toileting or moving about. According to WHO (2011) persons who require higher levels of support are isolated and segregated within their homes and communities around the world. This subsequently reduces the opportunities they have to live their lives based on their preferences and values (UN Committee on the Rights of Persons with Disabilities, 2017; UN OHCHR, 2017). The Convention on the Rights of Persons with Disabilities (UN CRPD) that came into force in 2007 recognises this challenge and addresses it as its first general principle (Art. 3): "Respect for inherent dignity, individual autonomy including the freedom to make one's own choices, and independence of persons" (UNGA, 2007). Ensuring that all persons with disabilities can enjoy their autonomy and freedom of choice on an equal basis with others in their community requires them to have adequate and appropriate support. Such support, according to the UN CRPD, must be 'user-led' and be a means to enable persons with disabilities to live independently (UN Committee on the Rights of Persons with Disabilities, 2017; UN OHCHR, 2017). To live independently does not mean living alone but rather implies that, with support, persons with disabilities should be able to adopt a living arrangement of their choice and live in a manner that they like, allowing them to enjoy personal autonomy on an equal basis with others in their family and community (UN Committee on the Rights of Persons with Disabilities, 2017; UN OHCHR, 2017).

By ratifying the UN CRPD India has agreed to uphold the standards described in it. The general obligations (Article 4) of the UN CRPD describe several steps for 
countries to achieve post-ratification. One of the key obligations is to harmonise the national laws and policies with the UN CRPD and indeed India has moved in this direction by enacting the Rights of Persons with Disabilities Act 2016. Having taken steps to adopt the UN CRPD, there is a need to investigate whether the new legislation has brought positive changes for persons with disabilities. Moreover, to assist in meaningful implementation of the legislation, a better understanding is required of what having personal autonomy and freedom of choice in their daily lives implies for persons with disabilities in the Indian context. Therefore, to gather insights into the situation of persons with disabilities and their families, through this research we explore how the new legislative framework extends the rights of persons with disabilities and investigate the personal autonomy and freedom of choice they have in their daily lives. We use the capability approach (CA) to theorise these aspects and to gain an in-depth understanding.

The Capability Approach was introdued by Amartya Sen, an economist and philosopher. It has proved to be an effective approach for assessing linkages between individual wellbeing and the existing social and political arrangements, and for proposing changes in society (Robeyns, 2011). Unlike the welfare approach that considers wellbeing in terms of equality in 'primary goods' such as income, wealth, and other social bases of self-respect, the CA considers these 'primary goods' merely as a means to achieve a valued end. Measure of wellbeing in the CA is the equality of opportunities individuals have to determine what they want, what they value and ultimately what they choose (Sen, 1999; 2009). According to Sen (2009), “[a] person with severe disability cannot be judged to be more advantaged merely because she has a larger income or wealth than her able-bodied neighbour. Indeed, a richer person with disability may be subject to many restraints that the poorer person without the physical 
disadvantage may not have" (p. 253). Most of these restraints are an outcome of how society and its institutions address disability. For instance, society and institutions often do not take into account the 'additional resources' persons with disabilities require to achieve the same level of wellbeing as a person without a disability (Robeyns, 2011; Sen, 2009). These 'additional resources', according to the CA, help to equalise the functioning of persons with disabilities so that they can enjoy the freedom to decide the way they live and what they do on an equal basis with others (Sen, 2009). Because the CA considers the equality of opportunities that individuals have to lead a selfdetermined life, and looks at social and institutional barriers that inhibit individuals and groups from leading such a life, it would seem to be an adequate framework with which to investigate the extent to which persons with disabilities are able to exercise autonomy and the freedom of choice they have in their daily lives in the post-CRPD policies environment.

\section{Disability and support services in India}

We begin by introducing the context in which this research took place and presenting an overview of the social and institutional situation of persons with disability in India. According to the 2011 census of India, $2.21 \%$ of the population lives with a disability. This estimation is far below the global estimation proposed by the World Health Organisation (WHO) which suggests that $15 \%$ of the global population consists of persons with disabilities (WHO, 2011). According to the United Nations, two-thirds of the global population of persons with disabilities live in the Asia Pacific region (UN ESCAP, 2015) of which India is the second most populous country. According to the literature one of the key reasons for the apparently low prevalence in India is the difference in the definition used of "disability". Other reasons discussed are variations in how respondents interpret disability, under-reporting due to the stigma attached to 
disability, and variations in the process of data collection in different districts of the country (Saikia, Bora, Jasilionis, et al., 2017; Dandona, Pandey, George, et al., 2019). However, irrespective of the quality of data available, according to the census India has a substantial number of persons with disabilities, of whom $69 \%$ live in rural parts of the country (Census of India, 2011). Consequently this research undertakes fieldwork in rural areas. A detailed overview of disability in India is provided in the third chapter.

In the wake of ratification of the UN CRPD, the government has taken several steps in order to improve the situation of persons with disabilities. The Department for Empowerment of Persons with Disabilities (DEPD) under the Ministry of Social Justice and Empowerment was set up in 2012 after ratification to provide a strong implementing structure. Subsequently, the Rights of Persons with Disability Act 2016 (RPDA 2016) was enacted, replacing the Persons with Disabilities Act 1995, to harmonise disability legislation with the UN CRPD. The RPDA 2016 has adopted the definition of a person with disabilities from the UN CRPD; for all administrative purposes, the definition considers those with $40 \%$ or more impairment as persons with "benchmark disabilities" who are the persons legally recognised as being disabled. The Act additionally introduces a new administrative category: persons with "high support" needs who include persons with disabilities who require additional support to undertake physical or intellectual activities.

While the new act recognises a category of persons with disabilities who require a high level of support, there is an absence of formal support services organised by the government in the country. There are a number of private services localised in big cities for providing support to older persons that also provide services to persons with disabilities but these are expensive. There are a number of non-governmental initiatives 
that address training and peer support for family caregivers, but they to do not themselves provide support services.

\section{Problematising support services in the context of India}

The literature indicates that many persons with disabilities in India are segregated and isolated in their homes because they are completely dependent on their families (Ghai, 2002, 2015). Researchers suggest that one of the reasons for the persistence of this segregation in rural life in India is that policy makers have not been obliged to create environments that can accommodate the specific needs of persons with disabilities (Ghosh, 2016). Researchers also link this situation to the traditional social belief that disability is an outcome of a tragic destiny, an outcome that the disabled person and their family must endure (Miles, 2002; Ghai, 2002, 2015; Ghosh, 2016). It is the family which is expected to look after the disabled family member and the response from the community is that of charity (Chakravarti, 2018; Ghai, 2002, 2015). Ghai (2002) suggests that disabled persons and their families have tried to fight this perception but the belief remains ingrained in some local communities.

However, post ratification in 2008 the Indian government has made significant efforts to align its actions with the UN CRPD. While the UN CRPD does not prescribe a specific model of how support should be provided to the disabled people in a country, the UN Committee on the Rights of Persons with Disabilities (2017) suggests that the support persons with disabilities receive must be designed in a way that it is individualized and chosen by them, enabling them to enjoy equal participation and opportunities in their homes and communities. There is little insight available into how the new disability act in India impacts support services and influences the daily lives of persons with disabilities and their living arrangements. Therefore there is a need to investigate the impact of the new legislation on the daily lives of persons with 
disabilities and their families and to get better insights into the lives of persons with disabilities and their families. To gain these insights the main question addressed by this thesis is: To what extent do persons with disabilities who require support in daily living activities and mobility perceive that they are able to live with autonomy in their daily lives?

To gain a holistic understanding of this main question following sub-questions are addressed:

1. How have the national legislative frameworks for support services operationalised the UN CRPD?

2. What are the perceptions of persons with disabilities living in rural areas of the challenges they face in their daily lives?

3. What are the perceptions of the family caregivers of the challenges they face in providing care and support to the disabled family member?

4. What can be done to improve the physical home environment of and the mobility devices available to people with disabilities to increase their mobility and independence?

\section{Methodology}

The work reported in this thesis is based in the interpretivist paradigm in which interpretations are derived from the perceptions of persons in relation to each other and their social context (Tolley, Ulin, Mack, et al., 2016). As is required in the interpretivist paradigm, the goal of research was to understand the 'lived experiences' of persons with disabilities and their families living in rural areas, with the research conducted in their natural settings rather than a controlled environment, allowing them to speak freely 
(Tolley et al., 2016). The research would follow a qualitative research design and use different methodologies under this paradigm.

The subjects of this research conform to two main criteria. First, it focuses on adults who were eighteen years and above, and secondly, it considers persons with disabilities who require support in undertaking activities of daily living and in mobility. The research was undertaken in three villages of the Anantapur District in Andhra Pradesh. Access to the community was gained with the support of a local development organisation, Rural Development Trust (RDT). This organisation works in many development areas, including working with persons with disabilities. The field staff of the organisation assisted in contacting potential participants for the research based on the set criteria. While they accompanied the field study, their presence was only to ensure smooth administration and not to influence the research process.

\section{Research Design}

The questions above were addressed using different qualitative methodologies. In chapter two the alignment of the laws of different countries addressing support services for persons with disabilities with the UN CRPD is investigated. The document method was used for this investigation and the existing legislative framework was systematically analysed using a framework developed from the CA. The laws of four countries were reviewed. These countries were India, Nepal, Philippines and South Korea. In this manner, the investigation was not limited to India but included other Asian countries also to get a broader understanding on the good practices and gaps that exist in aligning with the UN CRPD in the region.

After gaining an understanding of the legislative frameworks in India and the Asian region, in chapters three and four provide better insights into the lives of persons with disabilities and the family with which they live and from which they receive care 
and support. Semi-structured in-depth interviews were used for this research to allow the participants to speak freely while responding. There was no substantive theory used to develop the interview framework. As suggested by Tolley et al. (2016), this would enable the investigation to happen from the perspective of the participants. The analysis after data collection was based on the CA.

In chapter five, based on the insights gained from the earlier research, a tool was developed for community-based field workers to attune the home environments of the persons with disabilities with the mobility devices available to them so as to reduce the amount of support they require. The involves identifying physical modifications required to the home to better suit the mobility device and also considering the mobility device best suited for the individuals home environment. The methodology for developing the tool was divided in three steps. First, an initial tool was developed based on existing documents. Then the accuracy of the tool was checked by undertaking field visits and refining the tool based on ground realities. Finally feedback was invited by experts on the tool.

The main question is discussed in the sixth chapter, in which the findings of the previous chapters are consolidated. This leads to the construction of a better understanding of the interconnectedness of social and cultural practices and perceptions with the legislative framework provisions addressing support for persons with disabilities that influences their opportunities to have personal autonomy in daily lives, especially through undertaking the activities of daily living. This chapter also discusses the additional dimensions that the CA provided to the analyses. It also evaluates the findings to recommend actions to improve the situation and discuss potential areas of further research. 
References

Census of India. (2011). Houses, household amenities and assets. Accessed 2 April 2018.

http://planningcommission.nic.in/data/datatable/data_2312/DatabookDec2014 $\% 20314 . p d f$

Dandona R., Pandey A., George S., Kumar A.G. \& Dandona L. (2019). India's disability estimates: Limitations and way forward. PLOS ONE. DOI: 10.1371/journal.pone.0222159

Ghai, A. (2002). "Disability in the Indian context: Post-colonial perspectives." In Disability/ postmodernity: Embodying disability theory, edited by M. Corker and T. Shakespeare, 88-100. London: Continuum.

Ghai. A. (2015). Rethinking Disability in India. New Delhi: Routledge.

Ghosh, N. (2016). "Introduction: Interrogating Disability in India”. In Interrogating Disability in India, Edited by Nandini Ghosh, N, 1-22. India: Springer

Robeyns, I. (2011). The Capability Approach. The Stanford Encyclopedia of Philosophy (Winter 2016 Edition), Edward N. Zalta (ed.), URL = $<$ https://plato.stanford.edu/archives/win2016/entries/capability-approach/>.

Saikia N., Bora J.K., Jasilionis D. \& Shkolnikov V.M. (2017) Correction: Disability Divides in India: Evidence from the 2011 Census. PLOS ONE 12(2): e0172596. DOI.:journal.pone.0172596.

Sen, A. (1999). Development as freedom. Oxford: Oxford University Press.

Sen, A. (2009). The idea of justice. Cambridge: Harvard University Press.

Tolley, E., Ulin, P., Mack, N., Robinson, E., \& Succop, S. (2016). Qualitative Methods in Public Health: A Field Guide for Applied Research (Second edition). San Fransisco: John Wiley \& Sons.

United Nations Committee on the Rights of Persons with Disabilities (2017). General Comment No. 5 (2017) on living independently and being included in the community. 27 October, 2017. CRPD/C/GC/5. 
United Nations Economic and Social Commission for Asia and the Pacific (UN ESCAP). (2015). Disability at a Glance 2015. United Nations Publication. Thailand.

United Nations General Assembly (2007). The Convention on the rights of persons with disabilities. New York.

United Nations Office of High Commisioner of Human Rights (UN OHCHR) (2017).

Report of the special rapporteur on the rights of persons with disabilities, A/HRC/34/58, 24 February 2017. Retrieved May 2017, from http://ap.ohchr.org/documents/dpage_e.aspx?si=A/HRC/34/58

World Health Organization (2011). World report on disability. World Health Organisation \& World Bank, Geneva. 


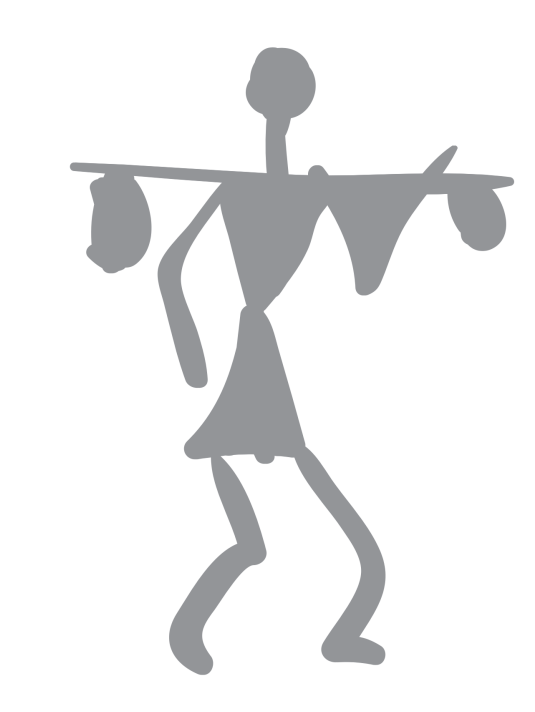




\section{Chapter 2}

Using the Capability Approach to Study

the Successes and Challenges in

Operationalising the UN CRPD

Gupta, S., Witte, L. De., \& Meershoek, A. (Submitted).

Using the Capability Approach to Study the Successes and Challenges in Operationalising the UN CRPD.

Alter - European Journal of Disability Studies 



\section{Abstract}

Implementation of the United Nations Convention on the rights of persons with disabilities (UN CRPD) requires countries to harmonise their legislative frameworks with it. This paper investigates the national legislative frameworks of four Asian countries to see the extent to which they provide support services in accordance with Article 19 of the UN CRPD. The UN CRPD requires persons with disabilities to have access to and choice and control over support services. To analyse the policy alignment with the UN CRPD, an analytical framework based on the Capability Approach (CA) was developed. The results show that most countries address support services only from the perspective of a social security measure for persons with disabilities living in poverty, failing to uphold the rights of those not meeting that eligibility criteria. However, while support services are inseparably linked to social security, they also are a right for persons with disabilities. Therefore, a paradigm shift is required in the approach of support services and the distributive systems of countries, from one that addresses persons with disabilities as those requiring care considered a burden, to one that considers them rights holders with equal opportunities, for which, support services are a pre-requisite.

\section{Introduction}

Persons with disabilities are known to face challenges in leading meaningful lives because of a lack of adequate and targeted support that enables them to exercise their human right to self-determination and equality. Several international agencies have confirmed that the provision of appropriate support is a key enabler for a large number of disabled people who are struggling to live self-determined lives, but the need for support for most remains largely unmet (WHO, 2011; UN Committee on the Rights of Persons with Disabilities, 2017; UN General Assembly [UNGA], 2017). To ensure countries uphold the rights of disabled people, the United Nations adopted the Convention on the Rights of Persons with Disabilities. In particular, Article 19 of the UN CRPD calls upon states to ensure that disabled people have access to a range of 
support services in their community that will enable them to live independently and participate effectively. Article 28 links it to social protection, requiring countries to make these available to persons with disabilities living in poverty (UNGA, 2007).

There is no specific definition of support services. According to the special rapporteur on the rights of persons with disabilities, "support is the act of providing help or assistance to someone who requires it to carry out daily activities and participate in society" (UNGA 2017, p.5). For persons with disabilities, it specifically includes a wide range of interventions that may be offered formally by paid service providers, or informally, primarily by their families and personal networks, and include a range of options from personal assistance to community living support, communication support, respite care services, information-and-decision making support, assistive devices support and so forth (UNGA, 2014; 2017; WHO, 2011).

The UN CRPD itself does not prescribe any model for providing support services, but provides overarching principles for delivering them, stating that all disabled people must have "equal access to, an equal choice of, and control over support services that respect their inherent dignity and individual autonomy and aim to achieve effective participation and inclusion in society" (UNGA, 2014, p. 10). Thus, the overarching principles look at access and choice and control as key elements for providing support services. To assess how countries address these two key principles, this paper investigates the question: "How successfully have the national legislative frameworks for support services operationalised the UN CRPD?" The focus of the research is largely on personal assistance services required for persons with disabilities for activities of daily living and mobility. The research looks at four countries in Asia, namely India, Nepal, the Philippines, and the Republic of Korea (South Korea). 
To operationalise the rights-based principles provided by the UN CRPD, most countries require to adopt these into their national legislative frameworks. However, adopting these may influence the manner in which social justice is defined, including the distributive mechanism of the country that determines how inequality is seen and compensated (Sen 2009). This research, which reviews the existing support services legislation, uses the CA to define the analytical framework. The existing welfare approach, which most of the reviewed countries follow, looks at social equality in terms of primary goods, such as resources, income and wealth. Sen (2009) suggests that these are not the appropriate indicators to consider equality when comparing the quality of life or standard of living. According to him, considering income or wealth as indicators falls short of addressing human diversity by ignoring that some individuals, especially those with disabilities, may require more resources to attain the same standard of living (Sen, 2009). He also suggests that the welfare approach that considers persons with disabilities as special needs, added into the institutional set-up retrospectively and makes primary goods the determents of the distributional system (Sen, 2009). In contrast, Sen $(1999,2009)$ and other proponents of the CA propose an alternative way of looking at equality, which is based on the opportunities and freedom individuals have, to choose from and lead a life they value.

The CA is considered appropriate for this study because it regards the support available to a disabled person as being important for them to benefit equally from the opportunities they have, and thus looks at the provision of support as a matter of justice contributing to equalisation of capabilities (Terzi, 2009). Specific to this paper, elaborating on access, choice and control of support services, we theorise policy eligibility to define the principle of access to support services. The notion of agency is used for an examination of the choice and control that support service policies offer. 
Besides, the role of the family in the delivery of support services influences choice and control, and this has also been theorised using CA in the next section.

\section{The analytical framework}

The CA is a broad, normative framework used to assess individual well-being and social arrangements. It has been used extensively in a wide range of fields including social policy (Robeyns, 2005; Ruiz, Durán, Palá, 2015; Trani, Bahkshi, Bellanca, Biggeri \& Marchetta, 2011). Sen (2009), elaborating on the equality of opportunities that the CA aims to achieve, defines conversion handicaps that are especially encountered by persons with disabilities to convert the income available into real opportunities, thus requiring support to overcome these. He also suggests that persons with disabilities may require additional resources to overcome these conversion handicaps to experience life on an equal basis with others. As a result, equality in income may yield different outcomes for persons with and without disabilities (Sen, 2009). Such conversion handicaps are not addressed by the welfare approach, which does not look at individual differences in the way the income may be used (Sen, 2009).

In the CA, the focus is on the opportunities individuals have, to lead a life they value, rather than income as a gauge for well-being. The assessment of opportunities individuals have, can be evaluated at two levels - the level of functioning and the level of capabilities (Sen, 2009; Mitra, 2006). Functioning are the opportunities a person has to achieve the state of being (such as being well-nourished, cared for) or doing (such as working, learning), and establishes their well-being. Capabilities are real opportunities or the freedom of choice a person has, to decide which of the various functionings to achieve. Their capability set comprises all the functionings they have the freedom to choose from (Mitra, 2006; Robeyns, 2005; Sen, 2009) and 
establish their choice and control. This flexibility of being able to evaluate at different levels has been used by disability scholars in policy evaluation (Ruiz et al., 2015; Trani et al., 2011). Scholars also appreciate that the approach considers the agency individuals have, as being central to the framework, which implies that persons with disabilities must be given the power and the opportunity to lead their life the way they desire (Robeyns, 2005a; Sen 2009). Thus, the CA requires looking at societal measures and the environment set-up that empowers individuals to have equal opportunities to live a life they value, regardless of their abilities (Sen, 2009; Harnacke, 2013). Support services may be seen as one of such measures required by some disabled people to have equal opportunities.

\section{Policy eligibility}

The CA does not propose a definite way of looking at policy eligibility. Therefore, we have explored the definition of disability and other criteria that are commonly considered for eligibility. The CA, although used extensively by disability scholars, does not have a specific definition of disability. However, scholars such as Terzi (2009) and Mitra (2006) have defined ways to understand disability based on the CA, which have been accepted widely. Terzi (2009) emphasises that in the CA, social policy must aim to eliminate inequalities in capabilities amongst people. This requires making interpersonal comparisons of capability that recognise human diversity, which, in turn, involves differences in people's personal and external situations, and differences to convert resources into capabilities (Sen, 2009; Terzi, 2009, Trani et al. 2011). Impairment in the $\mathrm{CA}$ is considered a personal feature restricting the functioning of the individual, which may result in disability in their interaction with their physical, economic, social and cultural environment (Terzi, 2009). Thus, disability is considered just one aspect of human diversity, comparable to age and 
gender (Terzi, 2009).

Wolff (2009) suggests differentiating between impairment and disability when looking at eligibility, and proposes two normal ranges of functioning: biological and social. According to him, "Disability is to find it harder than others to achieve within the normal range of secure social functionings, and part of the explanation of this is a biological impairment — a lack of functioning — defined in terms of species-typical attributes" (Wolff, 2009, p 127). Hence, eligibility must consider disability as a deprivation of equality in terms of the functioning and capabilities of a person, as a result of the interaction of the personal attributes of an individual with an impairment with their physical, economic, social and cultural environment. A broad consideration that addresses personal, social and environmental factors when considering the individual's lifecycle is important, as these situations are constantly changing.

\section{Agency}

The concept of agency is at the heart of the CA and it represents the freedom of choice a person has, to choose from all the practical opportunities available to them, based on what they value (Sen, 2009; Trani et al., 2011). The CA considers individuals to be active participants in their personal and community life rather than being passive spectators or recipients of welfare. According to Sen (1999), the opportunities people have to improve their lives, require expansion of human agency and freedom, both as an end in itself and as a means of further expansion of freedom. According to Sen (1999) what people can actually achieve, depends on their external factors such as their social, economic and political environments, and technological and social modernisation can influence the agency an individual can exercise.

Persons with disabilities attaining freedom and being actively involved in their personal and community life would often require them to have access to support 
services to achieve their capabilities. First and foremost, the policies must address support services as an enabler for them to have agency to lead a self-determined life. Support service policies must look at persons with disabilities having agency as an end, by offering a range of support options, with the freedom to decide what best suits their requirements (Biggeri, Bellanca, Bonfanti \& Tanzj, 2011). Looking at expanding the agency of persons with disabilities as a means would require policies to actively involve persons with disabilities in all processes of getting the support, including evaluation and granting of the service.

\section{Role of the family}

The CA does not look at a person in isolation, but as a part of a larger social and environmental structure, of which family is the first unit that can either support persons with disabilities to overcome their conversion handicaps, or act as a restraint (Trani et. al., 2011). According to Sen (2009) conversion handicaps experienced by persons with disabilities result in members of their family having to share their capabilities with the disabled family member (Sen, 2009; Trani et. al, 2011). For instance, if a person with disabilities is unable to walk, they may not be able to be mobile, unless they receive a mobility aid such as a wheelchair. However, even if they received a wheelchair, they may still not be able to move around because of reasons such as inaccessibility, lack of strength to propel the chair, and so on, and thus would need to depend on the members of the family to push their wheelchair. Sharing of resources by the family can increase agency of persons with disabilities, but at the same time, place the families of persons with disabilities at a disadvantage as compared to families without a disabled family member (Sen, 2009; Trani, 2011).

Also, the CA recognises that persons with disabilities have a double disadvantage; they earn less income compared to non-disabled persons on account of 
personal, social and environmental barriers, and second, they (and their families) incur extra costs of living with a disability, from expenses such as medicines, diet, assistive devices, accessible accommodation and transport. (Kuklys, 2005; Mitra, 2006; Sen, 2009; Trani et al., 2011). Therefore, the CA suggests that disability-related extra expenses must be considered when looking at the family income as an indicator of well-being (Sen, 2009; Kuklys, 2005).

\section{Methodology}

\section{Country selection criteria}

This paper reviews the primary legislative frameworks relating to support services of four Asian countries (India, Nepal, the Philippines and South Korea) to understand how they operationalise the CRPD. The CA has been used as the framework for the review. The four selected countries have been used as case studies to understand the general situation in the region. These countries have not only different support-service policies but also different economic, demographic and geographical characteristics. They have, however, all ratified the CRPD and therefore have agreed to comply with the principles and standards set by it. In addition, all four countries have submitted, under Article 33 of the convention, their initial country status reports on the status of implementation of the CRPD. Three of the four countries have post-ratification legislation and the fourth has amendments made to the legislation, post-ratification. This indicates that they have started the process of harmonisation. To ensure macrolevel regional similarities, only Asian countries were selected and they all concur on the regional instruments for the protection of rights of persons with disabilities, such as the Incheon Strategy for Persons with Disabilities in Asia and the Pacific (UN Economic and Social Commission for Asia and the Pacific, 2012). 


\section{Documents reviewed}

The four countries have diverse legislative documents that address different kinds of support services offered to persons with disabilities. These documents include legislative acts, policies and rules. The research is limited to investigating the primary legislative frameworks, as legal harmonisation of the primary legislation is one of the first steps towards operationalising the CRPD, and countries who ratify it are obliged to take. Moreover, the legislative framework is the starting point from which other policies and implementation mechanisms evolve. Verification of the data collected from these documents was undertaken by the information and data provided by the country governments in their initial state report to the CRPD committee.

\section{India}

- Rights of Persons with Disabilities Act, 2016

- The National Policy for Persons with Disabilities, 2006

\section{Nepal}

- The Act Relating to Rights of Persons with Disabilities, 2074 (2017)

\section{The Philippines}

- $\quad$ Republic Act 7277, 1991

- Republic Act 10754, 2015

- Implementing rules and regulations for RA 7277 and RA 10754

\section{South Korea}

- Welfare Law for Persons with Disabilities Act, 2013

- Act on Activity Assistance Services for Persons with Disabilities, 2011

- National Policy for Persons with Disabilities 2013 


\section{Document review process}

The review of the legislative documents used an analytical framework developed using the CA. The analytical framework presented in Table 1 elaborates on three principal factors: eligibility, agency, and the role of the family, with indicators to analyse each of these. Outcomes of the document examination were validated through a comparison with the initial state report to the CRPD committee.

There are three indicators used to investigate eligibility: first, how each country defines disability; second, whether any additional personal, social and environmental criteria are considered in eligibility assessments; and third, the evaluative processes adopted and whether only medical factors are considered, or functional and social factors are also taken into account. Three indicators were used to investigate agency: first, the purpose of the legislative act in question was considered to see if it focused on the agency of persons with disabilities; second, the range of support services offered was investigated to see if they allowed disabled people to exercise choice; and finally, the process of evaluating additional criteria for support services was examined to see if the opinions of disabled people and their families were taken into account.

The role of the family was looked at, using two criteria: the first indicator involved an analysis of the role legislation assigned to the family and whether it accounted for the extra efforts put in by the family for supporting a disabled family member; the second indicator examined whether the legislation addressed extra costs incurred by the disabled person and their family that were related to disability. 
Table 1. Indicators for the review of the primary legislation derived from the CA

\begin{tabular}{|c|c|}
\hline Capability Approach & Indicator \\
\hline \multicolumn{2}{|c|}{ Access $=$ Eligibility } \\
\hline $\begin{array}{l}\text { Looks at disability as a deprivation that } \\
\text { results from impairment and impacts the } \\
\text { ability of a person to convert resources } \\
\text { into capabilities. }\end{array}$ & $\begin{array}{l}\text { Does the definition of disability make a } \\
\text { distinction between disability and } \\
\text { impairment? }\end{array}$ \\
\hline $\begin{array}{l}\text { Deprivation faced by persons with } \\
\text { disabilities takes into account: } \\
\text { (a) personal factors } \\
\text { (b) social factors } \\
\text { (c) environment factors }\end{array}$ & $\begin{array}{l}\text { Eligibility criteria in addition to disability } \\
\text { considers other personal, social and } \\
\text { environmental factors? }\end{array}$ \\
\hline $\begin{array}{l}\text { Deprivation is considered across various } \\
\text { parameters acknowledging changes in } \\
\text { the person's personal, social and } \\
\text { environmental factors at different stages } \\
\text { of life. }\end{array}$ & $\begin{array}{l}\text { Does the evaluation process take into } \\
\text { consideration internal and external factors } \\
\text { through the life cycle approach? }\end{array}$ \\
\hline \multicolumn{2}{|c|}{ Choice and control = Agency } \\
\hline $\begin{array}{l}\text { Support services foster active } \\
\text { participation of people in their personal } \\
\text { and community lives. }\end{array}$ & $\begin{array}{l}\text { Does the purpose of the legislative } \\
\text { framework reflect on active participation of } \\
\text { persons with disabilities? }\end{array}$ \\
\hline $\begin{array}{l}\text { Persons with disabilities can exercise } \\
\text { choice and decide on the support they } \\
\text { think is best for them. }\end{array}$ & $\begin{array}{l}\text { Is there a range of services offered and is } \\
\text { there flexibility in the way these are } \\
\text { provided? }\end{array}$ \\
\hline
\end{tabular}




\begin{tabular}{|l|l|}
\hline $\begin{array}{l}\text { Persons with disabilities have agency and } \\
\text { are active participants in deciding the life }\end{array}$ & $\begin{array}{l}\text { Does the support service evaluation process } \\
\text { actively involve the beneficiaries in the } \\
\text { they want to live. }\end{array}$ \\
\hline \multicolumn{2}{|c|}{ Choice and control = Role of the family } \\
\hline $\begin{array}{l}\text { Family members are considered an } \\
\text { important resource and they agree to }\end{array}$ & Do the support service policies address the \\
share their capability set with persons & a disabled family member? \\
with disabilities to enable them to have & \\
basic capabilities. & Is there consideration of disability-related \\
\hline Evaluation of family income takes into & extra costs? \\
account all extra expenses related to &
\end{tabular}

\section{Investigating the primary legislation of the four countries}

The following section provides a review of the primary legislation for support services for persons with disabilities in the four countries, based on the indicators presented in Table 1.

\section{Eligibility}

First, the four-country legislations reviewed adopt similar approaches to describing a person with disabilities. The disability acts in India and the Philippines have adopted the definition from the convention and have the same definitions of a person with disabilities - "person with long-term physical, mental, intellectual or sensory impairment which, in interaction with barriers, hinders his full and effective participation in society equally with others" (Rights of Persons with Disabilities Act [RPDA], 2016, p. 3; Implementing Rules and Regulation of Republican Act [IRRRA], 10754, 2015, p.1). In Nepal, the Act Relating to the Rights of Persons with 
Disabilities, 2074, 2017 (ARRPD, 2017) defines a person with disability as "a person who has long-term physical, mental, intellectual or sensory disability or functional impairments or existing barriers that may hinder his or her full and effective participation in social life on an equal basis with others" (Act Relating to the Rights of Persons with Disabilities [ARRPD], 2017, p. 1). For implementing this broad definition of disability, India, Nepal and the Philippines provide a more medical definition or list of the impairments that supplement the definition. South Korea defines persons with disabilities as "those who are considerably restricted in their daily and social life for a long period of time due to their physical or mental disabilities" (Welfare Law for Persons with Disabilities [WLPD], 2013, p. 1), and categorises disability into 15 different impairments (National Policy for Persons with Disabilities, 2013).

Policies in all four countries apply an additional layer of qualifying criteria for eligibility for support services. In India, according to the RPDA 2016, persons requiring high support are eligible. High support is defined as "an intensive support, physical, psychological and otherwise, which may be required by a person with benchmark disability for daily activities, to take independent and informed decisions to access facilities and participating in all areas of life including education, employment, family and community life and treatment and therapy” (p. 3). Benchmark disability considers "persons suffering from not less than $40 \%$ disability" (RPDA, 2016, p, 3). In Nepal, the ARRPD, 2017 also defines helpless person with disabilities who are eligible for government support as "a person with disability who does not have any property or any family member or guardian to attend, care and serve him or her or who cannot earn their living by way of self-employment" (p.1). The Philippines provides support to marginalised disabled persons, who are defined 
as "persons who lack access to rehabilitative services and opportunities to be able to participate fully in socio-economic activities and who have no means of livelihood or whose incomes fall below the poverty threshold" (RA 7277, 1991, p. 3). In South Korea, only "persons with serious disabilities of a degree equal to or more severe than the degree of disability prescribed by Presidential Decree, who have difficulty in leading daily and social lives by themselves" (Act on Activity Assistance Services for Persons with Disabilities [AAASPWD], 2011, p. 2) are considered eligible to access support services. Other than the severity of the disability, South Korea also considers the standard of living of the family and levels of financial support. While calculating the cost of supports to the person with disabilities, the family's standard of living is considered.

All countries require a certificate or an identity card verifying a person with disabilities, which is a primary requirement to access support services offered by the government. In India, a disability certificate can be obtained from a certifying authority competent to issue it. The Gazette of India: Extraordinary Part II—Sec.3 (ii) issued in 2018 provides the guidelines for the assessment of various disabilities under the RPDA, 2016. It requires the disabled person to undergo a clinical examination by a medical doctor. In Nepal the certificate is given based on four classes: profound, severe, moderate and mild. These classes are defined based on the functioning of the person to undertake daily activities and participate in social activities. The certificate can be obtained from the local level ward officer who issues it if the disability is visible, and only where the disability is not visible, is a medical examination required (ARRPD, 2017). The Philippines depends on the Department of Health to evaluate persons with disabilities and a disability identification card is issued only after undergoing a medical evaluation (National Council of Disability Affairs, 2008). In 
South Korea, the severity of a person's disabilities is graded from 1 to 6 degrees of impairment through medical evaluation.

To summarise the eligibility mechanisms, all countries have two levels of evaluation: first, identifying who is legally disabled, since the services offered through the government-aided system are offered only to them. The definition of a person with disabilities in the legislative frameworks is broad, considering not just the impairment but also other internal and external factors that influence the functioning of the individual. However, the evaluation processes, as noted in this analysis, continue to look at the severity and type of impairment with a medical evaluation process that focuses solely on the impairment and requires a medical practitioner to undertake it. Therefore, the first level of evaluation is only concerned with the medical diagnosis, and the multi-dimensional definition of disability that is adopted in the law makes no significant impact on the ground. Second, an extra definition is adopted by the four countries, potentially expanding the scope of the eligibility criteria for accessing support services. For instance, the definition of high support needs in India expands the eligibility criteria to consider social and environmental factors. In the Philippines, the definition of marginalised persons with disabilities considers only the presence of a family as an additional criterion. The definition of homeless persons with disabilities from Nepal focuses on income and eligibility in South Korea considers the severity of impairment and the family's standard of living. The additional definitions adopted, however, do not result in addressing multidimensional factors in defining eligibility.

Agency

The first indicator suggests that, except for South Korea, none of the four countries have drafted specific legislation concerning support services, but rely on sections of 
general disability acts when addressing support services. Hence, support services fall under a broader scope of the act, in terms of the provision of rights and benefits at large. In India, Chapter 7 of the RPDA 2016 Act explains the process for providing support to persons with high support needs so that they can live and participate in all spheres of life. In Nepal, the purpose of the ARRPD 2017 is to uphold the rights of persons with disabilities to live in the community and elaborates "the persons with disabilities shall have the right to obtain assistive materials and community assistance in order to earn the living respectfully" (p.6). The RA 7277 of the Philippines is also a general disability act. Chapter 4 of this act focuses on auxiliary social services and describes the different types of support that can be offered. It is aimed at "ensuring that marginalised persons are provided with the necessary auxiliary services that will restore their social functioning and participation in community affairs" (RA 7277, 1991, p. 8). Similar to the legislation drafted in South Korea, the range of auxiliary social services prescribed in the act are aimed at community participation and on maximising the social functions of disabled people. The purpose of South Korea's Act on Activity Assistance Services for Persons with Disabilities is to "raise the quality of life of persons with disabilities by assisting persons with disabilities to live with selfreliance and lift the burden on their families through providing activity support allowance for persons with disabilities" (AAASPWD, 2011, p. 1).

The range and options of support services available directly, impact the choices that persons with disabilities have to lead self-determined lives. However, most countries have very limited options in terms of the support offered. In India, the act does not specify the particular type of support that can be offered, but leaves it open, stating that an eligible person may receive support "subject to relevant schemes and orders of the appropriate Government in this behalf" (RPDA, 2016, p. 14). 
According to the act, access to support is subject to relevant schemes, without any certainty in terms of when, what and how support services will be provided. In Nepal, the ARRPD 2017 also does not provide a list of the services that may be provided to persons with disabilities. In the Philippines there is a much wider range of services that are offered, including the provision of prosthetic devices, communication skills training, mobility training, and training in enhancing daily living capabilities (RA 7077, 1991). Most of the services offered are rehabilitative, and may not be available in the long-term. In South Korea, the act offers a wide range of support services, including bathing, nursing, and night-time support. Support may also be provided in the home of the disabled person. The person with disabilities receives a coupon from the authorities to buy the support required; these coupons can be used to obtain services from different government-recognised, service-providing organisations (AAASPWD, 2011), giving some choice and control to the disabled person in terms of who supports them. However, there is a top limit to the hours of care provided in a month, after which they have to pay the full cost of care or manage unsupported.

In India, the act states that persons requiring high support must request assistance by making an application to an authority who should then forward this request to an assessment board who decides whether the need for support exists, and the form and nature in which it is to be delivered (RPDA, 2016). In Nepal, government support is available to homeless persons with disabilities and there is no evaluation process elaborated, except by visual confirmation (ARRPD, 2017). In the Philippines, all services, except for substitute family care, are provided at the municipal and city government levels. The responsibility for providing services lies with the mayor, who appoints a social worker from the Department of Social Welfare and Development for effective implementation. The social worker and his/her team 
work closely with disabled people and their families in the community (RA 7277, 1991). In South Korea, to access support services, persons seeking it have to make an application, which is evaluated by the Entitlement Deliberation Committee (AAASPWD, 2011). The disabled people or their families are not a part of the committee, and therefore do not have a say.

To summarise, the level of agency that persons with disabilities are able to exercise, is closely related to the eligibility criteria and the evaluation process for getting support services. Of the four countries reviewed, only one has an act that addresses support services, while the rest address support services as a part of the main disability rights legislation. As may be expected, this has an impact on the amount of support available to persons with disabilities and the way it is provided, influencing the agency of persons with disabilities. As was evident from the secondary level definition of eligibility, countries that look at support services as a part of the main disability legislation, consider them only as a social security measure. However, where there is a separate act addressing support services, they are considered a pre-requisite for all persons with disabilities, in addition to being addressed as social security. Having a policy dedicated to support services also provides a greater range of services, thus increasing the choices available to the disabled person. However, the evaluation process does not necessarily include the disabled persons in deciding which support best suits them, thereby reducing the control they have.

\section{Role of the family}

The support offered in the four countries is closely linked to the family of the disabled person, regardless of their age. This was investigated using two indicators. First, for those with families, the family income or the standard of living is important when 
eligibility for support is being assessed. Those without a family are most likely supported in an institution-like set-up. In India, the RPDA 2016 does not hold the family responsible for disabled persons. However, it recognises the importance of families in terms of the provision of care and support. This act also requires creation of facilities for those without families. In Nepal, the ARRPD 2017 puts a specific legal obligation on the family to provide support in education and for hospital visits. It also requires the local government to impart training to the family members in providing care to the disabled family member. Similarly, South Korea identifies family members as "person(s) obligated to support persons with disabilities" (AAASPWD, 2011, p. 1). These countries thus impose a legal duty on the family. However, in the Philippines and South Korea, the family, together with the government and NGOs, shares the responsibility of ensuring that disabled people can live as independently as possible. They do this by providing support in the community (RA 7277, 1991; Protection and Welfare of Disabled People Rules [PWDPR], 1994).

In the Philippines, the range of services provided, addresses family needs such as developing the capacity of the family to respond to the needs of the disabled family member, and providing after-care services that enable such persons to settle into their family and community after returning home from institutional care (RA 7277, 1991). South Korean legislation illustrates the need for the governments and agencies involved in the care of disabled people to lift the burden of care from the family. The act requires "lifting the burden on their families through prescribing matters concerning an activity support allowance for persons with disabilities" (AAASPWD, 2011, p. 1). Adults with disabilities should be able to build lives of their own, where they have the choice of whether they would like to live independently or to be with their families. 
The second indicator looks at whether the extra expenses related to disability are addressed by the legislative document. Living with a disability may place an additional economic demand on disabled people and their families. Therefore, examining the impact of such disability-related extra costs is important. All four countries reviewed recognise that there are extra costs related to disability, but they address these in different ways. The act in India makes provisions for paying a caregiver allowance to the person with high support needs. This is a social security measure that can also be given to family caregivers. The National Policy for Persons with Disabilities (2006) in India also recognises that disabled persons, their families, and caregivers may "incur substantial additional expenditure for facilitating activities of daily living, medical care, transportation, assistive devices, etc..." (National Policy for Persons with Disabilities, 2006, p. 7). It discusses the possibility of offering tax exemptions to disabled people and their family members, and it also makes provision for a disability pension. The ARRDP 2017 in Nepal offers no support to the family, except for the training mentioned earlier. In the Philippines, a 20 per cent discount is offered to disabled people on many public services. Persons caring for and living with disabled people are offered Income Tax exemptions (Republic Act [RA] 10754, 2015). In South Korea, public enterprises are required to "endeavour to lighten the economic burden of the disabled and other persons supporting such disabled persons" by cutting taxes and reducing fees for public facilities. The AAASPWD 2011 requires the government to raise funds on an annual basis to assist disabled people to be more self-reliant, and to reduce the pressure of care and support on the families.

In summary, the legislative frameworks look at the family as being responsible for the well-being of the adult disabled family member. As a result of not having an option, such an arrangement can not only encumber the family but also compromise 
on the agency of both, the adults with disabilities and their family members. In South Korea, although a wide range of services is provided by the government, the family is supposed to be responsible, irrespective of the age of the disabled person or the family members. Putting an obligation on the community as is done in the Philippines may foster better inclusion of disabled people in community life, as the community at large is responsible for the well-being and inclusion of persons with disabilities. Moreover, while the four countries recognise disability-related extra costs, these are considered of the family and not of the person with disabilities. That leaves the disabled people largely dependent on their family, making it difficult for them to become independent or self-reliant.

\section{Discussion}

This research looks at how the legislative frameworks are operationalising support services for persons with disabilities that comply with the principles and standards defined by the CRPD. The research uses a framework based on the CA. The research was limited to investigating the primary legislations in India, the Philippines, Nepal and South Korea. The investigation revealed a variation in the level of compliance and varying degrees of success in terms of ensuring access, choice and control. While none of the four countries fully comply with all the indicators used, there are elements in compliance that may be seen as good examples. For instance, the definition of disability in all countries is according to the convention; in one of the four countries, support services are recognised as a pre-requisite for participation, and a specific act has been enforced to provide these. Moreover, not all countries consider the family to assume the legal responsibility for the disabled family member. Some countries also recognise the responsibility of the community in ensuring inclusion of persons with disabilities. Yet, there are areas where access, choice and control to support services, 
which are the basic principles the CRPD defines, can be better aligned. The gaps in alignment are discussed below.

Access to support services for persons with disabilities in all legislative frameworks is dependent on the eligibility process, for which the definition of disability is key. Reconsidering the definition of impairment and disability in the CA implies reframing these concepts in terms of functionings and capabilities - thus addressing the impairment that results in restrictions in an individual's functioning as a personal feature, and disability as a restriction of functionings resulting from an interplay of personal with social and circumstantial factors (Terzi, 2009). A restriction in functioning limits the capabilities of the individual and is a matter of injustice. Therefore, for persons with disabilities, having access to support services required for their functioning, becomes a right (Terzi, 2009). However, in legislative frameworks, access to support services is often considered a social protection measure, with only the poor or the homeless persons with disabilities having access to it. As per the analyses, only in South Korea can all persons with a certain level of severity of disability access support services. These persons with disabilities were charged for the service, in part or otherwise, based on family income. In the other three countries, since support services are considered a social security measure, eligibility is critical to access support services, and only those who were eligible have access to them.

Social security mechanisms in the welfare approach compensate inequality at the welfare level by considering the resources available to the person, such as loss of income, presence of family, and so on (Sen, 1999; Wolff, 2009), as was also seen in the analyses. The CA, however, suggests a different mechanism of looking at what needs to be compensated and suggests looking at the personal characteristics of the individual to convert resources into valuable ends (Sen, 2009; Terzi, 2009). This 
implies that disabled people must have access to extra provision that can support them to overcome their conversion handicaps as a matter of justice, and such provision cannot be limited to compensating the severity and type of impairment to determine who is included and who is excluded (Terzi, 2009). Furthermore, as Terzi (2009) suggests, access to support services is a matter of right and it cannot be limit to being a social security measure available to only certain persons with disabilities (United Nations Committee on the Rights of Persons with Disabilities, 2017).

Another limitation of support services being looked at only as a social security measure, is that the distribution system recognises only some selected needs of disabled people and offers predefined solutions based on this understanding (Stone, 1984). This conflicts with the need to develop support that is tailored to individual requirements, an approach that allows disabled people to live with dignity and to exercise autonomy as is required by the CRPD (United Nations Committee on the Rights of Persons with Disabilities, 2017). Alternatively, if the aid distribution system is one based on the equalisation of opportunities and recognises the principle of agency as suggested by Terzi (2009), it should focus on offering individualised support that enables disabled people to lead self-determined lives. Such an approach would also increase the choice and control that individuals have (Sen, 2009; Trani, Bakhshi et al., 2011; Nussbaum, 2011). However, Wolff (2009) points out that the distribution systems may focus on personal enhancement of the individual through medical interventions, conforming to a perfectionist approach or status enhancement by bringing change in the external environment conforming to a more pluralist approach. He suggests that whether the distribution system takes a perfectionist or a pluralist approach in the way they are offered, it is through targeting resources to overcome specified impairments or removing specific barriers respectively. This 
results in giving people only those specific pre-decided things, which will enable them to achieve a certain way of living that he terms as approved lifestyles (Wolff, 2009).

Elaborating on an approved lifestyle, based on the analyses it may be said that in all four countries the families of persons with disabilities are responsible for taking care of the disabled person, even if they are adults. Such an understanding significantly influences the support services offered to conform to the approved lifestyle suggested by Wolff (2009) that can either support people in their differences or limit them in leading a self-determined life. The legislative frameworks of some countries make the families legally responsible for disabled family members, other countries consider not having a family as a criterion for being eligible for receiving support. By making the families responsible, the legislation dictates to a large extent the lifestyle of the disabled person and their family, and that can have multiple outcomes. First, in a more positive light, such a system ensures that persons with disabilities are looked after, especially in countries where support services are underdeveloped and the economic situation of the country may not make it easy for the government to develop these. Second, though not as positive, by putting all responsibility of care and support on the family, the government is putting undue financial, physical and social burden on the family, as has been elaborated extensively in other literature (Kuklys, 2005; United Nations Committee on the Rights of Persons with Disabilities, 2017; WHO, 2011). Finally, there is research suggesting that such approved lifestyles that mandate families to look after the disabled person, may make it difficult for both, the disabled person and their family to have any choice or control of their life (Open Society Foundation, 2011; WHO, 2011). 
While legislation make families responsible for disabled family members, it also has started recognising the importance of the family in enabling the disabled family member to overcome their conversion handicap, as Sen (2009) puts it. This is evident as the legislations are addressing ways of supporting the family by offering training to the families in supporting persons with disabilities, and in some countries, offering a caregiver's allowance that may be useful in providing compensation for extra disability-related costs incurred by families caring for their disabled members. Some countries also offer incentives such as social security benefits, pension schemes, concessions, and tax benefits as compensation. While such systems are important in the present set-up for families to have incentives and monetary support to assume the role of primary support providers, in the long run, these do not address the support requirements of the disabled person, and thus do not look at changing the approved lifestyle of the disabled person or their family (UN General Assembly, 2014; 2017). Moreover, support for the family cannot to be considered a substitute for the support for the person with disabilities (UNGA, 2017). Another aspect to consider while offering compensation for the family or the disabled person is to be mindful of how these resources are distributed within the family and the control persons with disabilities have over it. For instance, according to Kuklys, disabled people may often receive much fewer benefits as compared to non-disabled family members, thus not addressing the differences in the standard of living of families with and without a disabled family member. Kelly (2019), however, points out that such grants may be the only regular family income in many cases, and therefore, if targeted for persons with disabilities rather than the family, can promote interdependence within the household, with persons with disabilities supporting the family financially in return for care. 
Considering that three of the four countries address support services as a part of the main disability legislation only as a social security measure for the poor, other than South Korea where access to support services is available to all, it becomes import to review the distributive system in these countries. Scholars such as Terzi (2009) and Wolff (2009) make strong discussion on distributive justice and eligibility, but changing the country's traditional distributive policies and practices is difficult. The existing distributional policies focus on compensating for loss of work, when strategies that compensate conversion handicaps while accessing equal opportunities are required. This calls for a radical shift in thinking and practice. Making such intrinsic changes may not be easy, as the support requirements of disabled people are diverse and not well recognised by society at large, which looks at caring for them as a family responsibility, thus reinforcing traditional ways of thinking (Stone, 1984; Miles, 2002). Moreover, scholars have also written about the challenges in making a shift in the evaluative process as a part of the distributive system. According to Stone (1984), each time a legislative or administrative body seeks to revise definitions and standards, it encounters difficulties as, on the one hand, there is a demand to broaden the spectrum so that social-economic and medical well-being factors are included in any assessment, and on the other, there is pressure to make evaluations more precise, so that less is left to the discretion of gatekeepers, thus ensuring that non-eligible persons are not accounted for. All of this makes change difficult (Meershoek, Krumeich \& Vos, 2007). Also, there is a lack of alternative evaluation systems that countries can easily adopt. The International Classification of Functioning, Disability and Health (ICF), proposed by the World Health Organisation, is considered more versatile in addressing social factors (WHO, 2002; Mitra, 2006; Dubois \& Trani, 2009). Yet, as literature suggests, further development of factors within the ICF is 
required, and actual application of the ICF as an evaluative tool may still not be easy (Ngyyen, Stewart, Rosenbaum, Baptiste, Kraus de Camargo, \& Gorter, 2018; Simeonsson, Lollar, Björck-Åkesson, Granlund, Brown, Zhuoying, et al., 2014). Countries continue with the idea that support services is about being cared for, and traditionally, this role is fulfilled by the family, irrespective of the age. Such an approach reduces persons with disabilities to being passive recipient of care or a burden on the family, rather than right holders where support is a pre-requisite for equal participation (UNGA, 2017). Such a perspective on the one hand limits the range of support services offered, leaving persons with disabilities with no choice and control. And on the other, since the family is responsible for providing care, the absence of alternate mechanisms leaves them without any choice or control. According to Lang (2009), in developing countries, since ideologically economic and social policies are based on the notion of charity and welfare, bringing radical shifts may raise challenges in making changes in the legislative framework, and in the way they are implemented (Lang, 2009). This is true even when we look at policies for support services where making them compliant with the CRPD remains a challenge, because it is not easy for countries to make radical changes in their existing and established systems, which focus on providing care and reducing the burden of the family. First, such perspectives reinforce the existing negative perception of disability, preventing persons with disabilities, their families and the community from demanding change (Miles, 2002). Second, while support services are linked with social security also in the UN CRPD, such services are a right, and therefore need to be viewed from a wider frame than addressing them only as a targeted social security measure for the poor. There is a need for further research on how persons with disabilities and their families consider the present support system, and the changes 
they seek. Further research is also needed to look at the distributive mechanism of the country, to understand what changes may be required to make a wider range of support services available to all persons with disabilities. Further study may also be required to investigate the impact of limiting the provision of support services to a certain category of persons with disabilities, on the development of the service at large.

\section{Conclusion}

Support services are a pre-requisite for equal participation of persons with disabilities, and thus having access to such services is a right for all persons with disabilities. However, existing policies addressing support services largely look at them only from the lens of social security that is largely offered to persons below a certain income threshold, thereby ignoring persons with disabilities who may be just above the threshold or those who can pay for the services. Moreover, legislation is required where support services are available to persons only with certain types and severity of disability, discriminating against other disabilities. With support services restricted to being addressed only as a social security mechanism, expecting the family to provide care to the disabled family member, negates the opportunities for persons with disabilities or their family to exercise any choice and control in their lives. It is therefore suggested that, to make support services more CRPD-compliant, a paradigm shift is required in the way these services are seen; one that considers support as a service available in the community, rather than being looked at as providing care by the family. Having adequate and appropriate support goes beyond providing care and reducing the burden, to one that enhances choice and control, persons with disabilities have on their lives. This may require countries to modify their understanding of support services and their social security mechanisms to one that allows all persons 
with disabilities to exercise their right to live in the community and have capabilities on an equal basis with others.

\section{References}

Act on Activity Assistant Service for Persons with Disabilities, Act no. 10426. (2011). Retrieved on February 2017 from www.mindbank.info/item/4082 Act Relating to the Rights of Persons with Disabilities, 2074 (2017). Retrieved on August 2019 from http://www.lawcommission.gov.np/en/wp-content/uploads/ 2019/07/The-Act-Relating-to-Rights-of-Persons-with-Disabilities-20742017.pdf

Bigger, M., Bellanca, N., Bonfanti, S. \& Tanzj, L. (2011). Rethinking policies for persons with disabilities through the capability approach: the case of the Tuscany region. ALTER - European Journal of Disability Research. 5(3), 177191.

Dubois, J. L., \& Trani, J. F. (2009). Extending the capability paradigm to address the complexity of disability. ALTER - European Journal of Disability Research. 3(3), 192-218.

Government of India (2015). First country report of India on the status of persons with disabilities. Advance unedited version. Retrieved on March 2017 from http://

tbinternet.ohchr.org/_layouts/treatybodyexternal/Download.aspx?symbolno=C RPD $\% 2 f C \% 2 f I N D \% 2 f 1 \& L a n g=e n$

Government of Nepal (2014). Initial report of the Government of Nepal on measures taken to give effect to the Convention on the Rights of Persons with Disabilities. Retrieved March 2017, from http://tbinternet.ohchr.org/_layouts/treatybody external/Download.aspx?symbolno=CRPD $\% 2 \mathrm{fC} \% 2 \mathrm{fNPL} \% 2 \mathrm{f} 1 \&$ Lang=en

Government of Philippines (2015). Initial report on the implementation of the Convention on the Rights of Persons with Disabilities. Retrieved on March 2017 from http://tbinternet.ohchr.org/_layouts/treatybodyexternal/Download.aspx? symbolno $=\mathrm{CRPD} \% 2 \mathrm{fC} \% 2 \mathrm{fPHL} \% 2 \mathrm{f} 1 \&$ Lang $=\mathrm{en}$ 
Harnacke, C. 2013. Disability and Capability: Exploring the Usefulness of Martha Nussbaum's Capabilities Approach for the UN Disability Rights Convention. Journal of Law, Medicine and Ethics, Winter 2013

Implementing Rules of Republican Act 10754 (2015). Retrieved on March 2017 from http://www.ncda.gov.ph/disability-laws/republic-acts/republic-act-no-10754an-act-expanding-the-benefits-and-privileges-of-persons-with-disability-pwd/

Inclusion International (2012). Inclusive communities - stronger communities: Global report on article 19: The right to live and be included in the community. Retrieved on May 2017 from http://inclusion-international.org/wp-content/ uploads/2010/05/Global-Report-Living-Colour-dr2-2.pdf

Jun-Hyun, S. (2013). Disabled people defy categorisation. The Hankyoreh. Retrieved on February 2017 from http://english.hani.co.kr/arti/english_edition/ e_national/ 613933.html

Kelly, G (2019). Disability, cash transfer and family practices in South Africa. Critical social policy. Vol. 39(4), 541-559

Kuklys, W. (2005). Amartya Sen's Capability Approach: Theoretical Insights and Empirical Applications. Berlin: Springer

Lang, R. (2009). The United Nations Convention on the rights and dignities for persons with disability: A panacea for ending disability discrimination? ALTER-European Journal of Disability Research 3 (2009), 266-285

Meershoek, A., Krumeich, A., Vos, R. (2007). Judging without criteria? Sickness certification in Dutch disability schemes. Sociology of Health \& Illness. 29(4), 497-514

Miles, M. (2002). Community and individual responses to disablement in South Asian histories: Old traditions, new myths? Retrieved March 2018, from https://www. independentliving.org/docs3/miles2002a.html

Mitra, S. (2006). Capability approach and disability. Journal of Disability Policy Studies 16(4), 236 - 247.

National Council of Disability Affairs. (2008). Administrative Order No. 001 Series of 2008. Retrieved on May 2017 from http://www.ncda.gov.ph/2009/07/applyfo-pwd-id-card/

National Policy for Persons with Disabilities. (2006). Retrieved in June 2017 from http://disabilityaffairs.gov.in/upload/uploadfiles/files/NationalPolicyForPerson swithDisabilities(1).pdf 
National Policy for Persons with Disabilities. (2013). Retrieved on August 2017 from https://www.mindbank.info/item/4080.

Nguyen, T., Stewart, D., Rosenbaum, P., Baptiste S., Kraus de Camargo, O., \& Gorter, J. W. (2018). Using the ICF in transition research and practice? Lessons from a scoping review. ALTER - European Journal of Disability Research. 72(2018), 225-239

Nussbaum, M. C. ( 2011). Creating capabilities: The human development approach. Massachusetts: Havard University Press.

Open Society Foundation (2011); A community for all: Implementation of Article 19; Open Society Public Health Programme.

Protection and Welfare of the Disabled Persons Act, 2039 (1982) Act No. 13 Retrieved on March 2017 from https://www.mindbank.info/item/1560 Republic Act 7277 (1991). S. No. 1286. H. No. 35091. Retrieved on April 2017 from http://www.ncda.gov.ph/disability-laws/republic-acts/republic-act-7277/ Republic Act 10754 (2015). Retrieved March on 2017 from http://www.ncda.gov.ph/ disability-laws/republic-acts/republic-act-no-10754-an-act-expanding-thebenefits-and-privileges-of-persons-with-disability-pwd/

The Republic of Korea. (2013). Implementation of the convention on the rights of persons with disabilities. Retrieved on May 2017 from http://tbinternet.ohchr. org/layouts/treatybodyexternal/Download.aspx?symbolno=CRPD $\% 2 \mathrm{fC} \% 2 \mathrm{fK}$ OR\%2f1\&Lang=en

Robeyns, I. (2005). The Capability Approach: a Theoretical Survey. Journal of Human Development, 6:1, 93-117.

Robeyns, I. (2005a). Assessing Global Poverty and Inequality: Income Resources and Capabilities. METAPHILOSOPHY. Vol. 36, Nos. 1/2. DOI:10.1111/j.1467-9973. 2005.00355.x

Ruiz, A. D., Durán, N.S., Palá, A. (2015). An Analysis of the Intentions of a Chilean Disability Policy Through the Lens of the Capability Approach, Journal of Human Development and Capabilities, 16:4, 483-500, DOI: 10.1080/ 19452829.2015.1091807

Sen, A. (1999). Development as freedom. Oxford: Oxford University Press. Sen, A. (2009). The idea of justice. Cambridge: Harvard University Press. Stone, D. (1984). The disabled state. Philadelphia: Temple University Press. 
Simeonsson, R. J., Lollar, D., Björck-Åkesson, E., Granlund, M., Brown, S. C., Zhuoying, Q., et al. (2014). ICF and ICF-CY lessons learned: Pandora's Box of personal factors, Disability and Rehabilitation, 36(25), 2187-2194.

The Welfare Law for Persons with Disabilities, (2013). Retrieved on May 2017 from https:/www.mindbank.info/item/4081

Terzi, L. (2009). Vagaries of the Natural Lottery? Human Diversity, Disability and Justice: A Capability Perspective. In Brownlee, K. \& Cureton, A. (eds.), Disability and Disadvantage. Oxford University Press. pp. 86--111 (2009)

Trani, J. F., Bahkshi, P., Bellanca, N., Biggeri, M., Marchetta, M. (2011). Disabilities through the capability approach lens: Implications for public policies. ALTER - European Journal of Disability Research. 5(3), 143-157.

United Nations Committee on the Rights of Persons with Disabilities. (2017). General Comment No. 5 (2017) on living independently and being included in the community. 27 October 2017. CRPD/C/GC/5.

United Nations General Assembly (2007). The Convention on the rights of persons with disabilities. Retrieved January 2017, from http://www.ohchr.org/EN/ HRBodies/CRPD/Pages/ConventionRightsPersonsWithDisabilities.aspx United Nations Office of the High Commissioner for Human Rights (2010). Monitoring the Convention on the rights of persons with disabilities: Guidance for human rights monitors. Retrieved March 2017, from www.ohchr.org/Documents/Publications/Disabilities_training_17EN.pdf

United Nations Economic and Social Commission for Asia and the Pacific. Incheon Strategy-To make the right real for persons with disabilities in Asia and the Pacific. United Nations Publication, Bangkok (2012).

United Nations General Assembly (2014). Thematic study on the right of persons with disabilities to live independently and be included in the community, A/HRC/28/37, 12 December 2014. Retrieved March 2017, from www.ohchr.org/EN/HRBodies/HRC/RegularSessions/.../A_HRC_28_37_EN G.doc

United Nations General Assembly (2017). Report of the special rapporteur on the rights of persons with disabilities, A/HRC/34/58, 24 February 2017. Retrieved May 2017, from http://ap.ohchr.org/documents/dpage_e.aspx?si=A/HRC/34/58 
Wolff. J. (2009). Disability among equals. In Brownlee, K. \& Cureton, A. (eds.), Disability and Disadvantage. Oxford University Press. pp. 112--137 (2009)

World Health Organisation (2002). Towards a common language for functioning, disability and health: ICF. World Health Organisation, Geneva (2002). Retrieved December 2017, from http://www.who.int/classifications/ icf/ icfbeginnersguide.pdf

World Health Organisation (2011). World report on disability. World Health Organisation \& World Bank, Geneva. 


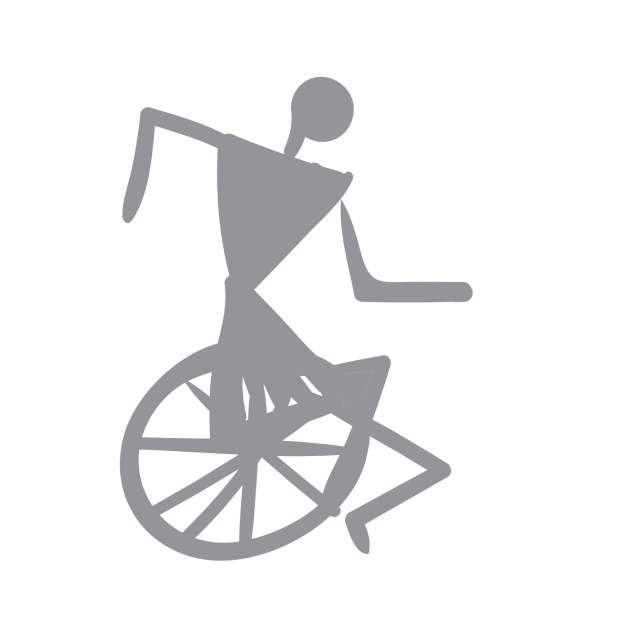




\section{Chapter 3}

\section{Dimensions of invisibility: Insights into the daily realities of persons with disabilities living in rural communities in India}

Gupta, S., Witte, L. De., \& Meershoek, A. (2020).Dimensions of Invisibility: Insights into the realities of persons with disabilities living in rural communities in India. Disability and society, DOI: 10.1080/09687599.2020.1788509 



\section{Abstract}

Persons with disabilities in rural India do not have the opportunity to lead a self-determined life and be included in their community as required by the convention on the rights of persons with disabilities. To investigate their experience of living everyday life and the amount of agency they are able to exercise, in-depth interviews were undertaken. The Capability Approach (CA) was used to analyse the situation that was seen in terms of outcome of the interplay between internal and external factors resulting in loss of agency. The results show that the dependency they experience due to lack of adequate support to undertake activities and being completely dependent on the family places them in a vicious circle of 'self-worthlessness'. Reducing the dependency disabled people face and changing perceptions of the community towards disability may break this circle.

\section{Points of Interest}

- In rural India persons with disabilities are unable to live a self- deter- mined life and to participate in home and community activities.

- The research shows that the interaction between personal, social and environmental factors makes it difficult for persons with disabilities to live a self-determined life and increase dependency.

- The dependency encountered, coupled with the negative attitude of the community towards disability, places the persons with disabilities in a vicious circle of 'worthlessness'.

- The recommendations suggest reducing the dependency of persons with disabilities on their families, improving the perception of disability in the community and increasing self-esteem of persons with disabilities.

\section{Introduction}

The opportunity to live and participate in one's community is a basic human right but achieving this is difficult for most persons with disabilities. They have historically been isolated within their families and segregated from their communities. Constant discrimination has encouraged disabled people to mobilise themselves to attain more choice and control over their lives, to vocalise their need for enhanced support and for 
more inclusively designed community facilities, and to demand more appropriate living arrangements (UN Committee on the Rights of Persons with Disabilities 2017). The United Nations Convention on the Rights of Persons with Disabilities (CRPD) was adopted to address these needs and to acknowledge the human rights of disabled people. Article 19 of this convention, in particular, supports this struggle since it calls for an end to the isolation and segregation that dis- abled people face within their families and communities.

The implementation of Article 19 has varied in success in different countries. Although the committee on the Rights of Persons with Disabilities has offered guidance for implementation in different country contexts, developing countries have found it especially challenging to implement such rights-based protocols (Lang et al. 2011; Trani et al. 2011; Grech 2015). While countries have begun to translate the Convention into national laws and policies, often these lack an effective implementation mechanism and the potential will and understanding of the government and civil society to implement them (Lang et al. 2011). In this paper we use the capability approach (CA) that suggests that the implementation process of a human rights instrument such as the convention must recognise that disabled people have the same level of agency to lead a life they value as others and emphasises the need to address the additional resources required for achieving this (Sen 2009). Its proponents argue that the extent to which people can exercise agency is the result of their ability to convert personal, social and environmental factors into real opportunities to lead a life they choose and do things they desire (Sen 2009) and having agency and its lack is seen as the result of interplay of these factors in specific contexts. Therefore, to improve the implementation of Article 19 and enhance the 
agency of disabled persons, it is important to get insight into the interplay of these factors.

India has formulated laws and policies to harmonise with the convention. However, in the context of rural India, the government has faced challenges in reaching and bringing change even after the harmonisation (National CRPD Coalition 2019). There is no existing research addressing how personal, social and environmental factors hamper or enhance the opportunities that exist for rural disabled persons to exercise agency, the absence of which results in their isolation and neglect. This paper aims to provide detailed insights into how these factors challenge persons with disabilities to exercise their agency in daily life. Such understanding can be useful for developing policies and programmes that are more responsive to the challenges faced by them. To achieve this understanding, the next section has a brief over- view of rural India, specifically providing information on the incidence of disability, the legislative framework, access to public facilities for persons with disabilities and the cultural norms towards disability. The third section elaborates on the CA concepts used to investigate the everyday experiences of persons with disabilities in rural India.

\section{Overview of disability in rural India}

\section{Incidence of disability}

According to the 2011 census, $2.21 \%$ of 1.2 billion persons in India are per- sons with disabilities, $69 \%$ of whom live in rural areas. The UN and WHO estimate prevalence of global disability at $10 \%$ and $15 \%$ respectively, making the Indian census data significantly below these projections (WHO (World Health Organisation) 2011). This suggests a much higher incidence of disability. Moreover, two-thirds of the global population of such persons reside in the Asia-Pacific region (UN 2015) of which India 
is the second-most populous country. This further questions the official projections.

Scholars have argued that the low official disability-incidence rate in India is a result of the government's definition of disability; one that assesses the severity of impairment without considering the social and psychological barriers faced by disabled persons (Ghosh 2016; Palaniappan and Rodriques 2018). According to these authors, this rate coupled with a lack of data that is disaggregated based on disability in different areas, compromises on the comprehensiveness of the strategies the government adopts to address dis- ability (Ghosh 2016; Palaniappan and Rodriques 2018).

\section{Legislative and administrative framework}

Legislative harmonisation and its effective implementation are primary steps towards incorporating the human rights perspective proposed by the convention into national mechanisms. Having ratified the convention in 2008, the Indian government has taken several steps to implement it, of which enacting the Rights of Persons with Disabilities Act in 2016 (RPDA 2016) has been the most significant. RPDA 2016 replaced an erstwhile Persons with Disabilities Act 1995 which focused on the distribution of entitlements rather than rights. The Department of Empowerment of Persons with Disabilities (DEPD) under the Ministry of Social Justice and Empowerment is the nodal agency for the implementation of the Act. A large part of the implementation is done through schemes run by the DEPD. However, according to the disability rights movement, schemes continue to be based on the former act without restructuring them to harmonise with the convention or the RPDA 2016 (National CRPD Coalition 2019, 4).

The key existing schemes impacting lives of disabled persons in rural areas include the District Disability Rehabilitation Centres (DDRCs) that aim to provide 
comprehensive rehabilitation services to disabled people at the grassroots level (Government of India 2015). However, only 256 districts of a total of 640 have DDRCs (Government of India 2016), creating a vacuum in villages for basic rehabilitation services. Another is the Scheme for Assistance to Disabled Persons for Purchase/Fitting of Aids and Appliances (ADIP Scheme), which makes assistive devices available to persons living below the threshold family income. Here too, the unmet need for assistive devices, especially in rural areas, remains high (WHO (World Health Organisation) 2011). In addition to these schemes, the Indira Gandhi National Disability Pension Scheme (IGNDPS) offers disability pension to disabled people between 18-79 years of age who live below the poverty line (Government of India 2015). However, the pension amount given being very low, it has only a limited impact on the lives of persons with disabilities (National CRPD Coalition 2019).

\section{Access to public services and facilities}

It is not disabled persons alone; others also suffer due to inadequate public services and facilities. Rural India lags in basic infrastructural development indicators for public services and facilities such as education, health, livelihood and social protection (Ghosh 2017) that in turn reduce the opportunities for persons with disabilities living in these areas because they are faced with additional disabilityspecific barriers such as negative attitudes and inaccessibility of the environment. For instance, only $6 \%$ of villages have access to rehabilitation services that are within a reach of ten km (WHO (World Health Organisation) 2012, 11). Disabled people have to spend extra to travel long distances to get the service or remain without the rehabilitation that allows them to gain self-care skills (Klasing 2007; Mitra et al. 2017; WHO (World Health Organisation) 2011). The educational infrastructure is poor and even if a village has a primary school, often parents do not see the point in 
sending their children to it (Ghai 2002; Buckingham 2011). Livelihood opportunities remain out of reach for a majority of disabled people. It makes them dependent on their families and necessitates their being provided for. This also renders persons with disabilities socially under- valued and excluded (Klasing 2007; Grech 2015).

\section{Cultural norms}

Finally, it is acknowledged that cultural perceptions of disability have a significant impact on the lives of persons with disabilities. Culturally, in the country and especially in rural areas, disability is viewed as an outcome of karma. The karmic theory is based on the principle of cause and effect and disability is seen as a result of past misdeeds. Such perceptions of disability stigmatise disabled people, rendering them invisible and causing them to be viewed as socially inferior (Miles 2002; Ghai 2002). Such cultural perceptions are so deep-rooted that according to Gupta (2011), the theory acts as a way to accept and cope with disability. The family is a part of the karmic retribution cursed by the birth of a disabled child because of their past sins, and therefore expected to assume the responsibility of caring for the disabled family member to wash away these sins (Miles 2002; Gupta 2011; Klasing 2007). Further, the inability of disabled people to perform religious rituals or undertake economic activities makes them unworthy of receiving an inheritance from their family (Buckingham 2011; Groce, London, and Stine 2014).

Although the government took initiatives to improve agency of persons with disabilities, environmental and social conditions in rural India seem to be far from ideal to enable this. How these conditions precisely impact everyday functioning of persons with disabilities is not known yet. The CA emphasises the need to look at such factors while considering the agency of people. Therefore, we use the CA to theorise the challenges faced by per- sons with disabilities to exercise agency by 
analysing the lived experiences of such people, based on their perception, to understand the impact of the interplay of such factors on their agency.

\section{Theoretical framework}

The CA offers a broad normative framework to evaluate aspects of people's wellbeing, including those related to inequality. Evaluation is undertaken in terms of disadvantages people face in leading a life they value (Robeyns 2005; Sen 2009). CA is increasingly used by researchers to theorise disability (Burchardt 2004; Mitra 2006; Trani et al. 2011), especially because it views disability as a social construct and encompasses the social model of disability by considering the external barriers faced by persons with impairments in their communities (Burchardt 2004; Mitra 2006; Robeyns 2005; Oliver 1996). It further goes beyond the social model and takes into account the lived experience and the pain of impairment, both physical and psychological, while looking at the barriers that are arguably denied by the social model (Ghosh 2016; Shakespeare 2014; Mitra 2006; Burchardt 2004), making the framework suitable for this study.

Disability in the CA is considered a deprivation in terms of capabilities or functioning that results from the interaction of the internal and external factors individuals face (Mitra 2006). The impact of the interplay of these factors on the lives of people can either limit them or work to their advantage to meet the aim of leading a life they value (Sen 2009). Each individual faces peculiar restraining or enabling circumstances as a result of the interplay of these factors they encounter in their personal, social and environmental lives. For persons with disabilities, the additional personal factor of their impairment makes it difficult for them to benefit from the social and environmental factors such as assets, income, family support, social capital, political stability, cultural aspects, infrastructural development, deforestation and so 
on (Trani et al. 2011; Sen 2009; Mitra 2006). For instance, even if they have the financial resources, the real opportunities or capabilities to use these to lead a selfdetermined life are limited as compared to non-disabled persons, because of the way their personal, social and environmental factors affect them (Sen 2009).

Since the interplay of personal and external factors influences the way an individual lives, the CA considers any evaluations based on financial well- being as being inadequate, as it does not consider individual differences in the interplay of these factors that are an outcome of the individual's circum- stances (Sen 2009). Instead, evaluation using the CA can be undertaken at two levels. First, at the level of 'functions' that refers to the state of being and the state of doing (Sen 1999; Mitra 2006). For example, being mobile and working respectively. Second, evaluation can be done at the level of 'capabilities' that are defined as the real freedoms or opportunities a person has to achieve these functions (Sen 1999; Mitra 2006). For example, if being mobile is a function, the real opportunity or capability for most individuals with mobility impairments would require them to have access to mobility devices (Sen 1999; Mitra 2006). The total of all the capabilities a person has is termed as their 'capability set', and this represents an individual's freedom to achieve wellbeing and agency (Sen 1999).

Agency is an important aspect and lies at the heart of the approach, where an individual may decide for themselves which capabilities they choose to achieve from their capability set. For example, persons with mobility impairments may have a mobility device and the means to go out of their homes when they desire, but how often they want to go out is their choice based on what they value. According to Robeyns $(2005,37)$ the CA looks at people “....as agents, who can and should be given the power and the necessary conditions to take their lives into their own hands". 
Further elaborating on agency, Sen $(1999,2009)$ suggests that while agency is an individual virtue, exercising it is dependent on a combination of internal conditions such as skills, motivation and confidence, and external conditions such as the environment, support services and culture. In this research, by looking into the perceptions of persons with disabilities living in rural areas and observing their environments, we examine the interplay of these personal, social and environmental factors that influences the agency of persons with disabilities in undertaking daily living activities and in participating, to draw lessons from it and improve actualisation of the CRPD in rural India.

\section{Methodology}

This qualitative research is undertaken in the interpretive approach that is about understanding the lived experiences of persons in a certain place at a certain time based on their interpretation of their reality, thus examining the topic through the eyes of those being studied (Green and Thorogood 2013; Tolley et al. 2016). The interpretative approach enables a better understanding and insight of the circumstances of human behaviour (Tolley et al. 2016), which is particularly important for this research that looks at the lives of persons with disabilities in rural India that are impacted by other internal and external circumstances of the individual.

\section{Participants}

The respondents for the research were identified with the support of the Rural Development Trust (RDT), a development organisation working to improve the quality of life of the rural poor in the Anantapur district of Andhra Pradesh, which runs a CBR programme that focuses on establishing self-help groups for adults with disabilities. These groups include disabled people and their families and work towards ensuring equal rights and opportunities for their members. Opportunities include 
access to special education, rehabilitative aids and treatment, the right to open bank accounts and the chance to achieve economic independence. They have reached thousands of disabled villagers from the district in their five decades of existence (RDT 2016).

All the selected participants were from the villages of two talukas (an administrative district for taxation) of the Anantapur district. They were identified with the assistance of the RDT staff who work with the persons with disabilities in the villages and have a strong grassroots network. The general level of awareness about pension was high in these villages and all participants received a disability or old-age pension. The pension was not necessarily thanks to RDT fieldworkers as not all participants were their service users; many participants who are not members of selfhelp groups accessed the pension with the help of their family.

The selection criteria included the participants being adults with physical disabilities who require some form of support for personal mobility and daily living activities. In the final selection, we made sure the respondents reflected relevant differences in personal characteristics, to attain rich data with all diverse and varying categories of persons accounted for even though it was a homogeneous group (Green and Thorogood 2013). The ages varied from 20-80 years and around half was female and half were male. All except one received pension and family income ranged from USD 128 TO USD 600 per month. Five participants had some basic education; two of these had a bachelor's degree. They all lived with the family with the woman of the family being the main care provider. Five were member of self-help group, the others not. Saturation was reached after 11 persons were inter- viewed as there was no incremental code development from the data that was being collected (Green and Thorogood 2013). 


\section{Data collection}

The researchers used qualitative interview techniques, which facilitated the capturing of diverse responses from the participants and enabled a deeper analysis of the lives of the disabled interviewees to emerge (Kelly 2010). Semi-structured open-ended questions were posed that explored the day-to- day realities of their lives, especially in terms of the choices available to them and whether they participated in family and community life (Kelly 2010). The interviews took the form of conversations that required the respondents to describe the details of their daily lives and were governed by an interview guide that was prepared in advance. Participants were provided with explanations about the nature and purpose of the interview. Before proceeding with the interview, consent - including the permission to audio record - was taken from each participant after explaining to them the purpose of the study and the process being followed. They were informed that anonymity would be maintained and that they had a choice of what they wanted to share. RDT workers - who are already working in and had the sup- port of the local community - gained prior permission and meeting time suitability from the participants and their families.

The interviews were undertaken with the support of an interpreter who was bilingual and able to speak in both the local language used by the respondents, that was Telegu and English used by the interviewer. According to Green and Thorogood (2004), the ability of the translator to add contextual information to what is being said adds to the quality, which the translator was able to as she was working as a special educator in a school with an extensive experience of working with persons with disabilities from the villages where the respondents resided. Further, an independent person proficient in both languages, who gave feedback after the first recording, verified the quality of the translation. 


\section{Analysis}

The data collected was analysed in inductive analyses where the themes and explanations are derived from a close reading of the data. Inductive analyses are more commonly used in the interpretive approaches (Green and Thorogood 2013).

The analyses began with transcribing the interviews followed by a close reading of the transcriptions. The close reading helped to identify the repetition of topics that aided the development of coding of these different topics (Green and Thorogood 2013). These codes were further divided into themes based on the social science literature related to disability (Green and Thorogood 2013) that include 'attitude towards the disabled person', 'infrastructural challenges faced by the disabled person', and 'choice and control on the activities they undertook'. The Atlas ti software used for the analyses helped organise the codes and themes (Green and Thorogood 2013). After the rigorous organisation of the data in different themes, certain interlinked common aspects emerged that were used for presenting the data in this paper. These four aspects identified were relating to basic functioning and daily lives of the persons interviewed and included:

(1) Undertaking daily living activities such as toileting, bathing, grooming;

(2) Relationship with their family and interactions with their community;

(3) Going out;

(4) Plans for the future.

Finally, the data was interpreted by making analytical conclusions on these four aspects to give symbolic meaning to the lived experiences of the respondents. These are presented in the next section. 


\section{Results}

\section{Daily living activities}

The first aspect examined was the extent of support available to the participants to undertake daily living activities such as bathing, eating, dressing and toileting, and the impact of this support on their lives. The women of the household provided support to all the participants interviewed. This was a common practice and the respondents were content in the way they led their daily lives and did not feel the need for additional support. They could not envision their life otherwise, therefore did not seek any change. Getting additional support at times from anyone other than the immediate family was unacceptable. Respondents saw their disability as a result of past misdeeds and seeking anything additional to cope with or reduce hardship was perceived as a hindrance to their karmic retribution.

According to J:

I would not like anyone to come to my house and serve. My wife will take care of me. I made some mistakes, because of which I am now disabled.... If I have someone to come and serve me, it will add to my bad karma.

The participants resided with their families in one-room ground floor houses that often had steps at the entrance. The entrance doors had high thresholds and there was a lack of manoeuvring space inside the house, which made moving around with their mobility devices impossible. Consequently, it was common for them to crawl or be carried within the house. Most homes had a toilet and bathroom; however, only a few respondents mentioned using these. It was common to use the toilet and the bathroom for storage or as a shelter for hens and goats. Respondents felt that if their homes and toilets were more accessible, they would require less support in daily living activities, which would enable then to lead a more independent life. I, for instance, said: 
I go crawling to the toilet and sit on the iron bowl my mother places there. It is not convenient, but there is no other way. I can wash myself. My mother will throw it out, once I finish.

Reflecting on life without his parents, he added:

If my parents are not around, I will do all my work myself. I will renovate my house in such a way that I don't require any help. Then it will be easy for me to go everywhere in the house. It's going to be difficult, but I will have to manage.

The overdependence on their caregivers made the respondents feel like a burden. As a response to these feelings, they adopted different ways to reduce the amount of care they required. At times this meant not undertaking activities such as bathing, turning at night and resting in the afternoon that they felt were not critical. For instance, B said:

My mother wakes up at 6 o'clock. She will finish everything, including puja (prayers), by 8:30am.... I don't want to trouble her by asking her to bathe me.

For critical activities such as toileting, they restricted their water and food intake to reduce the frequency. They did so also to cope during times when they were left unattended at home. For instance, K's mother goes out for daily wages to work at 8 am and returns by $6 \mathrm{pm}$, leaving $\mathrm{K}$ alone at home. Addressing this, $\mathrm{K}$ said:

I do not drink any water during the day after my mother leaves for work because I am alone; if I want to pass urine when she is gone, who will help me?

Such practices have an impact on their health, as was evident when K reported having a persistent stomach-ache. Their lives revolved around the support that was available to them and they had no freedom to do things as and when they wanted.

The sense of being a burden due to the dependency they faced had a strong impact on their relationship with their family, especially with the primary caregiver. It was laden with a feeling of intense appreciation for and gratitude towards the caregiver. For instance, G said: 
My wife is serving me, so I think that she is like my mother.

The dependence made them insecure about what would happen to them if their primary caregiver was no longer available. They had no idea how they would manage in such an eventuality. They expressed a fatalistic view, leaving it to God to sort the problem. For instance, when questioned about how he would manage if his wife was no longer around to take care of him, $\mathrm{J}$ said:

I have not thought about it. If someone else supports me, that's good. Else, God will take care of me.

Having lived in a certain support system, most respondents had no idea how to change their present situation and could not envision any alternative to improve their lives. They felt that their caregivers were over-burdened; having additional support for their primary caregivers would be beneficial. For instance, K said:

We need rations and for that, only my mother goes to work; if they help us with rations, my mother need not go to work and that would be nice for me.

To summarise, the respondents expressed not having any agency in when and how they undertook activities of daily living. Their agency was compromised as a result of the interplay between social and environmental factors that impacted them differently as compared to others without disability. Firstly, it was the inaccessibility of their home environment that made it difficult for them to undertake any activity independently. They were completely dependent on their families. Further, since the women alone in the family provided them support, the respondents felt they were overburdening them. That made them hesitant to ask for support unless it seemed critical. Such an attitude towards basic activities resulted in compromising their health and wellbeing. The cultural perception of disability impacted their agency by limiting culturally appropriate alternatives for support. Their situation and support system 
were socially accepted and making changes to it was considered as hindering their karmic retribution.

\section{Interaction and participation}

The researchers examined the social networks of the respondents and their contribution to develop such networks further. The first finding was that most respondents did not contribute to any family discussion because, on account of their dependency, their sense of worthlessness made them feel that their opinion was unimportant. They lost interest in family matters. For instance, E who lives with her husband, his second wife and children, stated:

My family tells me about the discussions in the house, but they do not ask for my suggestions. I don't give any either.

Those interviewed felt incapable of undertaking any kind of physical work, as a result of which they did not contribute to any domestic chores. For instance, F said:

I don't help with any home activities. I cannot do that much work as my hands are weak.

Consequently, they felt that they were not expected to undertake any work outside in the community and were simply whiling away their time. For instance, I, a young paraplegic man stated:

I sit outside the house all day. If anyone comes to talk, I talk; otherwise, I just sit and watch passers-by.

A said:

I wake up at 7 am and switch on the TV. It is on all day except when there is no electricity.

According to them, their sole contribution to the family was financial, as they turned over the money from their disability pension to help with home expenses. For instance, G said: 
I give my entire pension money to my son since he feeds me and takes care of me.

Other than not feeling capable of contributing to the family, they had a restricted social network. Their immediate families apart, the only people they interacted with were extended family and neighbours. However, this interaction depended on whether the immediate family got along well with such groups. For instance, A said,

Relatives who are close to us take care of me and sometimes give food and money too.... However, some relatives who have fought with my parents won't speak to me either, though I have no quarrel with them.

I said,

I go to the mango garden once a fortnight. My cousins take me there when I ask them.... I go there only for a change since I sit outside the house all day.

Good relationships with neighbours meant that the support provided could be supplemented by those living nearby. They provided additional food and helped with feeding the disabled person; this was especially crucial when primary caregivers were unwell. At times, the neighbours would assist in carrying the disabled person to the toilet. For instance, G said:

When I come out of the house for a bath, three or four people are required to help me. My neighbours and members of the SHG provide help.

Most respondents stated they had no friends. They had friends during their school days, but now, all of them were married and these friendships were lost. After they stopped going to school because of their disability, they stopped making new contacts. K said:

I do not have any friends. I had friends in school when I was 12 years old, before my accident. They are all married now and have gone off to other villages.... They must have forgotten me. 
They considered their disability the prime reason for not interacting with others. For instance, I said:

I became disabled in an accident at 19. At that time, I had friends of the same age group... But not anymore. They no longer come to meet me... I also do not go to their house because I feel embarrassed about going there in a wheelchair.

An exception was observed in the feeling of self-worth. Respondents with an achievement - for instance, a bachelor's degree, which was higher than the education level of most community members - had better self-worth and were able to foster relationships within the family, with their neighbours and with the community at large as they were able to reciprocate in several ways. For instance, $\mathrm{C}$, a young graduate with a disability is a very social per- son, always going around in his village with his uncle (a person with an intellectual disability) who supports him. He claimed to have numerous friends, both disabled and otherwise. He was active in his self-help group, advocating the rights of persons with disabilities. Compared to other respondents, he had education and support to push his wheelchair as he went around the village. He said:

If anyone does not have an Aadhaar card, a ration card or pension, they ask me the procedure to get these. If there is some news in the papers that could affect the villagers, I tell them; for example, if the government is disbursing funds or helping villagers.

In short, it was the psychological impact of living with a disability and the high level of dependence on the family that made disabled persons feel worthless. The worthlessness they experienced was a barrier to them having agency. Identification with their impairment made them feel incapable of reciprocating in any physical way for the care they received. This reinforced the worthlessness they experienced. However, they felt that their contribution to the family was financial as they gave their disability pension for family expenses. Self-worthlessness made them feel 
incapable of sharing their opinion on domestic matters. Their low self-worth denied them the person- hood to forge relationships with those other than immediate family, leaving them dependent on their family for emotional support as well. Such feelings also prevented them from making friends and they felt forgotten and left behind as their childhood friends moved on. Consequently, they had no social networks; a result of external factors such as inaccessibility and lack of support, and social outlook towards disability. However, those better educated than others around them were more confident about reciprocating the care they received. Their knowledge compensated for physical limitations, enabling them to have better social networks, beyond the extended family and neighbours.

\section{Going out}

The respondents expressed regret at being unable to attend community activities or participate in family events. They only left their homes to see doctors, vote or appear for exams. They offered many explanations for feeling inhibited about going out. One reason stemmed from their sense of being a burden, something which has already been addressed under 'Daily living activities'. For instance, D said:

I want to go out more often but, how would I? I don't want to trouble my son and daughter-in-law.

The second reason was infrastructure inaccessibility and the lack of mobility devices. For instance, K said:

There are steps in front of my house, which I cannot negotiate in a wheelchair and the road in front of my house is in bad shape.

D confirmed that lack of mobility devices constricted his life, saying:

If I had a wheelchair, I would roam around with the help of my grandchildren.

The third reason for their being trapped was the high cost of transport. Unlike non-disabled commuters, the respondents were unable to share an auto-rickshaw 
because they had to travel with their mobility devices and their assistants, thus being forced to bear the entire expense of the journey themselves. For instance, I said:

If I take an auto-rickshaw, I have to pay a lot of money since I need to book the entire auto for myself; none else can share it because of my wheelchair.

Additionally, leaving the house meant paying the wages of their travel companions, since going out alone was not an option. For instance, B stated:

I like to go out, but I don't. Money is the main reason is money. [Because] when I go out, I need to call a worker - whom I need to pay - to help me.

Most respondents complained about pain in their limbs. It discourages them from doing things at home and from moving around or going out. The pain was not medically diagnosed but some respondents took painkillers from the local community health worker. F remembered the time she went with her family to watch a drama ten years ago and the trouble she put her family through, as they had to carry her. She did not enjoy the outing for this reason but ascribed the reason for not going out to the pain she experiences. She said:

I can't sit for long periods as it causes pain in my back and knees; that's why I don't like going out.

The respondents explained that, given external support, they would like to emerge from their isolation. B said:

When my relatives visit, they invite me to family functions along with my family. If they carry me, I would like to go. But if I have to go alone, I will not go.

$\mathrm{D}$ made the following observation:

If I had a personal assistant, he would always be with me and I would move around more easily.

To summarise, the respondents hardly ever ventured out of their homes except to visit the doctor, vote or write an exam, but wanted to go out more often. The key 
reasons for not going out as often included the inaccessibility of the external environment, transportation and the lack of a mobility device. The lack of support to accompany them was also an important reason. The persistent pain in their limbs diminished their interest in going out. Additionally, the cost of hiring an entire autorickshaw further discouraged them. All these internal and external factors restricted their agency by making going out a difficult experience, not an enjoyable one.

However, not being able to go out impacted their participation in community events and interaction with community members.

\section{The future}

The participants expressed a sense of surrender to their dependency and the situation they were in. They were not happy with their lives but did not think that anything would improve. The only way things could improve was if they went back to being non-disabled again. I, a young man who became disabled from an accident felt that he was no longer 'normal' and all he wanted was his normal life back. He said:

I am not satisfied with my life because I was a normal person and I am disabled now. That's why I am dissatisfied. I want my normal life back... I just want my old life back.

It wasn't him alone; others also wanted a reduction in their impairment and wished for better medical treatment that could cure them of their disability. For instance, F said:

If I had a lot of money I would go to a hospital and get treatment to walk again. I want money for treatment and a cure.

Some expressed a sense of surrender to their dependency and to a situation where they were not happy with their lives, having reconciled to the fact that they could not get medical treatment or be better ever again. They had lost all hope for the future and left themselves at the mercy of God, with no will to live. For instance, K observed: 
I aim to die. God has to take me. I don't like this life. I do not have any future plans or goals.

E said:

I pray that God takes me. There is nothing that I want. I have no desires.

A few anomalies were noticed, especially in young men, some of whom had some education. They seemed to envision some kind of future for them- selves, where they wanted to do a job and were working towards achieving their goals. They expressed their frustration at the lack of opportunities and information available in their village to help them find a job or be meaning- fully involved with life. For instance, I said:

I would like to earn money and give it to my parents, but, how can I? I want to, but I can't, and I don't know how.

To sum up, respondents expressed that their future was bleak and with- out their having any agency to mould it in a way that could have better out- comes for their lives. They were not satisfied with their lives because of their impairments and were seeking a 'cure' that could make them 'able' again. However, medical and rehabilitation services remained beyond their reach, as the public health system in rural areas was inadequate. Getting medical treatment in cities away from their homes was beyond their means. While they hoped for financial support to get medical help, knowing that things were unlikely to change left them 'hopeless'. They saw death as the only escape. Younger respondents, especially men, were not as hopeless and longed for a better future when they could work and earn some money. However, they felt frustrated with the lack of opportunities, information and support in this regard.

\section{Discussion}

This paper reports on the insights gained into the lives of disabled people living in rural India based on the investigation carried out into the challenges they experience 
to exercise agency in their daily living activities. These challenges were looked at as a result of the interplay between internal and external factors in terms of their personal, social and environmental situations. These factors reinforce each other to create a vicious circle that pre- vents the disabled persons from having agency and restricts the possibility of them being able to exercise agency in the future. To begin with, disabled people are unable to fulfil even basic functions such as being well hydrated, using the toilet or turning at night as a result of the lack of support available to them. Their dependency for daily living activities increases because of the inaccessibility of their homes, preventing them from doing anything independently, leading to a feeling of being 'worthless'. The negative image of 'worthlessness' makes them feel incapable of reciprocating in any way for the support they receive. Not being able to contribute constructively not only reinforces the negative self-image but also impedes opportunities to create a social network for themselves, thus remaining dependent on their families for all kinds of support.

The 'vicious circle of worthlessness' they experience, reinforces the community's perception of disability. Disabled persons are limited by the sheer struggle to adjust to their situation and to lessen the physical and karmic burden they impose on their families. The concept of 'adapted preferences' proposed by the CA, enabled better understanding of the situation in which individuals adjust themselves and their lives, needs and aspirations in a way that they consider meets social perceptions and what is expected of them (Sen 2009; Trani et al. 2011; Nussbaum 2011). While it may appear 'natural' for the disabled people to alter their wishes as an outcome of their lived reality, these decisions cannot be considered as having been made out of choice (Begon 2014). Crucially, what happens is that disabled people seem to 'disappear' from their community because they are not able to exercise agency, a phenomenon 
that results in the community (and often the government) not recognising that there are 'unseen' people in their midst who have needs that must be met and that structures must be put into place to address those needs.

As at the internal level persons with disabilities adapted themselves to their situation with reduced self-worth without exerting agency, we explored the external factors that influence such outcome. We discuss other aspects such as the role personal, social and physical environment factors play in enhancing agency. We address the challenges in reducing dependency that disabled people face in their daily living activities that were identified as the key reasons for loss of agency. We argue that the dependency they face is the outcome of the lack of support to undertake activities and the inaccessibility of their homes that prevents them from undertaking activities independently, putting further 'burden' on the family.

According to Ghai $(2015,107-108)$ "In developing countries like India, disability rehabilitation is always primarily considered the responsibility of the family, which provides essential physical, emotional and economic support to its members with disabilities". Such a system results in inadequacy of the support structures available that can enable disabled people to undertake activities without feeling like a 'burden'. The present system where only the family provides support, makes disabled people adapt themselves to the situation without even realising, as the adapted preferences proposed by the CA suggest (Sen 2009). This family-based social and cultural system, that leaves all aspects of care and support to the family, is reinforced by the legislative framework. The RPDA 2016 addresses the importance of personal assistants by making provision for a 'caregiver's allowance' to be given to persons with disabilities as a social security measure, but the definition of a 'caregiver' in the Act suggests only the family as playing that role. Thus, it may be important to 
broaden the definition by recognising professional care and support providers and non-family members in the role. This may not only bring better acknowledgement of the care and support work but also make it an entitlement for persons with disabilities rather than favour they receive from their family.

It may not be possible to replace the role of the family in providing sup- port and care to disabled people because of the naturally existing manpower and free resources that the family constitute (WHO (World Health Organisation) 2011; 2012). However, there is existing evidence highlighting the negative impact of long-term caregiving on the informal care provider's social, mental and physical health that affects both, the caregiver and the care receiver (WHO (World Health Organisation) $2012,2002)$. Therefore, there needs to be further investigation of the impact of providing care and sup- port to disabled people in rural areas on the caregivers and its impact on the disabled persons they are providing care to. Further research is also required to look at ways of strengthening the existing system of care and support and further develop workable models for additional support structure for disabled people in rural areas.

Another external factor identified as increasing the dependency of disabled people is the inaccessibility of their home environments as a result of the absence of indoor mobility devices, forcing those unable to walk to crawl or bottom shuffle, thus denying them to be mobile within their homes. Narrating from personal experience, Ghai $(2015,217)$ has elaborated on the resultant lowering of self-image. In rural India, bottom shuffling is a common unaddressed practice. Considering that the flooring is not always cemented and uneven, regular bottom shuffling may result in injuries and medical complications. Therefore, it is important to address home 
accessibility in terms of the appropriate mobility devices for rural homes, which are significantly different from urban homes.

Investigating this further, one sees that the government as a social security measure under the Indira Awaas Yojana (IYA) scheme often pays for the construction of houses in rural India. A typical house built under this scheme is small with one room and a kitchen and lacks wheelchair manoeuvring space and accessibility. Closely related to the home design and manoeuvring space is the suitability of mobility devices for indoor mobility. Presently, persons with mobility impairments are given wheelchairs and tricycles under the scheme for Aids and Appliances (ADIP). However, these devices cannot be used indoors because of the lack of manoeuvring space, forcing users to bottom shuffle or crawl (Planning Commission of India 2013). Thus, further investigation is recommended to look at accessibility and house modification in rural environments along with the mobility devices that are suitable for use in these homes.

The use of the CA, whose core characteristic is focusing on the achievements of people in everyday life on the one hand, and options from which one can choose on the other, was suitable for this research in two ways (Robeyns 2016). First, it gave the flexibility to analyse the data at the level of capabilities where agency was important. Second, it allowed analysis at the level of functioning where agency did not play a role (Robeyns 2005b). Considering persons with disabilities in rural areas have no agency, such flexibility allowed the understanding of reasons for the loss of agency. The loss in agency was seen as an outcome of persons with disabilities not being able to achieve certain beings and doings (functioning) as a result of personal, social and environmental conversion factors (Robeyns 2005b). 
To summarise, using the capability approach framework to look at the agency persons with disabilities in rural areas can exercise shows that they seem trapped in a vicious circle that makes them feel 'worthlessness'. This self-perpetuating circle is a result of the interplay between internal and external factors in their personal, social and environmental spaces. The circle is further reinforced by the community's expectations from and attitudes towards disability that persons with disabilities imbibe, making themselves invisible. Therefore, it may be said that interventions made must be two pongs. First, they may address the external factors, especially those associated with decreasing their dependency. That includes the development of a better support structure, access to appropriate assistive devices and more enabling design of the environments they live in. Persons who had better education seem to have more agency but yet they struggle with basic functioning and the feeling of being a 'burden' remains. Second, and equally important is the need to influence the internal factors individuals live with as a result of adapting to their circumstances by addressing the 'worthlessness' they feel. This may require interventions that influence community attitude towards disability and those that work towards building selfesteem of per- sons with disabilities. Addressing the external or internal factors alone may not break the 'circle of worthlessness' that persons with disabilities in rural areas find themselves in. This research reaffirms that indeed it is a lack of different aspects related to the internal and external factors that prevents per- sons with disabilities from achieving even basic functioning. This research has not gone beyond discussing different reasons for not being able to achieve basic functioning. Further research is required to systematically look at how to address these barriers faced by the persons with disabilities through policy and institutional frameworks. 


\section{Conclusions}

Persons with disabilities living in rural India are still 'isolated' in their own homes and communities without having any agency. The research used the capability approach that enabled a robust investigation into the lived experiences of persons with disabilities in rural areas. The results show that the causes for persons with disabilities not able to live a life they value because of the interplay of personal, social and environmental factors they face. The approach enabled us to look at these factors as being internal and external to the disabled persons and their interplay that seemed to create 'vicious circle worthlessness', for the persons with disabilities. The key factor identified was the high level of dependency for daily living activities that the person with disabilities had on the family. Related to this was also non-availability of additional support other than the family. Inaccessibility of home environment and lack of appropriate mobility devices increased their dependency for daily activities on the family. Adding to this the CA also helped to correlate the negative attitude of the community towards disability that the disabled persons accepted and imbibed further increasing the 'sense of worthlessness' and a feeling of being a 'burden'. Therefore there is a need to address the dependency persons with disabilities face, by creating more awareness about disability, developing self-worth of persons with disabilities living in these area, besides creating more enabling and inclusive environments; developing better support structures for persons with disabilities in their community reducing their dependency on their family in a systemic manner that impacts the policy and institutional framework. 


\section{Reference}

Begon, J. 2014. "What are Adaptive Preferences? Exclusion and Disability in the Capability Approach.” Journal of Applied Philosophy. doi:10.1111/japp.12102.

Buckingham, J. 2011. "Writing histories of disability in India: strategies of inclusion, Disability \& Society, 26 (4), 419-431. doi:10.1080/09687599.2011.567792.

Burchardt, T. 2004. "Capabilities and Disability: The Capabilities Framework and the Social Model of Disability.” Disability \& Society 19 (7): 735-751. doi:10.1080/0968759042000284213.

Ghai, A. 2002. "Disability in the Indian Context: Post-Colonial Perspectives." In Disability/ Postmodernity: Embodying Disability Theory, edited by M. Corker and T. Shakespeare, 88-100. London: Continuum.

Ghai, A. 2015. Rethinking Disability in India. New Delhi: Routledge.

Ghosh, M. 2017. "Infrastructure and Development in Rural India.” Margin: The Journal of Applied Economic Research 11 (3): 256-289. doi:10.1177/0973801017703499.

Ghosh, N. 2016. "Introduction: Interrogating Disability in India.” In Interrogating Disability in India, edited by N. Nandini Ghosh, 1-22. India: Springer

Government of India. 2013. Indira Awaas Yojana: Guidelines. New Delhi: Ministry of Rural Development. Government of India. 2015. First country report of India on the status of persons with disabilities. Advance unedited version. UN OHCHR.

http://tbinternet.ohchr.org/_layouts/treatybodyexternal/Download.aspx?symbo $\operatorname{lno}=\mathrm{CRPD} \% 2 \mathrm{fC} \% 2 \mathrm{fIND} \% 2 \mathrm{f} 1 \&$ Lang $=\mathrm{en}$

Government of India. 2016. "District Disability Rehabilitation Centre as on April 2016." Community Date Gov.in. https://community.data.gov.in/districtdisability-rehabilitation- centres-as-on-april-2016/

Grech, S. 2015. Disability and Poverty in the Global South: Renegotiating Development in Guatemala. London: Palgrave Macmillan.

Green, J., and N. Thorogood. 2004. Qualitative Method for Health Research. London: Sage Publications Limited.

Green, J., and N. Thorogood. 2013. Qualitative Method for Health Research. 3rd ed. London: Sage Publications Limited. 
Groce, N. E., J. London, and M. A. Stein. 2014. "Inheritance, Poverty, and Disability.” Disability \& Society 29 (10): 1554-1568. doi:10.1080/09687599.2014.969831.

Gupta, V. B. 2011. "How Hindus Cope with Disability.” Journal of Religion, Disability \& Health 15 (1): 72-78. doi:10.1080/15228967.2011.540897.

Kelly, S. E. 2010. “Qualitative Interviewing Techniques and Styles.” In The Sage Handbook of Qualitative Methods in Health Research, edited by I, Bourgeault, R. Dingwall, and R. De Vries, 307-325. London: Sage publication ltd

Klasing, I. 2007. Disability and Social Exclusion in Rural India. New Delhi: Rawat Publication.

Lang, R., M. Kett, N. Groce, and J. F. Trani. 2011. "Implementing the United Nations Convention on the Rights of Persons with Disabilities: Principles, Implications, Practice and Limitations.” Alter 5 (3): 206-220. doi:10.1016/j.alter.2011.02.004.

Miles, M. 2002. "Some Influences of Religions on Attitudes Towards Disabilities and People with Disabilities.” Journal of Religion, Disability \& Health 6 (2-3): 117-129. doi:10.1300/J095v06n02_12.

Mitra, S. 2006. “Capability Approach and Disability.” Journal of Disability Policy Studies 16 (4): 236-247. doi:10.1177/10442073060160040501.

Mitra, S., M. Palmer, H. Kim, D. Mont, and N. Groce. 2017. "Extra Costs of Living with a Disability: A Review and Agenda for Research.” Disability and Health Journal 10 (4): 475-484. doi:10.1016/j.dhjo.2017.04.007.

National CRPD Coalition India. 2019. “CRPD Alternate Report for India.” OHCHR. https://tbinternet.ohchr.org/Treaties/CRPD/Shared\%20Documents/Ind/INT_C RPD_ICO_Ind_33886_E.docx

Nussbaum, M. C. 2011. Creating Capabilities. Cambridge, MA: Harvard University Press.

Oliver, M. 1996. Understanding Disability: From Theory to Practice. New York: St. Martin's Press

Palaniappan, D., and V. Rodriques. 2018. "Disability within Rawlsian Framework of Justice Challenging the Injustice Rationale.” In Disability in South Asia:

Knowledge and Experience. Kindle ed., edited by A. Ghai. SAGE Publications. 
Planning Commission of India. 2013. "Evaluation Study on The Scheme of Assistance to Differently Abled Persons for Purchase/Fitting of Aids/Appliances (ADIP).” December 2013. Accessed 10 January 2018. http://planningcommission.gov.in/reports/peoreport/peo/eva_adip1501.pdf

Rights of persons with disabilities Act. 2016. Act no. 49. Retrieved from http://legislative. gov.in/actsofparliamentfromtheyear/rights-personsdisabilities-act-2016

Robeyns, I. 2005. “Assessing Global Poverty and Inequality: Income Resources and Capabilities.” Metaphilosophy 36 (1-2): 30-49. doi:10.1111/j.14679973.2005.00355.x.

Robeyns, I. 2005b. “The Capability Approach: A Theoretical Survey.” Journal of Human Development 6 (1): 93-117. doi:10.1080/146498805200034266.

Robeyns, I. 2016. “Capabilitarianism.” Journal of Human Development and Capabilities 17 (3): 397-414. doi:10.1080/19452829.2016.1145631.

Rural Development Trust. 2016. Annual Report. Accessed 25 March 2018. http://rdtfvf.org/wp-content/uploads/2017/08/RDTAnnualReport_201516_Reduced.pdf

Sen, A. K. 1999. Development as Freedom. Oxford: Oxford University Press.

Sen, A. K. 2009. The Idea of Justice. Cambridge, MA: Harvard University Press.

Shakespeare, T. 2014. Disability Rights and Wrongs Revisited. 2nd ed. New York: Routledge.

Tolley, E., P. Ulin, N. Mack, E. Robinson, and S. Succop. 2016. Qualitative Methods in Public Health: A Field Guide for Applied Research. 2nd ed. San Francisco, CA: John Wiley \& Sons.

Trani, Jean-Francois, Parul Bakhshi, Nicolo_Bellanca, Mario Biggeri, and Francesca Marchetta. 2011. "Disabilities through the Capability Approach Lens: Implications for Public Policies.” European Journal of Disability Research 5 (3): 143-157. ALTER - doi:10. 1016/j.alter.2011.04.001.

UN Committee on the Rights of Persons with Disabilities. 2017. General comment No. 5 (2017) on living independently and being included in the community. 27 October. CRPD/ C/GC/5.

United Nations Economic and Social Commission for Asia and the Pacific. 2015.

Disability at a Glance: Strengthening Employment Prospects for Persons with Disabilities in Asia and the Pacific. Bangkok: UN ESCAP. 
WHO (World Health Organisation). 2002. Current and Future Long-Term Care Needs. WHO/NMH/CCL/02.2.

http://www.who.int/chp/knowledge/publications/ltc_needs.pdf

WHO (World Health Organisation). 2011. World Report on Disability. Geneva:

WHO

WHO (World Health Organisation). 2012. Situation analysis of community based rehabilitation in the South-East Asia region. Accessed 12 March 2018.

http://www.searo.who.int/entity/disabilities_injury_rehabilitation/documents/s ituationanalysisofcbrinsear.pdf 


$$
\text { 售 }
$$




\section{Chapter 4}

\section{Women's Capabilities and the Challenges of Caring for persons with disabilities: Experiences from Rural Areas of Andhra Pradesh, India}

Gupta, S., Witte, L. De., \& Meershoek, A. (Submitted). Women's Capabilities and the Challenges of Caring for persons with disabilities: Experiences from Rural Areas of Andhra Pradesh, India. Journal of Family Issues 



\section{Abstract}

Adequate support and care is a prerequisite for full participation and inclusion of persons with disabilities (WHO, 2011). In rural India it is predominantly the women of the family who offer this care and support to a disabled family member. As a result the lives of these women caregivers are closely linked to the lives of the persons with disabilities and it is important to understand this relationship, and account for the experiences of these women when considering strategies to improve the existing support system. Therefore, this empirical research undertakes interviews with women caregivers in rural India and uses the capability approach to analyse the experience of caregiving. The results suggest that the prevailing invisibility and negative perceptions of care work for the disabled, coupled with the lack of agency of the women caregivers, makes the situation unsatisfactory for both the women caregivers and the persons with disabilities.

\section{Key words}

Persons with disabilities, caregivers, capability approach, rural India, agency

\section{Introduction}

Life in rural India is far from easy because of the lack of community services and facilities, coupled with the general lack of employment opportunities (Mukunthan, 2015). Persons with disabilities living here face additional challenges because of the prevailing negative attitude towards disability and the lack of prerequisites for inclusion such as support services and compliance with accessibility norms (Gupta, de Witte \& Meershoek, 2019; 2020; Klasing, 2007). In particular, in the absence of any support services, persons with disabilities become overly dependent on their families for physical, emotional and any other support that they require for living (Ghosh \& Banerjee, 2017; UNGA, 2017). Similarly, the family which is providing support also encounters significant disadvantages in terms of the well-being of its members (Ghosh \& Banerjee, 2017; UNGA, 2017). The challenges of providing care to the 
disabled family member are intensified in rural Indian communities as the families are confronted with poverty, and often caregiving requires the caregiver to forego paid work, thus adding to their financial challenges (Brinda, Rajkumar, Enemark, Attermann \& Jacob, 2014; Grech, 2015; UNGA, 2017).

Traditionally, it is the women of the family who are entrusted with the responsibility of providing care and support to the disabled family member and they shoulder this in addition to several other responsibilities at home (Folbre, 2004; Ghosh \& Banerjee, 2017; Prasad \& Rani, 2007; Ugargol \& Bailey, 2018; WHO, $2002 ; 2012$ ). As a result the only support that is available to persons with disabilities is from women caregivers, which makes their lives closely linked to the lives of these caregivers. There is a paucity of research into the experiences of such women caregivers in rural areas. However, with the ratification of the United Nations Convention on the Rights of Persons with Disabilities (UN CRPD) (UN General Assembly, 2007) the Indian government is required to develop disability support systems in the community (UNGA, 2017). Therefore, there is an urgent need to investigate the lived experiences of the women caregivers who often effectively represent the only source of support for disabled persons in rural India. According to the UN CRPD, support services must be user-led and such that they increase the autonomy and choices of persons with disabilities (UNGA, 2017). In the context of rural India, since the family is the only option for support available, it becomes equally important to take into consideration the wellbeing and autonomy of the family caregiver so as to foster a healthy environment for all. Therefore, to gain a more indepth understanding of the enablers and challenges of caregiving, this research investigates, through their lived experiences, the well-being and agency of women who give care to persons with disabilities. 
Greater insight into the challenges faced by women in providing care to disabled family members is necessary when considering strategies for improving the situation of disabled people in rural India. We use the insight provided by the capability approach to better understand how the existing social, cultural, economic and political scenario in rural India influences the experiences of the caregivers. However, before discussing this, we begin by examining the existing scenario of care and support for persons with disabilities in India, and the attention that the government and other stakeholders give to it.

\section{The existing system of care in India}

Traditionally, the family has been recognised as the main care provider for persons with disabilities in India. It is customary for the family to look after the disabled and older persons, and this is often the only option available (Murthy, 2016; Prasad \& Rani, 2007; Ghosh \& Banerjee, 2017; Ugargol \& Bailey, 2018). The responsibility for care provision in India, a patriarchal society, is inherited by the male family member. Depending upon the age of the person requiring care, their parents may be responsible for its provision, with a son or brother next in line to become responsible (Prasad \& Rani, 2007; Ugargol \& Bailey, 2018). While the men of the family inherit the care responsibility, it is mostly the women who have to take on the role of primary caregivers (Ghosh \& Banerjee, 2017; Gupta, Rowe \& Pillai, 2009; Prasad \& Rani, 2007). This is universally accepted, making caregiving a gender-specific task with the majority of care provided by women (Gupta \& Banerjee, 2009; Ugargol \& Bailey, 2018).

Furthermore, socially, care responsibility is seen as being of the family and the family normalises the responsibility as being that of the woman of the family. Providing life-long care in the case of persons with disabilities without expecting any 
compensation makes life disproportionately more difficult for families with a disabled member than it is for families without a disabled member (Brinda et al., 2014; Carers Worldwide, 2016; Ghosh \& Banerjee, 2017; Grech, 2015). This is more so in rural areas where the families are already combatting poverty. The cost of providing lifelong care without compensation, along with the loss of the potential income of women caregivers who must forego wages due to their care work, makes it difficult for families to make ends meet. It also makes the disabled persons feel like a 'burden', making them adjust even their basic daily living requirements around the availability of the caregiver (Ghosh \& Banerjee, 2017; Grech, 2015; Gupta et al., 2020).

The situation is made harder for the caregivers by the general lack of awareness of possibilities for learning and the lack of rehabilitation services that results in disabled persons not acquiring the skills for undertaking daily living activities (Ghosh \& Banerjee , 2017). Government rehabilitation centres exist only at the district level that have several villages under them. Community-based rehabilitation (CBR) is adopted as a way to reach disabled people in the villages. However, the few CBR projects are unevenly distributed across the country, and only a handful of existing CBR programmes address aspects of making persons with disabilities more independent in selfcare or address the challenges of caregiving (M. Balasubramanian, personal communication, 3 September, 2018; WHO, 2012). Moreover, the inaccessibility of homes in rural India often means that persons with disabilities have to be lifted and carried by their caregivers, increasing further the burden of care (Gupta et al., 2019).

Support services for persons with disabilities have not received much attention in legislation until the Rights of Persons with Disabilities Act (RPDA), 2016, which recognizes 'caregivers' and defines them as family members who provide care to a 
disabled family member without any payment. According to the act, the government is required to provide alternate options for care and support in the absence of a caregiver (Gupta, deWitt \& Meershoek, submitted). The RPDA also addresses the informal or unpaid nature of the family care system in the country by requiring the government to pay a 'caregivers allowance' to persons with 'high support needs' as a poverty-targeted social protection measure. However, the provision of the caregivers allowance has not yet been implemented in any of the states of the country. The government has also tried to build a team of trained caregivers through the Sahyogi Scheme (Government of India, n.d.). Under this scheme, the government offers funds to organisations offering training to family caregivers or to other people aspiring to take caregiving as a job. However, the reach and impact of the scheme are limited (National CRPD Coalition India, 2019).

While the government has not addressed the issue of formal caregiving, the private sector has identified the need to create care and support systems, especially for the elderly, as a business opportunity (Dey, n.d.). Some of the enterprises that have seized this opportunity to identify persons with disabilities as their clients, but the focus of these initiatives is more on nursing care and well-being, and they do not consider enabling participation of disabled clients to form part of their mandate. Moreover, there are no government regulations covering the ethics, quality or cost of services offered by such enterprises.

The non-governmental sector has made small interventions through CBR programmes by offering training to families in a few projects. Carers Worldwide, an international non-governmental organisation, is doing exploratory work in two states of India, trying to develop and promote cost-effective, sustainable and replicable methods of providing support to carers in low- and middle-income countries (Carers 
Worldwide, 2016). One of their projects, run in collaboration with a local grassroots organisation in Andhra Pradesh, involves forming peer groups of caregivers who are then able to discuss and solve common problems (SACRED, 2013). These are promising initiatives but, being small in scale, their reach is limited.

In summary, as a result of an underdeveloped system of support, the family care system thrives in rural India. This system nurtures the traditional roles assigned to different members of the family and typically puts the entire responsibility on the women of the family. Next we theorise the caregiving system using the capability approach.

\section{Theorizing care work through the capability approach}

The capability approach (CA) is an alternative to the welfare approach that is concerned about the lack or differences in the resources available to people (Sen, 2009). The CA instead focuses on the equality of opportunities that people have to live a life based on their values and choices. One person's opportunities are fewer than another's if the former has fewer capabilities or the actual opportunities that they have to choose from to achieve a living they have reason to value (Sen, 2009). These opportunities are considered in terms of the well-being and agency of people (Crocker, 2008). Well-being is conceptualised in terms of capabilities and 'functionings'.

Functionings, which are fundamental to well-being, are the activities that people are able to undertake, and so, to do and to be as they want. According to Sen (2009) it is these 'beings' and 'doings' that make life meaningful; doings might include things like walking, reading, resting, and beings things like being cared for, being part of the community. Capabilities in the CA are conceptualized in terms of the achieved state of being and doing (functionings) from the various options available to 
people for which having the freedom to choose from those options is critical (Robeyns 2005). In the CA this freedom that people actually have to do or be things they value is critical and impacts their 'agency'. For instance, if the goal of a person is to travel from home to school, the various functionings or opportunities that are available to her may include riding a bicycle, driving a car, walking or taking public transport. She decides to walk to school. This decision she makes represents her freedom to choose, and thus her agency, while 'walking to school' is one of her capabilities. The totality of all the options available to her is termed her 'capability set'.

The agency of a person goes beyond what a person is able to do and is based on what is important to them, and respects their freedom to determine what they want, what they value and, ultimately, what they decide to choose (Sen, 2009). The agency or the freedom to choose is at the heart of the CA and it distinguishes between doing something and being free to do something (Sen, 2009). Such freedom to choose is dependent on the options or the capability set of a person. For instance, the primary caregiver of a person with disabilities may want to provide care only during certain hours and be engaged in other activities at other times. However, unless there are other options for supporting the disabled person they cannot do this, and therefore the caregiver's agency is not only dependent on their personal choice but also on the external context. According to Sen (1999), the agency of people is inescapably enhanced or constrained by the social, cultural, political and economic systems within which they live, and the opportunities that these provide.

According to Sen (2009), a person may act as an agent and change the world around them intentionally or unintentionally. An agent, according to the CA, is someone who rationally decides on a goal for herself or for others, and acts to fulfil 
the goal either alone or with others (Crocker, 2008). It is when the agent intentionally achieves her goal, even if it is with the support of others, that she acts as the author of her own life (Crocker, 2008). However, the social, cultural, political and economic opportunities (or the lack of these) may also affect the personal choices of the person. For instance a person may willingly accept dominance of other family members as a result of the existing socio-cultural norms or a lack of economic independence (Nussbaum, 2006; Sen, 2009). In scenarios where the person willingly gives up their agency they are prone to becoming media through which other agents impose their will (Nussbaum, 2006; Sen, 2009).

Finally, since a person's agency is affected by the internal and external forces that influence their decisions, this in turn affects not only the person but also the people around them (Crocker, 2008; Sen, 2009). This can be seen in the case of a woman who accepts the caregiver role 'naturally' because that is what is expected of her; such an expectation has an impact on the agency of the woman and consequently also on the nature of the care that she can provide. Therefore, in other words the agency of people influences the world around them (Crocker, 2008; Sen, 2009). Applying this understanding in the context of this research it is important to look at the agency caregivers have in achieving their caregiving goals, as it will influence the amount and quality of care and support the disabled family member gets. Further, the interrelatedness of agency with the social, political and economic systems and the opportunities available to people gives a chance to look at the experiences of the caregivers from the perspective of the influences and barriers that determine the options they have and the choices that they are able to make. 


\section{Methodology}

This research is a part of a larger research study undertaken to investigate the support structures available to persons with disabilities residing in rural areas who require support for mobility and in activities of daily living. One part of the larger research undertook a primary study with these persons with disabilities to look at the relationship of the support available to them and its impact on their lives (Gupta, Witte \& Meershoek, 2019). This paper, in continuation, studies the primary caregivers (all of whom were women) and other supporting family members of the disabled persons to look at their lived experiences as caregivers, focusing on aspects of life associated with caring work as described in the research design.

\section{Participants}

The participants were contacted with the support of the Rural Development Trust (RDT), which is a development organisation working in the Anantapur district of Andhra Pradesh. Its Community Based Rehabilitation department, which works with persons with disabilities in villages, supported the identification of the participants in the field. The participants selected were mostly members of the families of those persons with disabilities who were interviewed for the earlier primary research. However, there were a few new participants whose disabled family member was not interviewed during the earlier study. The new participants approached RDT field workers and consequently approached us through them. All the participants were offering care to persons with physical disabilities.

The only selection criterion adopted was that the participant had to be a primary caregiver or someone who provided any amount or type of support to a disabled person. Of the fourteen participants all were primary caregivers except two who supported care provision at times when the primary caregiver was unavailable. 
The participants were all women; their relationship with the disabled person varied, and included wife, mother, sister-in-law, daughter-in-law and aunt. All participants were between the ages of 40 and 60 years. All families were living below the poverty line and thus were eligible to receive disability pension or old age pension. All families were dependent on the daily wages earned mainly by working on the land or by rearing animals.

\section{Research Design}

A qualitative interview method was used with semi-structured questions being posed to the participants. An interview guide was prepared before going into the field. The first question aimed to ascertain the participant's attitude towards disability. The questions that followed were intended to gain an understanding of their experience of caregiving and its impact on different aspects of their lives, especially in relation to achieving the following capabilities: 1 . Physical health; 2. Mental wellbeing; 3. Social relations; 4. Domestic and care; and 5. Paid work. These, according to Robeyns (2003) are few of the basic capabilities that may be used to be assessed inequalities based on gender.

The interviews were mostly undertaken in groups of three, with participants answering each question individually. The reason for holding interviews in a group was to make the participants confident and comfortable in answering questions they may have never addressed before. Saturation in the answers was achieved after 14 interviews.

The purpose of the interview was explained to each participant, followed by seeking their consent for participating in the research and for audio-recording the interviews. The interviews were undertaken in Telugu, the local language with the support of a translator, and were transcribed into English later. 


\section{Analysis}

The qualitative data for this research, which was in the form of interview transcripts, was coded in ATLAS.ti. Based on the frequency of occurrence of a code, ten themes emerged. These included 'care experience', 'community involvement' and 'additional support'. Patterns were identified in these themes and based on these patterns, the analysis has been organised under the following four aspects:

a. Activities undertaken

b. Impact of providing long-term care to a disabled family member

c. Reasons for accepting the caregiving responsibility

d. Additional support the caregivers wanted

\section{Results}

\section{a. Activities undertaken}

The participants, all women, were responsible for multiple tasks at home and for providing support to the disabled family member. They provided various kinds of support and to varying degrees. This included help in daily living activities.

Participant L, for instance, talking of her husband said:

"He crawls and goes to an open area for toileting, but he cannot clean himself, I have to clean him. I also need to empty his urine bowl. He cannot dress himself either, I have to help him with everything."

Apart from assisting the disabled family member at home, the participants supported them in outdoor activities. F said:

"When my mother-in-law goes to a hospital, my husband and I have to carry her and take her in an autorickshaw."

The participants also shared additional activities they performed to maintain or improve the health of the person they provided care to. Participant I said:

"Someone prescribed an Ayurvedic oil to massage him and a powder to eat for bowel movement... I massage daily..." 
In addition to all the care work the participants undertook, they also took care of the home, which meant cooking and cleaning. G, for instance, said:

"When there is an opportunity to get daily paid work, I go for it. After returning from work, I cook for everyone and clean the house."

Along with providing care to disabled family members and looking after all domestic chores they also had to go out often for daily labouring work to earn money.

This was important to sustain their home expenses. K, for instance, said:

"I must go out and earn otherwise we cannot manage. When I go out my mother takes care of my father, but she is deaf and often cannot hear when he calls for something. So when I return I help them both and do the other house work."

At times when the participants were not able to go out because of care work, they did some paid work from home. L said:

“...because I can't go out for daily work now, I keep a buffalo at home and I sell its milk. That is the way I am earning."

The participants multitasked, taking primary responsibility for two critical tasks: First, the care and support they provided to the disabled family member. The support they provided included helping the disabled family member in undertaking activities of daily living such as toileting, bathing, grooming and feeding, supporting them in outdoor activities such as visiting the doctor, and supporting them in maintenance therapies. The second task was to attend to all domestic tasks such as cooking, washing and cleaning. In addition, and even though the women took on all the responsibility at home including the care of the disabled family member, the expectations for them to earn money did not reduce. What may be noted is that the women caregivers were agents for the achievement of many basic functionings of all other members of the family in terms of their eating well, living in a clean environment, being financially stable and, with respect to the disabled family 
member, they were additionally responsible for basic functionings for survival such as toileting, feeding, dressing and so on.

\section{b. Impact of providing long-term care to a disabled family member}

It was hard for the women to provide care to the disabled family member in addition to all the other work they were responsible for. Caregiving often demanded a lot of physical strength and required them to be constantly available. This had a negative impact on their physical wellbeing. The physical effects of caregiving seemed to be felt more by participants who had been providing care for a long time and those who were older. For instance, participant I complained of having a back pain as a result of long-term caregiving for her husband. She said:

"My husband is very heavy, I have to help him with everything (...) and because of that I now get pain in my neck, shoulders and back. (...) At times I have to take painkillers, only then can I do anything or sleep."

Similarly A, who provides care to her adult son said:

"My son is quite healthy so I cannot lift him alone. Sometimes I get fed up. When he was a child it was fine but now when he is a young man caring is very difficult."

Caregiving responsibility also seemed to impact the mental wellbeing of the caregiver. At times they felt resentful about the caregiving work and felt forced into it. The pressure of caregiving at times made them wish ill upon the disabled family member. $\mathrm{H}$, for instance, said:

"I get very irritated with my sister-in-law and I am not caring for her from the bottom of my heart. When I am angry, I say things like: why are you alive, why don't you go somewhere and die?

Other times it was just the frustration of not being able to provide adequate care that disappointed them. For instance, B, who cares for an adult daughter, said:

"I have to carry my daughter to the toilet and clean her. Sometimes I get very tired and start scolding her." 
Apart from affecting mental and physical wellbeing, the participants felt that providing long-term care did not allow them to have a social life. They said that it restricted their social participation as they had to be at home most of the time and could not leave the disabled person unattended. They were also not able to attend family functions. N, who provides care for her grown-up daughter, said:

"I cannot leave my daughter and go anywhere. Even when my other daughters needed my support at the time of their child births, I could not go."

This made them feel restricted and frustrated with the responsibility, and was also a cause of mental stress. Participant I narrated an incident when her husband was extremely angry with her for leaving him unattended and going out. She said:

"Last week there was a drama in the village. I went to see it after he fell asleep and returned late at night. At that time he quarrelled all night, accusing me of leaving him alone in his condition. I can't go out and must remain in his presence."

They experienced social isolation also as a result of negative attitudes of the community towards disability and the caregiving work, attitudes that prevented them from going out to social gatherings, especially with the disabled family member. D, for instance, experienced unwelcoming inquiries as she went out with her son. She said:

“Any stranger would come to us and ask us about our son and his disability even though they can already see he is disabled, being in a wheelchair. This makes us sad and frustrated and we do not take him out often."

Another consequence of caregiving the participants stated was the loss of daily wages they incurred from not being able to go out for work as long or as often. Being already poor, the loss of daily wages reduced the money available to the family to buy food. This was identified as a big problem (as elaborated further in point $\mathrm{d}$ below.) Earning money is important. N, for instance, who is a single mother, narrated that she helped her daughter to undertake all daily living activities in the morning and then left 
for work and returned in the evening. During the time she was out her daughter remained unattended. She said:

"I must earn for us to live. I help my daughter in toileting and other daily activities at $6.30 \mathrm{am}$ and then return home in the evening and help her toileting at about $7.30 \mathrm{pm}$. During the day she sits in the verandah and does not drink anything as there is no one to help her."

Other women who could not go out to earn, found alternative ways to add to the family income through working from home. F, for instance, said:

"My husband told me not to go out for labouring work and to look after my mother-in-law. But we have to work to buy food. That is why I keep a buffalo. I earn some money by selling its milk."

There were some participants whose husbands did not contribute financially to the household. These women felt deprived and were concerned about their poor financial condition, which made them responsible for earning money as well in addition to providing care and doing domestic chores. This severely heightened their mental stress. H said:

"He [her husband] drinks too much. He walks drunk on the streets and scolds and abuses me. He doesn't give any money to the family for food, etc."

The anxiety could be vented on the disabled person. Later, while narrating a fight she had with her disabled sister-in-law, H said:

"I scold her saying that I cannot serve you (...), he [her husband] is a drunkard, I am providing for him and his family food, and in addition, I have to serve you. Why do I have to serve you?"

E's husband wasn't contributing adequately to family expenses either. In addition to her husband's negative attitude towards work, she saw the lack of work opportunities in the village as a problem that made it difficult for them to earn enough to feed themselves. She explained:

"There are no work opportunities here, and if we go for fieldwork, we earn only INR 100 [i.e a little more than 1 USD] a day. Also, it is seasonal and not always available." 
Providing care to the disabled family member was not an easy responsibility for the caregivers and all participants experienced a negative impact on their physical health and mental wellbeing, and experienced social isolation and a financial burden. Physical health challenges were more for women who were providing long term care and had to lift and carry the disabled person. Mental stress was felt by most caregivers due to different reasons the negative societal attitudes towards disability and caregiving and the financial encumbrance as a result of the caregiving work. Financial encumbrance was more profound for the caregivers who did not have other earning family members and they had to shoulder thee responsibility to earn as well. To summaries, the responsibility for care had a negative impact on the wellbeing of the caregivers and reduced their capabilities to maintain good physical and mental health, and social and economic wellbeing.

\section{c. Reasons for accepting caregiving responsibility}

Irrespective of the negative impact of caregiving, the participants continued to provide care. There were three main reasons identified for their acceptance of the responsibility of looking after disabled family members. The first reason expressed was the societal expectation that the woman should provide care to a disabled family member. Within the family the expectation that she should take care of the disabled family member was well-instilled as a norm and families considered fulfilling this responsibility to be the "right way" of living. G said:

"Our family is very decent. We will not ask anyone for help. We will work together and whatever is in the house will be shared."

For the women who were the actual care providers within the family also felt that fulfilling this duty was important for them to gain social acceptance. For instance, participant I said: 
"I will serve him (her husband) for a long time. Everyone says that I am taking very good care of him. I have to earn a good name from everyone."

Having accepted the care responsibility, families did not seem to be open to considering alternative options for providing care. For instance, F, talking of her mother-in-law, said:

"My husband will not agree to send her to an old age home where she can be looked after well. He says that he has looked after for so many years, he is the son so he will take care as long as she lives".

However, in cases where the primary caregiver had an in-law relationship with the disabled person, acceptance of the role was not as natural, and the women felt that social pressures left them with no option. They felt cheated into a situation where they were forced to provide care for the disabled family member without their consent. For instance, $\mathrm{H}$ narrated that she started looking after her sister-in-law once she and her husband returned to the village after working in the city for some years. She said:

"Five years ago my husband and I were working in Bangalore. At that time the three other brothers-in-law were taking care of my sister-in-law. When we returned from Bangalore, they left her with us, saying that, 'Until now our wives have looked after her. Now, you have to take care of her.' They left her with us and went away. Many a time I have quarrelled with the brothers to take her (...) but they don't."

Women caregivers also appeared to have felt deceived when they were not informed before marriage that they were expected to provide care to a disabled family member. It was the negative attitude of the community towards disability that seemed to make families conceal this information when forging new relationships. $\mathrm{L}$, who is seeking a marriage proposal for her son, said:

"Our son is not married yet. We are looking for a wife for him. When seeing a girl, we do not mention that his father is disabled (...)."

As a result of such social practices, E did not know that her prospective fatherin-law was disabled and needed support. Once married, she didn't have the option of 
terminating the marriage and had to assume the responsibility. The main reason for her to accept the responsibility was the fact that the society considered it improper for a woman to think of making a life for herself away from her husband's home. She said:

"When I came after marriage (...) my husband said that I have to take care of his disabled father. Suddenly my mind was completely blank. (...) At that time I cried and told my maternal uncle that I have to take care of him [the fatherin-law] and earn money too. My aunt advised me that if you stay back with us, people will say that you did something wrong because of which you had to return to us, so it is better for you to go back to your husband's house and take care of your father-in-law as that is the only safe place for you."

The second reason for accepting the caregiving responsibility, closely linked to social pressure, was the strong family ties the caregiver felt towards the disabled family member. It made the caregiver feel morally responsible towards them. The women stood by their family and if not driven by love and affection, their strong moral fibre did not allow them to leave the disabled family member unattended, regardless of their own feelings. L said:

"When we got married, we accepted each other. We have to share our troubles. When he was not disabled, we fell in love and married. Now, when we have a problem, we have to bear it."

G, who is also the sister of her husband's second wife, expressed sympathy for her disabled sister and willingly accepted the role of caregiver for her. She said:

"I am happy to take care of my sister because it was only after my marriage that she became disabled. I feel very sad for her and that is why I am taking care of her myself."

It was strong family ties with the primary caregivers and not the disabled person that made extended family members offer support in caregiving. They considered caregiving as a burden on the caregiver and offered to help for that reason. For instance, $\mathrm{J}$, whose aunt is a primary caregiver for her [the aunt's] husband, said: 
"I am married and settled in their village, so I support them at times. I cook for them and sometimes support her in taking care of the disabled uncle. I help only when my aunt asks me to."

Similarly, C, who is the sister of a primary caregiver, said:

"We don't ask anyone to come and help us to support my niece. If her mother is unwell then I will come and take care of her. If both of us are ill then we will ask my children to come and help".

The third reason expressed that influenced their decision to provide care was the cultural belief in the karmic theory that good deeds are rewarded and bad deeds punished. They seemed to find solace in the belief that God was witnessing the caregiving work they were undertaking. E, for instance, although she felt deceived into having to provide support to her disabled father-in-law without her consent, found acceptance and solace in the fact that God existed and appreciates her work. She said:

"He is my husband's father, I have to and I will serve him. God exists and He is aware of everything."

They seemed to believe that God had assigned them the duty of providing care, which they had to undertake to earn the approval of God. For instance, C, who is a maternal aunt of a disabled woman, said:

"God punished her with a disability and she has to bear it. She was born in our family, so we have to take care of her and serve her. God will bless us for it."

Though such beliefs consider disabled persons as being undesirable and as someone incapable of reciprocating like other family members, they ensure that the families and the caregivers continue providing care. D, talking about her son, said:

"It would have been better if we didn't have a disabled child. If he did not have a disability then he would study nicely, go out and grown up well, he would do a job and look after us."

Further she recognised that if he had better functionality and required less care it would have made things easier. She said: 
"If he could sit in his wheelchair himself then it would have been very good for us. But that is not possible so no point in being sad. I will serve him no matter what."

The participants accepted the responsibility for several reasons related to the social practices and their cultural beliefs. Social norms left no choice for the women but to accept the responsibility to provide care that they accepted at time unwillingly but by choice in blood relationships. With in-law relationships, the women caregivers often felt cheated and forced to take on the responsibility after marriage, unless the person with disabilities was the husband. Most often before marriage they were not informed about the disabled family member who they would be expected to look after and once married, they were bound as it was not considered righteous for women to live away from their husband's family. These social beliefs held families together, creating strong family ties where caring for a disabled member was a family responsibility. Strong family ties at times worked in favour of women caregivers as occasionally their maternal family supported them in caregiving and in housework. Lastly, cultural beliefs that God was aware of the service they were providing and they would be justly rewarded, made them accept the responsibility. This belief does, however, reflect on the way care is perceived by the caregivers and the community at large. The perception of disability was also framed in such social cultural beliefs and, though proving care was seen as an unrewarding task because no reciprocation was expected from the disabled persons, still it was considered a good deed worthy of being rewarded by God. The caregivers recognised that if the disabled person were more functionally independent it would make caregiving easier. While it has already been noted that the women did not have agency to consider the tasks they wanted to be responsible for, and especially the caregiving task, it was the social and cultural beliefs of the community that resulted in the loss of their agency and their inability to 
think differently about the care work they did. Both these beliefs not only reinforced the women's role in the family and community but also dictated the way care work and disability were considered - a punishment to be borne by the family.

\section{d. Additional support the caregivers wanted}

Considering that the participants had no real choice in whether they wanted to undertake care or not, they were burdened by the responsibility in different ways. Nonetheless, the caregivers were not seeking additional support, except they unanimously wanted more food for the family and cover medical expenses. The only source of income for the families was earning daily wages and the pension of the disabled member given by the government. This made it difficult for them to manage their basic expenses. This problem became acute as the caregivers grew older and were unable to earn daily wages. M, who is a caregiver for her mother, said:

"Now, as I am becoming old, I do not have the strength to provide care and also to do labour-intensive work. I need help. I want food rations. (...) I am asking for food, not money."

Since they were already used to getting a ration subsidy from government, they were able to articulate the demand for more food grains. E, for instance, said that the rations they were getting from the government were not sufficient and they needed more food. She said:

"We don't want money, we want food. My children, my disabled father-inlaw and I have to eat. We get government rations but that is not enough for my home."

Other than buying food, they also expressed the need for financial support to address the additional health issues of the person with disabilities. Participant A, for instance, narrated an accident that hurt her son that put a financial burden on them:

"One day when I was carrying him he fell and hurt himself. Now he has a lot of pain in his leg and we have to take him to the doctor, we are spending a lot on that." 
They found the medical expenses whether their own as a result of caregiving or those of the disabled person, difficult to bear and wanted additional money to cover them. L, for instance, said:

"Last month he [her husband] had a skin problem and my son had to take him to the doctor. It cost INR 2000 and the total money per month that we have is INR 2500.”

The disabled persons gave their pension willingly to the family, in return for the care they received. The caregivers, however, felt that the pension was not enough to look after the disabled person, as there were needs other than basic food, which could not be addressed with the amount given. F, for instance, said:

"She gets only INR 1000 as pension but she is asking for so much. She wants bread in the morning and biscuits in the evening. We also provide food. For INR 1000 we are giving her everything. If she falls ill we just give her some tablets because we cannot take her to the hospital with that money."

Remarkably, in addition to financial support, the participants did not, in general, consider it important to have additional support to compensate for the toll on their physical and mental health as a result of caregiving. They expressed mixed feelings about engaging a formal caregiver. Some, especially those who were young, found the idea not worth discussing. L, who is the caregiver for her husband, said:

"We do not want anyone to come and work for us. I can take care of my husband. Why do we need someone to come and help us?"

However, once the caregivers became old and were unable to provide care they at times saw value in engaging a formal caregiver. B, who was looking after her disabled daughter, felt:

"If we have more money, we will engage a servant after three/four years, when we become old and cannot do the work."

Some older caregivers were even ready to bear the expenses themselves. Participant I, for instance, said: 
"These days, because I am not feeling well, I am looking for someone in the village who will come and work for us and help in looking after him. I am offering a salary of INR 5000 but nobody is coming."

Participant I further explained that it was a challenge to find people willing to provide care, since supporting the person in toileting was considered a dirty task and she did not feel anyone would agree to help, even for a good salary. She said:

"Who will do the work of cleaning him? People earn only INR 150 as daily wages for working in the field, but for them that is better than doing this dirty work."

The caregivers themselves did not think that they would like to provide support to any disabled person other than their family member, even if they were paid for it. When asked, E further suggested that going to someone else's house to provide care would not be acceptable. She said:

"No, I would not like to. Even if I agree, my family will not allow me." G had similar thoughts. She felt that she could go and volunteer caregiving support at times, but not as paid work. She said:

"I am already serving my sister. I would not like to go anywhere to serve someone for money. However, if someone asked for help at times and it is close to my house, I may go to help, but not for money."

The participants did not have any expectations of additional except to receive financial help that could reduce the pressure on the caregiver to go out and work in addition to caregiving. Due to the financial stress experienced by the family the disabled family member gave the disability pension to the family for home expenses that was mostly used to buy food. However, the participants did not think the pension money was adequate to enable them to look after the person with disability well. They also hoped for additional support in getting food for the family as rations, rather than cash. It was not until the participants were older and had been providing care for a long time, did they seem to accept the need for external support in caregiving, as they 
become unable to manage everything. They wanted to employ someone who would help them in caregiving, but they did not think anyone would work for them, even for a good salary. They did not think that they would like paid care work either, as according to them, providing care and supporting in toileting was a dirty job. It is ironic that while, on one hand, providing care work is seen as a noble task to be rewarded by God, on the other, it is seen as a dirty task that non-family members would not take on, not even for good money.

\section{Discussion}

This paper reports the results of an investigation into the wellbeing and agency of primary caregivers, all women, of adults with disabilities, through their lived experiences of daily lives. The analysis revealed that while the primary caregivers were responsible for supporting the disabled and other family members in achieving their capabilities there was hardly any reciprocation from the family to support the women caregivers. As a result their physical health and mental wellbeing suffered since the support they provided demanded significant physical effort and resulted in mental stresses. Furthermore, caregiving had a significant impact on their social relationships, as they were unable to go out as often as they wanted and faced indirect discrimination from the community because of the disabled family member. They did not have any agency to change anything, neither for themselves nor for others in their family, and accepted the responsibility in spite of the negative impact on them of long-term caregiving.

The results show several reasons for the women not having any agency in terms of their caregiving responsibility. One reason stemmed from traditional social customs that expected the women to undertake this role. Existing literature suggests that post-marriage, in India it was customary for the daughter-in-law to take on the 
responsibility of providing care to the husband's disabled or older family members (Gupta et al., 2009; Ugargol \& Bailey, 2018), This research highlights that, while it was customary for them to take on the responsibility of caregiving, it was not considered necessary for the women to know before marriage about the caregiving role they were expected to play. Not accepting the role after marriage could see them made outcasts. Another reason for the loss of agency was rooted in the cultural perception of disability, which is seen as an outcome of bad karma (deeds) undertaken in past lives, and families were expected to look after the disabled person as good karma that would be rewarded by God (Ghai, 2002; Gupta et al., 2011; Miles, 2002a; Ugargol \& Bailey, 2018). Such beliefs helped the caregivers to cope and continue providing care (Gupta et al., 2011). These social and cultural norms played an important role in the lives of the families of persons with disabilities, and the women caregivers accepted them naturally and did not feel the need to have any agency in the matter, or even to recognize the loss of it (Nussbaum, 2006).

These socio-cultural perceptions also molded the way care for disabled persons is perceived. Having a disability is considered a tragedy for the person with disabilities and it is equally unfortunate for families to have a disabled family member (Ghai, 2002). Furthermore, persons with disabilities are seen as a burden, since they are not expected to reciprocate and support the family in any way (Gupta et al., 2020). Such beliefs made the men of the family alienate themselves from disabled persons and their care, not considering it important enough for them to intervene (Ghosh \& Banerjee, 2017). This left the 'unvalued' disabled person's care the entire responsibility of the women and also made caregiving an unimportant task, belittling the efforts of the caregivers (Ghosh \& Banerjee, 2017; UNGA, 2017; WHO, 2012). 
As an outcome of this belittling of their work, the caregivers submissively imbibed such beliefs and adapted their situation to fit the expectations of the family and the community (Nussbaum 2006, 2013; Sen, 1999). This research shows that they could neither oppose this situation nor think of any change to improve their lives, and felt that adapting to the situation was the only option. Such adapted preferences have also been seen amongst persons with disabilities living in villages, who perceived themselves to be a burden and, hence, would compromise on their basic care requirements (Gupta et al., 2020). This research had similar results, with the women caregivers seeming to have adapted to the situation. Seeking support for caregiving from people other than close family was not considered respectable. Therefore, it was not until they were old and unable physically to provide care, did they start considering getting external support (that they were also willing to pay for).

Unfortunately, when the family caregiver did try to hire someone to assist with caregiving they were unable to find anyone willing to do the job. While, on the one hand, the community believed that providing care was a good deed that would be rewarded by God, on the other hand, the caregivers recognised that the community considered caregiving as dirty job that no one will take up, not even for high wages. In fact, women who were already providing care felt that would not consider providing care as a paid job to anyone other than family members, and did not think their families would allow them to do so either. A reduction in the extent of external care available could also be an outcome of the communitarian value set that makes the family, and not others, responsible. Such a finding may also question the possibility of having an adequate workforce to undertake caregiving work whenever the government begins to provide formal care. There is a need to investigate this issue further. 
In addition to the socio-cultural norms that reduce their agency, it was also reduced by the economic challenges that they faced. On the one hand, as a result of the care work they often had to forego going out to earn daily wages or settle for reduced wages; on the other, providing care to a disabled family member was unvalued, which made the work they did unimportant. This put them in a hopeless situation where their contributions to the family were never appreciated. Scholars suggest that it is the unpaid nature of care work that makes it invisible and unregistered in conventional accounting for welfare expenditure (Bittman, Fast, Fisher \& Thomas, 2004; Folbre, 2004). One reason for not recognising care work in economic terms has been the utility of the care worker being given no consideration, as opposed to the utility for the consumer (Folbre, 2004). However, since the consumers in this case are persons with disabilities who are already undervalued in their community (Gupta et al., 2020) there may be a need to investigate the correlation, if any. Moreover, at times when the men of the family were not earning enough, the women caregivers were also the main breadwinners of their families. Such a situation not only put them at a disadvantage within their homes, as they still had to continue being the main caregiver, but also within the community where women without disabled family members did not have to do so much. Thus, no matter what they did, they were prevented from becoming agents of their own lives and living in the way they valued. Therefore, more research is required to look at ways of making care of disabled people more visible and valuable in the economic market.

Paradoxically, even though women are the main caregivers of persons with disabilities, this role of women is not an accepted and debated area in government policies and there is inadequate literature addressing this. It is therefore not surprising that the new disability Act does not address the role women of the family play in 
caregiving. Moreover, with the government continuing to consider support for persons with disabilities as a prerogative of the family, asserted even by law, there is inadequate attention paid by the government to developing a sustainable formal support mechanism that could complement the support provided by the family or offer respite care (Gupta et al., Submitted). While the government's Sahyogi Scheme (Government of India, n.d.) offers caregivers training, it does not have any financial mechanism that will enable a disabled person to hire the trained caregivers. It may be that the 'caregiver's allowance' announced under the RPDA 2016 could be used to complement the Sahyogi Scheme by adding a financial support component for hiring trained caregivers. Furthermore, there are inadequate efforts by the government to provide habilitation and rehabilitation services to persons with disabilities in rural areas, which makes them more dependent on the caregivers, and in turn resulting in the caregivers having to put more time into care work or else putting the disabled persons at an disadvantage (Ghosh, 2016; Gupta et al., 2020).

Finally, the lack of agency in deciding how much they can do has an impact on the agency of the disabled family member they provide care to. Being responsible for multiple activities that include all the domestic work, the caregiving task and the need to earn money, without any options, left them with no control over their time. They struggled to balance the time required to undertake these activities on the one hand, and their personal and social activities on the other (Armstrong et al., 2008; Robeyns, 2011). The lack of time autonomy of the primary caregiver impacts upon the agency of the disabled person as the caregivers were not always available to support them when needed, which as a result required them to adapt their lives, even their daily living activities, around the times when the caregiver was available (Ghosh \& Banerjee, 2017; Grech, 2015; Gupta et al., 2020). 
To summaries, the women caregivers had a hard time providing care without support, choice or control in various as aspects of their lives. Their care work remains invisible due to the social, cultural, economic and political reasons discussed. As a result, there is no demand from the women or the community for developing disability support alternatives and more community-based support structures. The existing social, cultural, economic and political forces maintain the oppression of women caregivers and also ensure that care is available to disabled family members.

Therefore, to challenge the situation and create alternate support structures in the community there is a need to make care work visible and recognisable in the economic market, and for which enhancing the agency of women caregivers is important (Folbre, 2004). This in turn will improve the lives of persons with disabilities living in rural areas. The obstacle, however, is the submissive acceptance of the women that diminishes the chances of care work becoming more visible and curbs any challenging of the family care system, and so makes unessential the development of other support alternatives for care (Stone, 1984). Feminist research indicates that it must not be left to the women alone to deal with the stresses and challenges of providing caregiving; rather, the responsibility should be shared by the family, the community and the government (Armstrong et al. 2008; Nussbaum, 2006; Shaji et al., 2012). The feminist movement that challenges those tasks that are looked down upon as being 'apt' for women (Armstrong et al., 2008; Hooyman et al., 1999; Kittay et al., 2005; Nussbaum, 2006) and by adding the situation of the caregivers for persons with disabilities to such feminist debates may help in improving the visibility of these women

\section{Conclusion}

This research shows that women engaged in caregiving of disabled family members 
have no agency because of the existing complex and deep-rooted social, cultural, economic and political practices. In addition, negative perceptions of disability and care work further devalued the women caregivers. This makes life difficult for both the women and the persons with disabilities they care for. There is a correlation between the time available to the women caregivers and the autonomy of persons with disabilities: when the former have less time, the latter are not able to receive support at the time and in the manner of their preference. Furthermore, the negative perception of disability and disability care work reduced the possibility of creating community-based disability support structures and effectively eliminated any options for engaging additional support for caregiving. The lack of agency of the women made it difficult for them to bring about any positive changes in their own lives or in the lives of the disabled person. Therefore, it is important for the government to create a more supportive community and community-support structures for persons with disabilities, first, by recognizing the economic value of care work; secondly, by raising positive awareness about disability and care work; and finally, by investing in better habilitation and rehabilitation services for disabled persons to make them more functionally independent and thus reducing the amount of care they require.

\section{References}

Armstrong, H., Armstrong, P., \& Scott-Dixon, K. (2008). Critical to care - The invisible women in health services. Toronto: University of Toronto Press.

Gupta, S, Witte, L \& Meershoek, A (Submitted). Using the Capability Approach to Study the Successes and Challenges in Operationalising the UN CRPD. Alter - European Journal of Disability Studies.

Bittman, M., Fast, J.E., Fisher, K. \& Thomas, C. (2004). Making the invisible visible: the life and time(s) of informal caregivers. In N. Folbre and M. Bittman (Eds.), Family Time (pg. 7-24). London: Routledge. 
Bogaert, K.D. \& Ogunbanjo, G.A. (2009). Feminism and the ethics of care. South African Family Practice, 51:2, 116-118, DOI:

10.1080/20786204.2009.10873822

Brinda, E.M., Rajkumar, A.P., Enemark, U., Attermann, J. \& Jacob, J.S. (2014). Cost and burden of informal caregiving of dependent older people in a rural Indian community. BMC Health Services Research, 14:207. DOI: 10.1186/14726963-14-207

Carers Worldwide, (2016). An invisible workforce: understanding the issues and the needs of family carers in India. Retrieved from NGO website: https://www.carersworldwide.org/wp-content/uploads/2018/01/INDIABASELINE-SURVEY-REPORT-2016.pdf

Dey, A. B. (no date). Health and Long term care of old persons in India. Presented at the All India Institute of Medical Sciences. Delhi. [PowerPoint presentation] Retrieved on: at http://www.unescapsdd.org/files/documents/Item\%203\%20\%28c\%29\%20Lon g-term $\% 20$ care $\% 20$ in\%20India.pdf

Eide, A. H \& Ingstad, B. (2011). Disability and poverty: A global challenge. London: Policy Press.

Folbre, N. (2004). The Theory of Misallocation of Time. In N. Folbre and M. Bittman (Eds.), Family Time (pg. 7-24). London: Routledge.

Ghai, A. 2002. Disability in the Indian context: Post-colonial perspectives. In M. Corker and T. Shakespeare (Eds.), Disability/ postmodernity: Embodying disability theory, (88-100). London: Continuum.

Ghosh, N. \& Banerjee, S. (2017). Too Much or Too Little? Paradoxes of Disability and Care Work in India. Review of Disability Studies Journal, 13(4).

Gnanaselvam, N.A., Vinoth, K.S.P. \& Abraham, V.J. J. (2017). Quality of life of people with physical disabilities in a rural block of Tamil Nadu, India. Journal of Psychological Rehabilitation and Mental Health, 4, Issue 2: 171177. DOI: $10.1007 / \mathrm{s} 40737-017-0095-8$

Government of India (n.d). Sahyogi: Care associate training scheme. The National Trust for Welfare of Persons with Autism, Cerebral Palsy, Mental Retardation \& Multiple Disabilities. Retrieved 1 May, 2020 from http://www.thenationaltrust.gov.in/content/scheme/sahyogi.php 
Grech, S. (2015). Disability and poverty in the global south: Renegotiating development in Guatemala. London: Palgrave Macmillan.

Gupta, R., Rowe, N. \& Pillai, V.K. (2009). Perceived caregivers burden in India. Journal of Women and Social work, 24:1, Page 69-79

Gupta, V. B. (2011). How Hindus Cope with Disability. Journal of Religion, Disability \& Health, 15:1, 72-78. DOI: 10.1080/15228967.2011.540897

Gupta, S., Witte, L. \& Meershoek, A. (2019). Barriers to using mobility devices in rural homes in low resource settings: development of a practical assessment tool for local fieldworkers. Edited by Layton, N. \& Borg, J. Global Perspectives on Assistive Technology-Proceedings of the GReAT consultation 2019. WHO Headquarters: Geneva, Switzerland. 23-24 August 2019.

Gupta, S., Witte, L., \& Meershoek, A. (2020). Unveiling the hidden: increasing agency of disabled people in rural India. Disability \& Society. DOI: 10.1080/09687599.2020.1788509

Hooyman N. R. \& Judith G. G. (1999). A feminist model of family care: Practice and policy directions. Journal of Women \& Aging, 11 (2-3), 149-169, DOI: 10.1300/J074v11n02_11

Kittay, E. F., Jennings, B. \& Wasunna, A.A. (2005). Dependency, Difference and Global Ethics of Long-term Care. Journal of Political Philosophy, 13(4), 443469. DOI 10.1111/j.1467-9760.2005.00232.x

Klasing, I. (2007). Disability and social exclusion in rural India. New Delhi: Rawat Publications.

Miles, M. (2002a). Community and Individual Responses to Disablement in South Asian Histories: Old Traditions, New Myths? Independent Living Institute. Retrieved from: https:/www.independentliving.org/docs3/miles2002a.html Ministry of Statistics and Programme Implementation (2016). Disabled People in India: a Statistical Profile - 2016. Government of India

Mukunthan, A. (2015, December 5). Rural India is far behind Urban India in every Indicator of Progress. Factly. Retrieved on 21 May, 2019 from: https:/factly.in/rural-india-behind-urban-india-in-progress-indicators/

Murthy, R. (2016). Caregiving and caregivers: Challenges and opportunities in India. Indian Journal of Social Psychiatry. 32:1, Page 10-18.

National CRPD Coalition India (2019). CRPD Alternate Report for India. OHCHR. 
https://tbinternet.ohchr.org/Treaties/CRPD/Shared\%20Documents/Ind/INT_C RPD_ICO_Ind_33886_E.docx

Nussbaum, M. (2006). Frontiers of Justice: Disability, Nationality, Species Membership. Cambridge: Belknap Press.

Nussbaum, M. (2013). Creating Capabilities - The Human Development Approach. Ranikhet: Permanent Black.

Prasad, B. D. \& Rani, N. I. (2007). Older Persons, and Caregiver Burden and Satisfaction in Rural Family Context. Indian Journal of Gerontology, Vol. 21, No. 2, pp. 216-232

Robeyns, I. (2003). Sen's Capability Approach and Gender Inequality: Selecting Relevant Capabilities. Feminist Economics, 9:2-3, 61-92, DOI: 10.1080/1354570022000078024

SACRED (2013). Carers Worldwide UK: Progress report for the period for 1 April 2013 to 30 September 2013. Viewed on NGO website: http://www.sacredcbr.org/Reports/Carers\%20\%20reporting\%20\%20\%20SACRED.pdf

Sen, A. K. (1999). Development as Freedom. New York: Alfred A Knope, Inc. Shaji, K.S. \& Reddy, M.S. (2012). Caregiving: A Public Health Priority. Indian Journal of Psychological Medicine, 34(4), 303-305. DOI: 10.4103/02537176.108191

Stone, D. (1984). The Disabled State. Philadelphia: Temple University Press. The Government of India. The National Trust Scheme Guidelines issued by the Department of Empowerment of Persons with Disabilities. Retrieved from: http://thenationaltrust.gov.in/upload/uploadfiles/files/sahyogi_eng.pdf

Tronto, J. C., \& Fisher, B. (1990). Toward a Feminist Theory of Caring. In E. Abel, \& M. Nelson (Eds.), Circles of Care (pp. 36-54). Albany, NY: SUNY Press.

Ugargol, A. P. \& Bailey, A. (2018) Family caregiving for older adults: gendered roles and caregiver burden in emigrant households of Kerala, India. Asian Population Studies, 14:2, 194-210, DOI: 10.1080/17441730.2017.1412593

UN General Assembly (2007). Convention on the Rights of Persons with Disabilities: resolution / adopted by the General Assembly, 24 January 2007, $\mathrm{A} / \mathrm{RES} / 61 / 106$

United Nations General Assembly (2017), Report of the special rapporteur on the rights of persons with disabilities, , A/HRC/34/58, 24 February 2017. 
World Health Organisation (2002). Current and Future Long-Term Care Needs.

$\mathrm{WHO} / \mathrm{NMH} / \mathrm{CCL} / 02.2$. Retrieved online:

http://www.who.int/chp/knowledge/publications/ltc_needs.pdf

World Health Organisation (2012). Situation analysis of community-based rehabilitation in the South-East Asia region. India: World Health Organisation.

World Health Organisation \& the World Bank. (2011). World report on disability. Geneva, Switzerland: World Health Organisation. 
朝闻 


\section{Chapter 5}

\section{Barriers to using mobility devices in rural homes in low resource settings: development of a practical assessment tool for local fieldworkers}

Gupta, S., Witte, L. P. de., \& Meershoek, A. (2019). Barriers to using mobility devices in rural homes in low resource settings: development of a practical assessment tool for local fieldworkers. Edited by Layton, N. \& Borg, J. Global Perspectives on Assistive Technology - Proceedings of the GReAT consultation 2019. WHO Headquarters: Geneva, Switzerland. 23-24 August 2019, (Pg. 270-284) 



\section{Abstract}

The usefulness of mobility devices can be totally undermined by an inaccessible environment. In low and middle income countries home modification is not addressed while providing mobility devices.

Especially in rural areas existing assessment tools are not suitable as these are designed for settings that are completely different from conditions in the rural settings. In order to improve the situation, in this study we developed a basic tool to systematically assess barriers in the environments in which persons with mobility impairments will be using their individual mobility devices, with an aim to recommend solutions for increasing their mobility. The tool was designed based on review of existing standards and relevant literature, it was improved based on field visits to see whether the tool adequately addressed all areas and sub areas in rural houses and the draft tool was shared with experts for their feedback. It is an easy to use tool for non-technical CBR and other fieldworkers who are working in these rural areas.

\section{Keywords}

Evaluation-tool, Rural-area, Fieldworkers, mobility devices, home modification

\section{Introduction}

For effective home mobility, in addition to a suitable mobility device, the physical environment in which these would be used, is equally important for making the user more mobile and independent $[1,2]$. Most often it is the non-availability of one of the two that poses a barrier to mobility. In high income countries where mobility devices and physical infrastructure are more standardized, there are also better established systems that look at mobility devices along with home modifications required to use these devices comfortably. Moreover, some countries have also started looking at the issue from the point of universal 
design where all homes are designed to be accessible to all users irrespective of the type of mobility devices they use [3, 4].

Such systems, however are not yet applied to the context of rural areas in the low and middle income countries. The key challenge in making personal mobility within rural home environments for persons with mobility impairments seamless stems from the environmental structure and internal design of the home not matching the requirements for using the specific mobility devices. There are several reasons for this mismatch for instance, first, the accessibility design standards in these countries often address only public areas [5] and guidance used for accessible housing are largely based on western homes that are very different from homes in rural areas in the global south countries, as a result there are no accessible design specification for homes in rural areas.

Second, the mobility devices that are available to disabled people are mostly not designed to address the requirements in the context of their environments. The design standards for these devices are again based on western research that addresses the requirements for western environments and population that may not always be best suited for rural environments and to the life style of indigenous people that live in rural areas. Third, most efforts to address accessibility have been focused on urban public environments with also the ISO document focusing on accessibility of urban public areas [6] creating a dearth of standards and guidance on rural accessibility. Fourth, is the lack of awareness about home modifications and accessibility of home environments amongst field workers who are unable to always identify barriers and suggest simple solutions to users of mobility devices. However, considering that majority of the global disabled population live in rural parts of the global south countries [7] and that they are disproportionately impacted by the lack mobility 
devices and home environments that complement each other $[8,9]$, there is an urgent need to undertake further research to see how the mobility devices and the environments they are used in can be better attuned to ensure better home mobility for persons with disabilities living in less-resourced settings.

This research considers the physical home environment of persons with mobility impairments in rural areas in relation to the mobility devices that are available for them. The objective of this project is to design an easy to use tool for non-technical community based rehabilitation (CBR) and other fieldworkers to systematically assess barriers in the environments based on the mobility devices being used. The tool is intended to be used primarily in rural areas of low and middle income countries where physical accessibility of homes is not considered as an important criteria associated to the use of the mobility devices.

\section{Methodology for developing the draft tool}

There were three steps undertaken to prepare the tool that included 1. Designing the tool 2. Field visits to ensure all areas and sub areas of rural homes were adequately addressed in the tool and 3. Seeking expert feedback on the tool

\section{Designing the tool}

In order to design the tool, literature search was undertaken in two areas. We started by exploring the various types of mobility devices that were commonly available to persons with disabilities. With regards to mobility devices we searched through the online database such as Able Data, EASTIN catalogue that put forward a wide range of mobility devices, we also looked at the list assistive devices and technology available to the person with disabilities through government Scheme for assistive devices (ADIP) in India [10]. Since there was a large disparity in the range of assistive devices shared in the online databases and what is actually available through 
government schemes, we decided to use the WHO Priority Assistive Products list (APL) [11] The APL is a model proposed by the WHO for countries to adopt while looking at their own national assistive products list on and thus the APL has the maximum reach and global acceptance.

With regard to assessing environments we began by searching scientific research catalogues using keywords 'rural', 'accessibility' 'tool' 'physical accessibility' 'India' 'home modification', 'WASH' in different combinations. However, we did not get adequate literature through scientific research search platforms and therefore did an open web search of resource documents generated by development organizations, UN organizations and international donor organizations on their work related to disability [12-14]. We also looked at the international standards organizations (ISO) standards on physical accessibility [6] and we gathered some literature on accessibility in rural areas through these sources.

Analyzing the information literature we designed a tool which combined two sides. On the one hand we categorised the mobility devices; on the other we categorized the common spaces in the home. The categories of common spaces were further elaborated by breaking them into sub-areas with descriptions specific to these areas. These common areas and the accessibility solutions for them were related to the different mobility devices that users could potentially use and this indicated the design of the environment specific to the mobility device. The mobility devices were listed in the ' $x$ ' axis and since different kind of physical environment was required to enable easy movement these accessibility solutions were listed in the ' $y$ ' axis. Therefore the tool elaborates on the accessibility requirements in different areas of the home in relation to the three categories of mobility devices and gave suggestions on how to 
make adjustments to the environment to use device more effectively. The tool is described in more detail in the next section and tool itself is presented in the appendix.

\section{Field-visit to check adequacy of the tool}

To check the adequacy of the draft tool prepared on the existing literature, field-visits were undertaken in fourteen homes of persons with mobility impairments in three villages in the Ananthapur District of Andhra Pradesh in India. The participants for the field visit were identified with the support of the Rural Development Trust (RDT), a development organisation working to improve the quality of life of the rural poor in the district, they also run a CBR programme focusing on persons with disabilities. Before visiting their homes the participants were provided with information on the nature and purpose of the visit. Before proceeding with the home visit, a consent - including the permission to take photographs of different areas of their homes and audio recording of our conversation was taken from each participant. They were informed that anonymity would be maintained and that they had a choice of what they wanted to share. RDT workers - who are already working in and have the support of the local community - gained prior permission and meeting time suitability from the participants and their families.

The basic criteria for selecting these participants was that they were all adults with disabilities who had a mobility impairment and required a mobility device to move around. The different mobility aids these persons were using included wheelchairs, lower limb prostheses, lower limb orthoses, leg braces; sticks; crutches and walker. During these visits the list was verified in relation to the main areas and the sub areas in a typical rural home and additional barriers, sub areas and descriptions that were seen were added to the tool. Photographs were taken to document the situation and all the 14 persons with disabilities visited who were asked to describe their mobility within their homes, thus elaborating on the barriers they 
faced and the solutions they had developed or hoped to develop to remove these barriers.

The homes visited helped not only validating the adequacy of the areas and sub-areas of a typical rural home in the tool but it also highlighted the inadequacy of a wheelchair to be used in rural homes because of their small size. Therefore to address individual mobility of persons who were not using ambulatory devices, further literature search of mobility devices was undertaken. The mobility boards in ISO category 12.27.15 from the EASTIN catalogue was considered suitable. Thus an additional category of persons using floor boards was included to the tool.

\section{Seeking expert feedback on the tool}

The draft tool was shared with eight experts from three different domains: assistive technology, accessibility and community based rehabilitation (CBR) with experience of working in low resourced setting. The draft tool was shared with them with a background and objective of the project via email. They were asked to share their thoughts on the tool and specifically the adequacy of the tool while addressing mobility devices in the three categories and the areas in the typical rural homes. Feedback was received from 4 experts and amongst them they represented each of the three domain experts we had originally identified. Their feedback was related to the structure of the draft tool and applicability of the tool. The feedback received was carefully considered and adjustments were made accordingly.

\section{Results}

In developing the tool we decided to cluster the different assistive devices that were identified from the APL and the EASTIN catalogue, into three different groups of potential users that included -- wheelchair users, floor board user and the ambulatory devices uses. A table indicating the different device categorization can be found as Table 1 below. 
Table 1: Categorization of mobility devices

\begin{tabular}{|c|c|c|c|}
\hline $\begin{array}{l}\text { Source of } \\
\text { AT }\end{array}$ & $\begin{array}{l}\text { Users moving in } \\
\text { chair sitting } \\
\text { position }\end{array}$ & $\begin{array}{l}\text { Users moving } \\
\text { in floor } \\
\text { sitting } \\
\text { position }\end{array}$ & $\begin{array}{l}\text { Users able to walk } \\
\text { a little }\end{array}$ \\
\hline $\begin{array}{l}\text { WHO Priority } \\
\text { Assistive } \\
\text { Products list }\end{array}$ & $\begin{array}{l}\text { wheelchair manual } \\
\text { for active use; } \\
\text { wheelchair manual } \\
\text { - assisted } \\
\text { controlled; } \\
\text { wheelchair manual } \\
\text { with postural } \\
\text { support; tricycle; } \\
\text { wheelchair electric } \\
\text { powered; } \\
\text { Handrails/grab } \\
\text { bars; portable } \\
\text { ramp }\end{array}$ & $\begin{array}{l}\text { Handrails/grab } \\
\text { bars; portable } \\
\text { ramp }\end{array}$ & $\begin{array}{l}\text { Club foot brace; } \\
\text { canes sticks; } \\
\text { crutches, auxiliary } \\
\text { elbows; orthoses } \\
\text { lower limb; } \\
\text { prostheses lower } \\
\text { limb; rollators; } \\
\text { walking } \\
\text { frames/walker; } \\
\text { therapeutic } \\
\text { footwear; } \\
\text { Handrails/grab } \\
\text { bars }\end{array}$ \\
\hline $\begin{array}{l}\text { EASTIN } \\
\text { catalogue } \\
\text { ISO category } \\
12.27 .15\end{array}$ & & Floor boards & \\
\hline
\end{tabular}

The reason for categorizing them in these three clusters was related to the differences in the basic physical accessibility requirements for persons with mobility impairments as gathered from literature that included aspects like

1. the minimum dimensions of a given space,

2. height of operating elements in the environment,

3. change in levels

4. minimum width of spaces to pass through.

5. Floor finish 
The key findings gathered were that the minimum dimensions of the space required for maneuvering a wheelchair was much larger as compared to the other devices. And since this minimum space was not usually available in rural homes people were crawling to move within the house or had to be carried. Thus a floor board was seen as an alternative that could enable them to have better mobility without having to make major changes to their homes and floor boards also enabled floor level activities that was the common way of life.

The height of the operating elements in the environment varied for persons performing the activity from floor level as compared to those who performed sitting on a chair or those who did it standing and therefore these had to be addressed differently for the three mobility device categories.

For the change in level, persons who use ambulatory devices may not find the ramp as their most preferred option instead they may prefer steps unlike the other two categories for whom ramp was mandatory to negotiate level differences.

The minimum width required to pass through areas such as the door was different for different devices. While a minimum width was a mandatory requirement for wheelchair users it was not as rigid for the other two categories.

A firm, cement and non-swampy and slippery floor finish was a requirement for all the three categories.

The basic idea of the tool is to provide accessibility requirements for each of the basic areas in a typical rural home that most often was on the ground floor and had a very simple layout comprising of five main areas: the courtyard, the living room, kitchen and the toilet and bathing room. Each of these areas had a sub areas that comprised of different spaces within them. These accessibility requirements are defined for the three categories of assistive devices users based on the understanding 
presented above. The tool itself, which has a tabular format, can be found as Table 2 in the appendix. Below is elaboration on the aspects of accessibility in the areas that the tool addresses. The presentation of information below has been made by separating the aspects of the environment that were common to all mobility devices and aspects that were specific to certain devices.

\section{Access route and Courtyard}

\section{Common aspects for all mobility users}

All different mobility device users required an access route leading to the house that was levelled, cemented, dry and without any obstacles like open drain in the route.

\section{$\underline{\text { Mobility device specific aspects }}$}

First, the access route to the courtyard had to be levelled from the road and incase it was not levelled, a ramp may be provided for persons using wheelchairs of floor boards. However, steps may be preferred for ambulatory devices users. Second, the access route may have resting benched for persons using ambulatory devices to rest.

\section{Courtyard}

\section{$\underline{\text { Common aspects for all mobility users }}$}

The courtyard required to be cemented and non-swampy for all mobility devices users.

\section{Mobility device specific aspects}

First, the minimum dimension of the courtyard is important for wheelchair access while it is not as important for other device users. Second, a bench in the courtyard may be useful for an ambulatory device user. 


\section{Living room}

\section{Common aspects for all mobility users}

First, the thresholds at the entrance door may be avoided for all mobility device users. While this is a requirement but the tool recognizes the cultural and religious importance of the threshold and offers way of addressing the threshold at the entrance. Second, ensuring that internal doors are minimized and are without a thresholds for all mobility device users.

\section{$\underline{\text { Mobility device specific aspects }}$}

First, the minimum internal dimensions of the living room for a wheelchair were important, however this wasn't so for the other devices. Second, the height of the storage shelves, switches were dependent on the mobility devices used as that dictated the reach of the user. Third the entrance door at times had a level difference from the courtyard where a ramp was required for wheelchair and floor board users but not necessarily for an ambulatory device users.

\section{Kitchen}

\section{Common aspects for all mobility users}

First, the lack of plumbing made water storage in the kitchen for cooking and washing important for all different mobility devices users and the water storage needed to be close to the cooking slab and to the utensil washing area.

\section{Mobility device specific aspects}

First, the height of the stoves used for cooking required to be adjusted differently for different mobility device users. Second, accommodating a wheelchair user in the kitchen required larger internal dimension while this was not so for the other devices users. Third, for cleaning utensils the height of the areas where this activity was undertaken was important, for instance 
a washbasin height was better for wheelchair users and ambulatory devices users while for a mobility boards users ground level was required.

\section{Toilet and bathing area}

\section{$\underline{\text { Common aspects for all mobility users }}$}

First the lack of plumbing in the toilet or the bathing areas was a barrier identified that impacted the way the toilet and bathing areas were used by all mobility device users. Not having plumbing in the toilet and bathing area required having a water storage preferably within the toilet or shower area as carrying water with a mobility device is challenging. Second, the location of the toilet and the bathing area was identified as an important aspect in the tool that was important for all mobility devices users. Third, well drained cemented floor was important for all users.

\section{Mobility device specific aspects}

First, the internal dimensions of the toilet and shower room and the width of the door that were important only for the wheelchair users. Second, the type of toilet seat used was based on cultural preference and an Indian style toilet was used as a given in these villages. Indian seats were useable by persons using mobility boards, however for persons using a wheelchair or ambulatory device required a higher seat that could be made available by replacing the Indian seat with a western style seat or placing a bench or a stool over the Indian seat. The bathing area required similar considerations with a need for an additional stool or a bench to sit while bathing for ambulatory devices users or wheelchair users. Third, the useable height of clothes hook, toiletry shelf, or the door lock, placement of grab rails were different for different device users.

In the tool we systematically present aspects of physical accessibility of rural homes in relation to the mobility devices in a tabulated form in a way that is very 
simple and can be used by CBR and other community workers without having prior training on aspects of accessibility

\section{Discussion}

The aim of this paper was to develop a tool that attunes the mobility devices used by persons with disabilities with the physical home environments in rural areas where they live. Based on a literature review, a pretest in rural India and an expert consultation we conclude that it is relevant to distinguish the mobile devices into three categories based on the way the users of these mobility devices interact with the environmental. Each of these devices require different conditions in the internal environment to make it possible to use their devices and the environment efficiently. For different spaces in rural homes in rural India, we identified five common areas and defined the physical accessibility requirements for these areas in relation to the three categories of mobility devices.

This is a first attempt and although we think it is potentially useful for other rural areas in low and middle income countries. There may be a need to make it more context specific through testing and further developing it depending on the location, for instance, Ananthapur is a dry area with ground that does not retain water. Therefore, it does not have issues related to water stagnation and loose mud that may not be in some other villages. We also feel that there may be a need to adjust it for specific conditions such as disaster especially because there was nothing found in literature and the field area that was used for check the adequacy of the tool was not a disaster prone area, therefore, this aspect has not been addressed in this tool.

Although further development is needed, the tool demonstrates already that there is a need for such an instrument adjusted to rural areas in low and middle income settings. It deviates from existing tools for instance in taking into consideration the fact that people in rural India, culturally all perform home activities 
such as eating, sleeping, sitting cooking in many cases at the floor level [15].

Therefore, the floor board as a device for indoor mobility is suggested as being most suitable. Thus even if the house is made to suit a wheelchair, the user may not be most comfortable being on the chair and may prefer being on the floor while at home.

While using a floor board may not be considered as the most dignified way of mobility by urban or western standards, but from the life style of persons with disabilities living in rural areas and the rural homes, it seemed the only option for not crawling or being carried every time by someone else. It is therefore also recommended that floor mobility devices such as a mobility board may be added as a part of the APL [11] to influence the national governments to include these in their assistive devices programmes as an additional device for home or indoor mobility.

Some of the experts consulted mentioned that it may be of relevance to make use of universal design principles. Although we do think that these principles are what we must strive for, we also think that realizing these principles in rural India is not easy and will take years if not decennia to achieve their application. However, until we progress to achieving full realization of personal mobility and home accessibility in rural areas [16] we think it is important to begin working towards making personal home mobility possible in a more urgent manner by taking a more reasonable and achievable approach that can be implemented more easily, such as using such a tool that supports attuning the existing physical environment with the mobility device in a simple manner to enable better indoor mobility for persons with disabilities in rural areas. In the future we intend to translate the tool in local language and work with the CBR workers to see what change it can bring in the lives of persons with disabilities living in rural areas. 


\section{Conclusion}

Not having a suitable mobility device significantly lowered the mobility and independence to undertake activities at home of persons with mobility impairments living in rural homes. Especially in rural areas in low income setting this is a big problem as often persons with disabilities are unable to use the mobility device within their homes as a result of inaccessibility of homes or cultural preferences to be at floor level. The existing tools for evaluating physical accessibility are not adjusted to these rural settings and neither do they address differences in personal homes spaces based on the mobility device used by individuals. The tool we have designed and presented here will contribute to a better assessment of the environment in rural settings and better attune the environment with the mobility devices people use, contributing to making people more mobile.

\section{Reference}

[1] Wearmouth, H. \& Wielandt, T. 'Reserve is no place for a wheelchair': Challenges to consider during wheelchair provision intended for use in First Nations community. Disability and Rehabilitation: Assistive Technology. 2009, 4:321-328. Available from: doi:10.1080/17483100902807120

[2] Ureta, S. To Move or Not to Move? Social Exclusion, Accessibility and Daily Mobility among the Low-income Population in Santiago, Chile. Mobilities. 2008, 3:2, 269-289. Available at doi: 10.1080/17450100802095338

[3] Centre for Excellence in Universal Design \& NDA. Universal Design Guidelines for homes in Ireland. NDA; 2015.

[4] Goodman, C. Lifetime Homes Design Guidelines. Habinteg Housing Association. Berkshire: IHS BRE; 2011.

[5] Ministry of Urban Development. Harmonized Guidelines and Space Standards for Barrier Free Built Environment For Persons with Disabilities and the Elderly Persons. Delhi: Government of India;2015. 
[6] International Standards Organisation. ISO 21542:2011(E). Building construction — Accessibility and usability of the built environment. Geneva:ISO; 2011.

[7] World Health Organisation \& the World Bank. World report on disability. Geneva, Switzerland: World Health Organisation; 2011.

[8] Borg, J., Lindström, A. \& Larsson, S. Assistive technology in developing countries: A review from the perspective of the Convention on the Rights of Persons with Disabilities. Prosthetic \& Orthotic International. 35(1), pg 20-29, 2010

[9] Grech, S. Disability and poverty in the global south: Renegotiating development in Guatemala. London: Palgrave Macmillan; 2015.

[10] Ministry of Social Justice and Empowerment. Revised Scheme of Assistance to Disabled Persons for Purchase/Fitting of Aids/Appliances, Applicable w.e.f 1 April, 2014. New Delhi: Government of India; 2014.

[11] World Health Organisation. WHO Priority list of Assistive devices. WHO, 2016. [12] AusAID. Accessibility design guidelines: Universal design principles for Australia's aid program, AusAID, Registration no. 13, 2013.

[13] UN-HABITAT. Accessibility of housing: A handbook of inclusive affordable housing solutions for persons with disabilities and older persons. Nairobi: UNHabitat, 2014.

[14] Raheja, G. Enabling Environments for mobility impaired in rural areas: An inclusive design approach for rural context. Germany: LAP LAMBERT Academic Publishing; 2016

[15] Gupta, S., Witte, L. \& Meershoek, A. (Submitted). "Unveiling the hidden: increasing agency of disabled people in rural India". Disability and Society [16] UN General Assembly. Convention on the Rights of Persons with Disabilities: resolution / adopted by the General Assembly. A/RES/61/106; 2007 


\section{Appendix}

Table 2: Tool for attuning home environments to the mobility devices

\begin{tabular}{|c|c|c|c|c|c|}
\hline Areas & Sub-areas & Description & $\begin{array}{l}\text { For wheelchair } \\
\text { users }\end{array}$ & $\begin{array}{l}\text { For floor } \\
\text { mobility } \\
\text { device users }\end{array}$ & $\begin{array}{l}\text { For walking } \\
\text { aids users }\end{array}$ \\
\hline \multirow[t]{8}{*}{$\begin{array}{l}\text { Access } \\
\text { route }\end{array}$} & $\begin{array}{l}\text { Surface } \\
\text { finish }\end{array}$ & Step free & $\mathrm{OK}$ & $\mathrm{OK}$ & OK \\
\hline & & With steps & $\begin{array}{l}\text { Ramp with } \\
\text { gradient less than } \\
1: 12\end{array}$ & $\begin{array}{l}\text { Ramp with } \\
\text { gradient less } \\
\text { than } 1: 12 \text { and } \\
\text { handrails on } \\
\text { both sides of } \\
\text { ramp }\end{array}$ & $\begin{array}{l}\text { Handrails on } \\
\text { both sides of the } \\
\text { steps }\end{array}$ \\
\hline & & cemented & OK & $\mathrm{OK}$ & OK \\
\hline & & $\begin{array}{l}\text { Covered } \\
\text { drains }\end{array}$ & $\mathrm{OK}$ & OK & OK \\
\hline & & $\begin{array}{l}\text { Remains dry } \\
\text { without } \\
\text { stagnated } \\
\text { water }\end{array}$ & $\begin{array}{l}\text { cross slope less } \\
\text { than 1:50 }\end{array}$ & OK & OK \\
\hline & $\begin{array}{l}\text { Minimum } \\
\text { width }\end{array}$ & & $\begin{array}{l}\text { Minimum } 0.9 \mathrm{~m} \\
\text { for wheelchair \& } \\
1.2 \mathrm{~m} \text { for tricycle }\end{array}$ & -- & -- \\
\hline & $\begin{array}{l}\text { Resting } \\
\text { spaces }\end{array}$ & & -- & -- & $\begin{array}{l}\text { After every } 50 \\
\mathrm{~m}\end{array}$ \\
\hline & Illuminated & $\begin{array}{l}\text { Well } \\
\text { illuminated at } \\
\text { night }\end{array}$ & OK & OK & OK \\
\hline \multirow[t]{5}{*}{ Courtyard } & Entrance & Step free & OK & OK & OK \\
\hline & & With steps & $\begin{array}{l}\text { Ramp with } \\
\text { gradient less than } \\
1: 12\end{array}$ & $\begin{array}{l}\text { Ramp with } \\
\text { gradient less } \\
\text { than } 1: 12 \text { and } \\
\text { handrails on } \\
\text { both sides of } \\
\text { ramp }\end{array}$ & $\begin{array}{l}\text { Handrails on } \\
\text { both sides of the } \\
\text { steps }\end{array}$ \\
\hline & $\begin{array}{l}\text { Entrance } \\
\text { Gate }\end{array}$ & & $\begin{array}{l}\text { Minimum } 0.9 \mathrm{~m} \\
\text { for wheelchair \& } \\
1.2 \mathrm{~m} \text { for tricycle }\end{array}$ & -- & -- \\
\hline & $\begin{array}{l}\text { Floor } \\
\text { surface }\end{array}$ & $\begin{array}{l}\text { Levelled and } \\
\text { cemented }\end{array}$ & OK & OK & $\mathrm{OK}$ \\
\hline & $\begin{array}{l}\text { Size of } \\
\text { courtyard }\end{array}$ & & $\begin{array}{l}\text { Minimum } 1.5 \mathrm{~m} \\
\text { X } 1.5 \mathrm{~m} \text { for } \\
\text { wheelchair \& } 2\end{array}$ & $\begin{array}{l}\text { OK. To allow } \\
\text { to park and } \\
\text { transfer to }\end{array}$ & -- \\
\hline
\end{tabular}




\begin{tabular}{|c|c|c|c|c|c|}
\hline Areas & Sub-areas & Description & $\begin{array}{l}\text { For wheelchair } \\
\text { users }\end{array}$ & $\begin{array}{l}\text { For floor } \\
\text { mobility } \\
\text { device users }\end{array}$ & $\begin{array}{l}\text { For walking } \\
\text { aids users }\end{array}$ \\
\hline & & & $\begin{array}{l}\mathrm{m} \times 2 \mathrm{~m} \text { for } \\
\text { tricycle }\end{array}$ & $\begin{array}{l}\text { ground } \\
\text { mobility device }\end{array}$ & \\
\hline & Bench & & -- & -- & $\begin{array}{l}\text { A seat or parcel } \\
\text { shelf may be } \\
\text { provided for rest } \\
\text { opportunities }\end{array}$ \\
\hline \multirow[t]{9}{*}{ In Door } & $\begin{array}{l}\text { House } \\
\text { entrance }\end{array}$ & Step free & OK & OK & $\mathrm{OK}$ \\
\hline & & With steps & $\begin{array}{l}\text { Ramp with } \\
\text { gradient less than } \\
1: 12\end{array}$ & $\begin{array}{l}\text { Ramp with } \\
\text { gradient less } \\
\text { than 1:12 and } \\
\text { handrails on } \\
\text { both sides of } \\
\text { ramp }\end{array}$ & $\begin{array}{l}\text { Handrails on } \\
\text { both sides of the } \\
\text { steps }\end{array}$ \\
\hline & & Door width & Minimum $0.8 \mathrm{~m}$ & -- & -- \\
\hline & & $\begin{array}{l}\text { Threshold } \\
\text { absent }\end{array}$ & $\mathrm{OK}$ & OK & OK \\
\hline & & $\begin{array}{l}\text { If threshold } \\
\text { present }\end{array}$ & $\begin{array}{l}\text { Lower than } \\
35 \mathrm{~mm}\end{array}$ & OK & $\mathrm{OK}$ \\
\hline & & & $\begin{array}{l}\text { Portable ramp on } \\
\text { both sides of } \\
\text { gradient } 1: 8 \text { with } \\
\text { a connected } \\
\text { landing of } 0.28 \\
\mathrm{~m}\end{array}$ & $\mathrm{OK}$ & -- \\
\hline & & & $\begin{array}{l}\text { alternatively a } \\
\text { threshold that } \\
\text { slides out be } \\
\text { provided }\end{array}$ & OK & OK \\
\hline & $\begin{array}{l}\text { Inside the } \\
\text { house }\end{array}$ & Dimension & $\begin{array}{l}\text { Internal } \\
\text { dimension of } \\
\text { living room to all } \\
\text { wheelchair } \\
\text { manouvering } \\
\text { space }\end{array}$ & -- & -- \\
\hline & & $\begin{array}{l}\text { Internal } \\
\text { mobility }\end{array}$ & $\begin{array}{l}\text { Doors absent } \\
\text { where privacy is } \\
\text { not required. No } \\
\text { thresholds on } \\
\text { internal doors }\end{array}$ & $\mathrm{OK}$ & OK \\
\hline
\end{tabular}




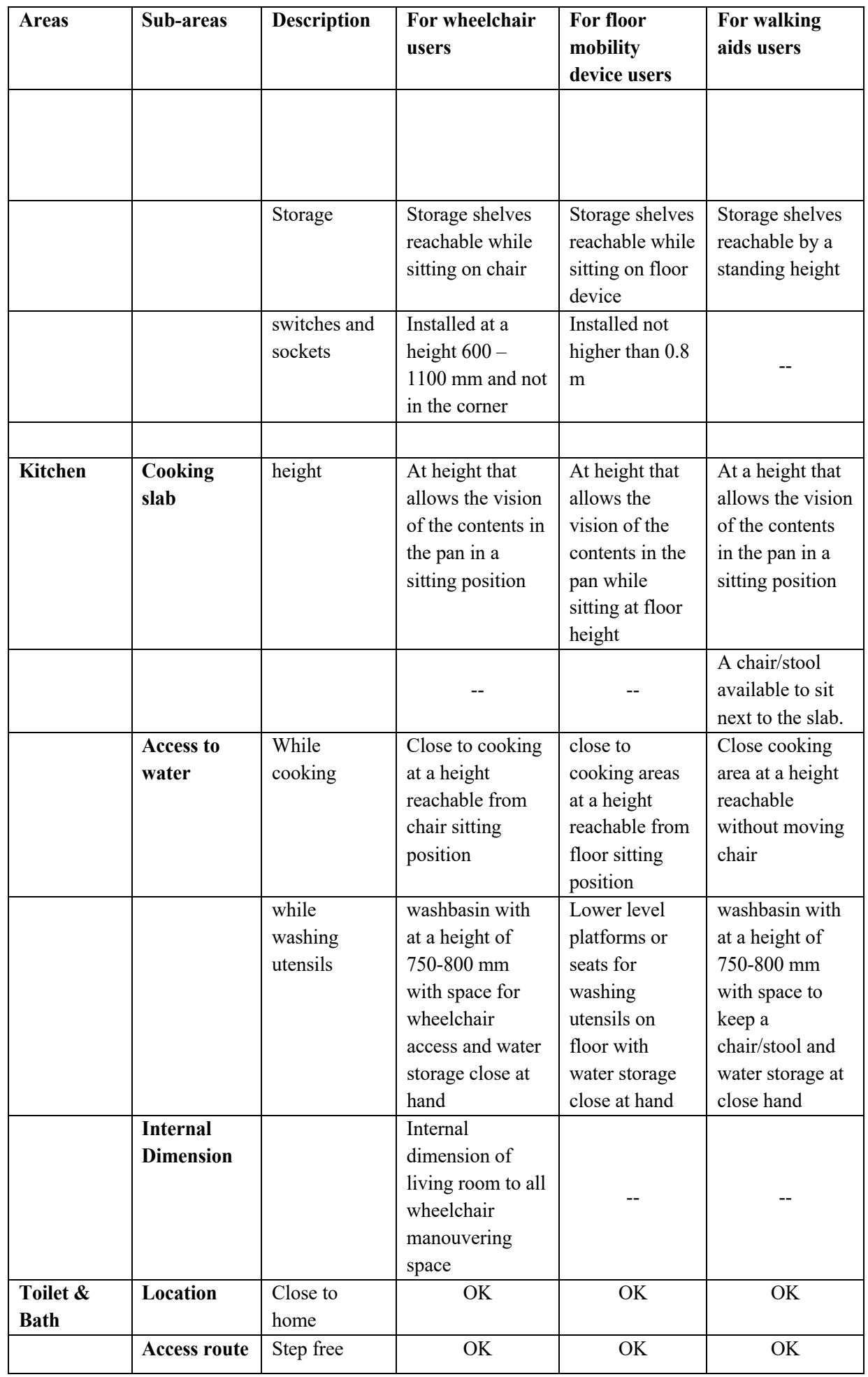




\begin{tabular}{|c|c|c|c|c|c|}
\hline Areas & Sub-areas & Description & $\begin{array}{l}\text { For wheelchair } \\
\text { users }\end{array}$ & $\begin{array}{l}\text { For floor } \\
\text { mobility } \\
\text { device users }\end{array}$ & $\begin{array}{l}\text { For walking } \\
\text { aids users }\end{array}$ \\
\hline & & With steps & $\begin{array}{l}\text { Ramp with } \\
\text { gradient less than } \\
1: 12\end{array}$ & $\begin{array}{l}\text { Ramp with } \\
\text { gradient less } \\
\text { than 1:12 and } \\
\text { handrails on } \\
\text { both sides of } \\
\text { ramp }\end{array}$ & $\begin{array}{l}\text { Handrails on } \\
\text { both sides of the } \\
\text { steps }\end{array}$ \\
\hline & & cemented & OK & $\mathrm{OK}$ & OK \\
\hline & & $\begin{array}{l}\text { Covered } \\
\text { drains }\end{array}$ & OK & $\mathrm{OK}$ & OK \\
\hline & & $\begin{array}{l}\text { Minimum } \\
\text { width of } \\
\text { pathway }\end{array}$ & & $\begin{array}{l}\text { Minimum } 0.9 \\
\mathrm{~m} \text { for } \\
\text { wheelchair \& } \\
1.2 \mathrm{~m} \text { for } \\
\text { tricycle }\end{array}$ & -- \\
\hline & Toilet room & $\begin{array}{l}\text { Internal } \\
\text { Dimension }\end{array}$ & $\begin{array}{l}\text { Internal } \\
\text { dimension of } \\
\text { living room to all } \\
\text { wheelchair } \\
\text { manouvering } \\
\text { space }\end{array}$ & -- & -- \\
\hline & & Door width & Minimum $0.8 \mathrm{~m}$ & -- & -- \\
\hline & & $\begin{array}{l}\text { opening } \\
\text { outwards }\end{array}$ & OK & OK & OK \\
\hline & & $\begin{array}{l}\text { Door handle } \\
\text { and lock }\end{array}$ & $\begin{array}{l}\text { Reachable from } \\
\text { chair sitting } \\
\text { height. D-shaped } \\
\text { handle preferred. }\end{array}$ & $\begin{array}{l}\text { Reachable from } \\
\text { floor sitting } \\
\text { height. D- } \\
\text { shaped handle } \\
\text { preferred. }\end{array}$ & $\begin{array}{l}\text { Reachable from } \\
\text { standing height. } \\
\text { D-shaped handle } \\
\text { preferred. }\end{array}$ \\
\hline & & $\begin{array}{l}\text { Threshold } \\
\text { absent }\end{array}$ & OK & $\mathrm{OK}$ & OK \\
\hline & & $\begin{array}{l}\text { If threshold } \\
\text { present not } \\
\text { higher than } \\
0.15 \mathrm{~m} \text { and } \\
\text { bevelled }\end{array}$ & OK & $\mathrm{OK}$ & OK \\
\hline & & Floor finish & Cemented & OK & OK \\
\hline & & & Well drained & OK & OK \\
\hline & & & Non-slip & OK & OK \\
\hline & & $\begin{array}{l}\text { Indian style } \\
\text { toilet seat }\end{array}$ & $\begin{array}{l}\text { Provide a bench } \\
\text { of chair with a } \\
\text { hole }\end{array}$ & OK & $\begin{array}{l}\text { Provide a bench } \\
\text { of chair with a } \\
\text { hole }\end{array}$ \\
\hline & & $\begin{array}{l}\text { Western style } \\
\text { toilet seat }\end{array}$ & OK & -- & $\mathrm{OK}$ \\
\hline
\end{tabular}




\begin{tabular}{|c|c|c|c|c|c|}
\hline Areas & Sub-areas & Description & $\begin{array}{l}\text { For wheelchair } \\
\text { users }\end{array}$ & $\begin{array}{l}\text { For floor } \\
\text { mobility } \\
\text { device users }\end{array}$ & $\begin{array}{l}\text { For walking } \\
\text { aids users }\end{array}$ \\
\hline & & $\begin{array}{l}\text { Location of } \\
\text { seat }\end{array}$ & $\begin{array}{l}\text { Located against } \\
\text { the wall diagonal } \\
\text { from the entry } \\
\text { door with center } \\
\text { line of toilet } 450 \\
\text { to } 500 \mathrm{~mm} \text { from } \\
\text { the wall }\end{array}$ & -- & $\begin{array}{l}\text { Located against } \\
\text { the wall } \\
\text { diagonal from } \\
\text { the entry door } \\
\text { with center line } \\
\text { of toilet } 450 \text { to } \\
500 \mathrm{~mm} \text { from the } \\
\text { wall }\end{array}$ \\
\hline & & $\begin{array}{l}\text { Grabrails to } \\
\text { support in } \\
\text { transferring } \\
\text { or standing }\end{array}$ & $\begin{array}{l}\text { Grabrails } 200 \mathrm{~mm} \\
\text { above toilet seat }\end{array}$ & $\begin{array}{l}\text { Grabrail } 200 \\
\mathrm{~mm} \text { above } \\
\text { floor height }\end{array}$ & $\begin{array}{l}\text { Vertical grabrail } \\
\text { fixed on wall } \\
\text { next to the seat } \\
\text { to help in } \\
\text { standing from } \\
\text { sitting position }\end{array}$ \\
\hline & & $\begin{array}{l}\text { Water storage } \\
\text { at arms } \\
\text { distance from } \\
\text { seat }\end{array}$ & OK & OK & $\mathrm{OK}$ \\
\hline & $\begin{array}{l}\text { shower } \\
\text { seat/bench }\end{array}$ & $\begin{array}{l}\text { shower } \\
\text { seat/bench } \\
\text { height }\end{array}$ & $\begin{array}{l}\text { Height } 0.45-0.50 \\
\mathrm{~m}\end{array}$ & At floor height & $\begin{array}{l}\text { Height 0.45- } \\
0.50 \mathrm{~m}\end{array}$ \\
\hline & & $\begin{array}{l}\text { Clothes hook } \\
\text { and toiletry } \\
\text { shelf }\end{array}$ & $\begin{array}{l}\text { reachable while } \\
\text { sitting on bench }\end{array}$ & $\begin{array}{l}\text { reachable from } \\
\text { floor height }\end{array}$ & $\begin{array}{l}\text { reachable while } \\
\text { sitting on bench }\end{array}$ \\
\hline
\end{tabular}


\$ 
Chapter 6

Discussion \& Conclusion 
This chapter presents a discussion correlating the findings of the four earlier chapters to provide a comprehensive answer to the main research question guiding this thesis: To what extent do persons with disabilities who require support for daily living activities and mobility perceive being able to live with autonomy in their daily lives? In summary, the findings of the research show that persons with disabilities who require support for daily living activities and mobility perceive having no autonomy in the way they undertake these activities. To get a more holistic understanding of the situation this research addresses the main question from four different perspectives by investigating: the existing legislative framework; the perceptions of persons with disabilities; the perceptions of their primary caregivers; and, finally, ways of reducing the amount of human support persons with disabilities require in their daily lives.

Elaborating on the first perspective, we looked at the legislative frameworks of four Asian countries for disability-specific support provisions in those countries by addressing the question, How have national legislative frameworks for support services operationalised the $U N C R P D$ ? Disability-related support was defined using the capability approach and seen as a pre-condition for persons with disabilities to overcome to some extent their disability and convert the resources available to them into opportunities (Sen, 1999). The analysis of the national legislations of the four countries in question (India, Philippines, Nepal and South Korea) is given in chapter two of this thesis. It showed that, while the UN CRPD sees support services as a pre-condition to the inclusion of persons with disabilities, with the exception of South Korea, which has a robust legislation for support services, the national legislations in the countries reviewed do not see them as a pre-requisite. One of the main inadequacies identified in the legislations of all the countries reviewed was the limited way of looking at eligibility for support services. All countries have two levels of eligibility tests for receiving government-managed support services. At the first level the individual has to be recognised 
as being a person with disabilities. Here the analysis suggests that, while the definition of disability used in legislation is based on the UN CRPD, the evaluation process continues to focus on loss in functionality in isolation, that is, without considering the other social, economic or environment circumstances of the individual. At the second level, factors including whether the person with disabilities has a family, the income of the family and the severity of the disability are assessed. In all four countries, a second-level eligibility assessment is used to decide who is eligible to receive government-aided and -managed support services. The challenge is that the legislation does not address support services for persons who meet only the first level of eligibility criteria. Furthermore, except in South Korea, the various legislations in the first instance put the entire responsibility of providing support to the disabled person on the family, with any government-support mechanism available only in the absence of the family, even for adults with disabilities. Thus, by making the family primarily responsible for support, the existing support services legislation fails to offer any choice and control to persons with disabilities.

The second perspective concerned the perceptions of persons with disabilities. This was dealt with in chapter three by addressing the question, What are the perceptions of persons with disabilities living in rural areas of the challenges they face in their daily lives?

The analysis showed that persons with disabilities are trapped in a 'vicious circle of worthlessness' as a result of the different internal and external factors they experience. These factors result from their being dependent on family for daily living activities, something which makes them feel like burdens on their families. The sense of being a burden is amplified due to the poverty that exists in rural India where the families face additional challenges associated with poverty. Moreover, not being able to reciprocate the support they receive makes them feel more worthless, isolating them without capabilities to build social capital and ensuring they remaining fully dependent on the family. As a result persons with 
disabilities 'adapted their preferences', a phenomenon described in the capability approach, by adapting their self-image and desires to conform with the negative social norms and customs that exist in the community, resulting in hopelessness and a fatalistic attitude (Sen, 2009; Trani et al., 2011; Nussbaum, 2013). However, persons with some level of education reported different experiences, feeling better able to reciprocate and so to be included and respected by their family and community. The capability approach, unlike the social model of disability that focuses only on external barriers, allows account to be taken of the internal strife experienced by a person in addition to the external factors. This enables an understanding to be gained of how external factors reinforce the internal impressions the individuals have of themselves (Mitra, 2006; Burchardt, 2010).

Closely linked to the perceptions of persons with disabilities are the perceptions of their family caregivers. We studied those by addressing the question: What are the perceptions of the family caregivers of the challenges they face in providing care and support to the disabled family member? Our analysis showed that women who were entrusted with the caregiving responsibility, in addition to many other home and family responsibilities, feel physical, economical and mental stress resulting from giving care to the disabled family member. The capability approach suggests that the lack of recognition of the care work as 'real' work makes women providing care invisible to the point where they are often considered a means for others (husband, children, in-laws) to achieve their goals (Nussbaum, 2006). Disempowered and unable to have their worth recognised, they have no choice or control over whether to take on the responsibility of providing care. While many women feel overwhelmed with the responsibility of caregiving and at times are in want of external support to accomplish the task, there are no support options available in the community: it is felt that the community considers providing support for daily living activities to be a 'dirty' task. Thus, women caregivers are overworked and lack agency to catalyse any change in their 
lives or in the lives of those they care for (Nussbaum 2006; Sen, 1999). Since women caregivers cannot take decisions about the amount of care they provide and when they provide it, they are not able to allocate specific times to care provision and instead provide care only when they are free or sparingly between other tasks. As a result, persons with disabilities do not receive the amount of support they require and have to regulate their requirements to those times when their caregivers are available for them.

Since building human support structures would require fundamentally changing the basic outlook of the community towards disability and support provision, in this thesis we adopted an alternate approach in search of more pragmatic strategies. We looked at ways of decreasing the level of dependency faced by persons with disabilities by addressing the following question: What can be done to improve the physical home environments and mobility devices for people with disabilities to increase their mobility and independence? The analyses showed that the mobility devices that persons with disabilities in rural areas have, which are mostly given to them by the government or non-governmental organisations, are not suitable for indoor mobility at home, thus doing little to reduce their physical dependence on the family. Moreover, home accessibility is not an aspect that is considered when homes are built, whether that be through government-aided schemes or by non-governmental organisations. Given the complex on-the-ground realities of rural persons with disabilities, in this chapter we explore a small part of the problem by providing examples of several interventions that are required by developing a simple tool for community-based workers to improve the indoor mobility of persons with disabilities by adapting their home environment to the mobility device they have.

\section{Synthesising the findings}

According to the UN CRPD, having adequate and appropriate support is a right for persons with disabilities that must be seen as a pre-requisite for their inclusion in the community (UN 
Committee on the Rights of Persons with Disabilities, 2017; UN OHCHR, 2017). The support available to them must enable them to live with dignity and have personal autonomy on an equal basis with others in their family and community (UN Committee on the Rights of Persons with Disabilities, 2017; UN OHCHR, 2017). The research reported in this thesis suggests that this support is not yet available for disabled persons living in rural India. Persons with disabilities and their families, who are their primary support providers, do not consider it a right for persons with disabilities to have access to this support. Existing literature on disability in India suggests that, traditionally, persons with disabilities who require a higher level of support are not required to earn a living for themselves, but rather are expected to live with their family, which is responsible for their wellbeing (Miles 2002; Ghai, 2002; 2015). Such an understanding is instilled in the traditional beliefs that having a disability or having a disabled person in the family is an outcome of bad deeds, and the suffering of the person with disabilities and of their family members due to the impairment represents karmic justice (Miles 2002; Ghai, 2002; 2015; Grech, 2015). This thesis adds to this existing understanding by introducing the impact of karmic justice on the support that is available to persons with disabilities. As a result of existing social beliefs, persons with disabilities and their families consider getting additional external support to be a sin that will interfere with their karmic retribution (Chapters $3 \& 4$ ). Such beliefs have existed for centuries and are thoroughly internalised by persons with disabilities, their families and the community at large, none of whom believe that any change is required to improve their situation. Thus there is a discrepancy in the way support for persons with disabilities is perceived: on the one hand, the UN CRPD sees the availability of disability-specific support as a right, while, on the other, persons with disabilities, far from considering it as their right, feel indebted for the support they receive, the family sees providing support to the disabled person as a way of cleansing their past sins, and the community does not identify with the 
issue and remains outside the karmic cycle of the family and the disabled person. As a result of being completely dependent on their family for survival creates a charitable perception towards support for persons with disabilities and thus, the primary challenge in enshrining support for persons with disabilities as a right is the existing discrepancy in the way it is perceived by the different stakeholders.

Furthermore, the literature suggests that persons with disabilities living in rural areas are isolated and they live in mere 'survival mode'. This has been linked adequately to poverty (Ghai, 2002; Grech, 2015; Yeo \& Moore 2003). In this thesis, we additionally link this situation to the lack of support available to persons with disabilities. The fact that persons with disabilities are not expected to earn and to become contributing members of the family devalues them, which in turn has an impact on the support available to them. Support is seen as being important only for their basic survival and not associated with enabling them to work or to lead more fulfilling lives. The patriarchal structure of the society, where women are expected to provide care for the old, young and disabled members of the family, and have little say in the matter, makes availability of services even more sparse (Ghosh \& Banerjee, 2017; Ugargol \& Bailey, 2018). This research suggests that women continue to provide care to the disabled family member despite themselves experiencing physical and mental stress and social segregation (Gupta, Rowe \& Pallai, 2009; Nussbaum, 2013; Ugargol \& Banerjee, 2018). As a result, not only are they overburdened with other responsibilities but often feel resentment for having to look after a disabled family member, particularly one from their husband's family (Chapter 4). Moreover, they have no agency in the matter and to be socially accepted must continue providing care to the disabled family member (Chapter 4).

Surprisingly, the policy review suggests that, while culturally women are expected to provide care, there is no recognition of this in legislation (Chapter 2). The findings suggest that this condition of women has a negative impact on the support that is available to a person with 
disabilities, who receives support only when a female caregiver finds the time. This leads the person with disabilities to adapt their existence to the availability of the support, often with repercussions for their health (Chapters $3 \& 4$ ). Therefore, while the UN CRPD requires disability-specific support to be offered to persons with disabilities to enable them to have more choice in and control over their lives, the reality is that the support available to them is adequate only for mere survival (Chapters $3 \& 4$ ). There is a need to actively consider the support for persons with disabilities as an issue closely related to feminism, and address it as such, as this research, validating the capability approach, suggests that increasing the agency of the women of the family would improve the quality of support received by persons with disabilities (Chapter 4; Sen, 1999).

Finally, this thesis scrutinises the new disability legislation in India that came into force in 2016 with a focus on its application to support services. To have a broader understanding of legislative harmonisation with the CRPD legislations addressing support services from four countries including India were studied. What seems common is that the legislations, including that of India, seem to harmonise with the UN CRPD but fall short of addressing disability support as a right (Chapter 2). With the exception of that of South Korea, according to the legislations government responsibility for developing and providing support is limited to cases where persons with disabilities are living in poverty or where they do not have a family. In South Korea, in contrast, the government recognises that all persons with a certain severity of disability require disability-specific support to live independently and that it must be made available to them. Persons with disabilities are means-tested to assess their eligibility for receiving government aid. As a result, the government not only offers financial support to persons with disabilities below a certain income threshold, but also engages in the development of a market ecosystem where different kinds of support services 
are available, thus ensuring that the legislative framework addresses the support requirements of all persons with disabilities.

Furthermore, in India the legislative framework reinforces existing cultural norms and practices that require the family to take lifelong responsibility for and provide care to a person with disabilities. Coupled with the fact that support services are poverty-targeted, rather than directed to all disabled persons, this makes these services seem to be charitable activities. Such an outlook does not guarantee disabled persons access to appropriate and adequate support services, thus denying them the right to live with dignity and exercise autonomy in undertaking their daily living activities.

The impact of not considering disability support for undertaking daily living activities as a right and as a prerequisite for inclusion is felt not just in the way human support is provided but also in the way mobility is addressed. Persons with disabilities are not able to exercise autonomy in terms of personal mobility and the existing literature suggests that the mobility devices provided to them by the government are sparingly used and often abandoned (Planning Commission of India, 2013). The current research suggests that persons with disabilities in rural India have little indoor mobility as a result of the inaccessibility of their home environment, coupled with the unsuitability of the provided mobility devices for rural homes (Chapter 5). This makes persons with disabilities more dependent on the family and also makes supporting them more difficult as they often have to be physically lifted. In an effort to reduce the dependency experienced by the persons with disabilities, in the context of this research a tool has been developed to adapt the home environment to the mobility devices that persons with disabilities have in rural India, thus enabling them to have better indoor mobility and to become more independent. 


\section{Reflecting on the methodology}

To gain in-depth insights into the lives of persons with disabilities a qualitative research methodology was adopted in this thesis. Different qualitative research techniques were used in different chapters to answer different questions. In chapter two, document analysis of the relevant primary legislation was undertaken. The scope of the document analyses was not limited to reviewing only the legislation from India but expanded to other countries to get a better perspective of how the legislations address support services in their respective regions and also to extract good practices from different countries. To investigate the documents an analytical framework based on the capability approach was used. Having a well-defined analytical framework based on a priori theory helped to make the inter-country analyses more plausible and focused (Giacomini, 2010). While the research gave significant findings, it might be argued that the review would have benefitted from the inclusion of an Asian country closer in economic status to India and with formal support services mechanisms in place. However, the difficulty with this argument is that there are no such countries in the region, since support services legislation exists largely in high-income countries. The scope of the legislative investigation here was limited to primary legislation and did not delve deeper into implementational aspects of the law. We addressed aspects of the impact of the legislation by correlating the understanding of support services gained from the legislation review with the perceptions and on-the-ground realities of persons with disabilities in the real world. Further research to investigate the implementational challenges of the legislation with respect to the specific barriers to implementation that exist in different countries is suggested.

Chapters three and four gathered the perceptions of persons with disabilities and the perceptions of those who provide support within their families respectively, by using the indepth semi-structured interviews technique. The technique is popularly used to gather the perspectives of persons in an unrestricted manner (Kelly 2010) and indeed for this research it 
was appropriate. One challenge that was faced was that the researcher did not speak the language of the respondents. Thus, the interviews were conducted with the support of an interpreter who was familiar with the environment and the context. Moreover, having a local person as the translator proved to be beneficial specially because it made the respondents more comfortable about sharing their life experiences (Green \& Thorogood, 2004). The research had a limited scope and was confined to persons meeting certain eligibility criteria from three villages in one district. These results may be considered as being valid not only for the small area where fieldwork was conducted but for all the rural parts of the country as the social structures and cultural beliefs towards persons with disabilities are consistent throughout these rural areas, and as a result the support structure remains the same. It is also noted that the provision of support services is a matter for individual states, a fact that could result in differences in the provision of mobility devices and in the value of the disability pension. But considering there is no difference in the manner in which these are provided, namely driven by a 'charity' approach to support services, this fact would not make any significant difference to the findings if this research was replicated in the rural parts of other states of the country.

Chapter five addresses the barriers faced by persons with disabilities while using their mobility devices in a given environment. We used document analyses followed by field visits to verify the data collected from the documents. The combination of the two methods was useful as not only were few documents available on the topic but also their content did not reflect fully the actual on-the-ground realities of the homes of persons with disabilities in rural areas. The limitations of this research include, first, the tool developed is specific to houses in a certain geographic location. Since the design of houses may differ in other locations, there may be a need to adjust the tool to suit local designs. Secondly, the range of mobility devices that presently are available to disabled persons living in those regions is not 
large and the devices do not necessarily address mobility for all users. The tool is dependent on the mobility devices available and also limited to what is presently available.

\section{Theoretical reflections}

The capability approach (CA) was used for theorising the analysis in this research. As an approach that provides a detailed ideational framework that can be used in different domains of study such as economics, political science, and social science, and which addresses aspects such as poverty, rights, and social arrangement (Robeyns, 2005; 2005b; Sen 2009), it gave us the flexibility to theorise the ideational framework in the context of this research. This flexibility enabled the findings to address personal and social situations and institutional setups in an inter-related manner. Moreover, being a theory used to define justice in the context of substantial freedoms that individuals have to lead a self-determined life, the approach echoes the UN CRPD in many abstractions, a feature that was beneficial for our work, which takes the UN CRPD as its starting point. Some of these notions have already been examined in this discussion. The most critical concept that made the CA suitable for this research is that it considers the equality of opportunities available to people to lead their lives in the way they would like as the main indicator for the evaluation (Sen, 1999). Thus, unlike the welfare approach, the CA does not look at wellbeing in terms of monetary provisions that are available to an individual but instead considers wellbeing in terms of the equality of opportunities and the freedom to choose from those opportunities that an individual has (Sen, 2009; Robeyns 2005b). In this thesis, we elaborate on the equality of opportunities and the freedom of choice in terms of the opportunities that persons with disabilities have to undertake their daily living activities with dignity and the agency they have to undertake these activities as and when they like, which is closely linked to the support available to them (Sen, 1999; 2009). 
The CA does not offer a prescribed format for analysing service provision or legislative frameworks. Since this research covers aspects such as the experiences of people and legislation, these may have been better analysed through the use of different tools or theories. However, the CA gave us a single, robust theory through which to approach the different interconnected concepts and to undertake a legislative review and an ethnographic study while keeping the focus throughout the investigation on the equality of opportunities for persons with disabilities. This unified and coherent focus significantly added to our findings.

\section{Conclusion}

Providing support to persons with disabilities in rural India is seen as a charitable action by the family and the community. Such an approach towards support is largely an outcome of the way disability and support are perceived through the lens of karmic justice, which holds the belief that the 'suffering' endured due to an impairment will wash away the past sins of the disabled person and their family. While this karmic belief is still widely prevalent in rural parts of the country, the charitable approach towards support for persons with disabilities is reinforced in the legislative framework that addresses support services only from the perspective of persons with disabilities living in poverty. The legislative framework also reinstates the common belief that family members are responsible for the wellbeing even of adults with disabilities and are expected to be the primary lifelong caregivers for the disabled family member.

As a result, and especially in rural India where poverty rates are high and all people, men and women alike, have to work hard to make ends meet, it is a struggle to provide 'adequate' and 'appropriate' support that goes beyond the basic survival needs of the persons with disabilities. Persons with disabilities, on the other hand, as they are fully dependent on their families, feel worthless and like a burden. The ramifications of this are that persons with 
disabilities live not only in a mere survival mode but adjust their daily living activities, including toileting and feeding, to the times when their family caregivers are available. The situation is compounded by the absence of adapted home environments and suitable mobility devices for indoor mobility. This lack increases the dependency experienced by disabled persons and makes the caregiving role more strenuous.

The existing literature has often made the link between rural persons with disabilities and poverty, suggesting that it results in their merely surviving. This research links such basic survival to inadequate access to the appropriate support that is required for them to become more independent and lead more meaningful lives. This leads to the conclusion that disabled persons in rural India will continue to live in 'survival mode' unless the amount and quality of support they receive improves. Making support more rights-based goes beyond merely providing enough 'care' to survive, to providing the 'support' that offers persons with disabilities a chance to live with dignity and agency. This transformation would require multiple interventions through the legislative frameworks and implementation mechanisms including:

1) Recognising support as a right of and a prerequisite for inclusion for all persons with disabilities;

2) Changing the perception of disability-related support amongst all stakeholders by looking beyond 'care' to provide the 'support' that offers more autonomy to the disabled person;

3) Developing more support structures in the community in addition to that of the family;

4) Addressing ways of reducing dependency through suitable assistive devices and improved accessibility. 
To summarise: India needs to shift from the 'care' paradigm, in which persons with disabilities need care to survive, to a 'support' paradigm that enables equalisation of the opportunities available to them.

\section{Implications for research}

This research shows that while India has ratified the UN CRPD and has taken steps to implement it, support services for persons with disabilities, especially for those living in rural India, far from being considered a right, continue to be considered a charitable endeavour. Reasons for this are numerous, and include:

- The inadequate social understanding of disability and the support required by disabled persons;

- The poor economic capacity of people in rural areas, which makes life particularly challenging for persons with disabilities and their families because of the effect on their daily wages of the 'care' that families are required to provide to the disabled family member;

- The inaccessibility of home environments and lack of assistive devices that could make disabled persons more independent;

- The unavailability of persons from within the community who could provide support;

- And, finally, a legislative framework that does not address support services from a rights perspective but rather reinforces negative social perceptions.

These findings have a number of implications for research, practice, policy and education, which are presented below.

\section{Involving the invisible}

To begin, the lived experiences of persons with disabilities living in rural communities are not similar to the experiences of the disabled persons living in urban areas, with the possible exception of urban slums, common in all Indian cities. Persons with disabilities from these 
areas are never consulted nor their voices heard, and as a result the way practices are approached or policy debated is based on the urban perspectives of rural needs, perspectives that fail to address their real concerns. Therefore, engagement of persons with disabilities from rural locations in decision-making processes organised by different stakeholders must be considered important. There is a vast gap in research, both quantitative and qualitative, that addresses the lives and needs of rural persons with disabilities. Such research is critical in order to frame the policies and practices developed by the government, the private sector or community initiatives. Considering education hubs are largely located in urban areas and attract limited numbers of students from rural areas, there is an urban perception of rural lives which is not always appropriate. Therefore there is a need to be sensitive to and provide a deeper understanding of differences between urban and rural settings. Rural visits and similar initiatives will help to better equip students to practice once they graduate.

\section{Rights-based approach}

Further implications arise from the finding of this research that disability has traditionally been viewed from a charitable perspective by Indian society and that these views are reinforced in the legislation. The charitable approach has been reinforced also in the way the legislation is implemented through the schemes and programmes that are meant to provide 'welfare' to persons with disabilities but not equality of opportunities. Such an approach in relation to support services limits them to offering support for basic survival only. Unless the approach shifts from 'welfare' to 'rights' by addressing equality of opportunities, persons with disabilities will continue to be passive recipients of 'care' and 'charity' and never become equal and contributing members of society. To bring about this change, one that is also required by the UN CRPD, a paradigm shift is needed in the way policies are designed, practices operate, education is provided and research is undertaken. Much more participatory research is required to contextualise the different articles of the convention in different 
regional, national and local settings, as attempted by this research, and then use insights from the findings of that research to redefine the existing legislation and practices. Education systems that reinforce professional authority in matters of disability, health and rehabilitation may consider adopting more of a supporting role that respects the choice and control of disabled people. Practitioners need to begin placing persons with disabilities at the centre of their practice and come to appreciate them as the experts they are in the matter of their own lives.

More specific to this research, a rights-based approach is required when looking at social protection mechanisms for persons with disabilities, especially since support services are closely linked to social protection. A social protection mechanism that does not include persons with disabilities universally but instead uses poverty-targeted methods for support services, not only denies the majority of disabled persons the right to access support services, but is also likely to have a negative impact on the development of those support services. Therefore, further research is also suggested to look at the impact on the development of a robust support services system of a policy of targeting support services provision only at poor persons with disabilities.

\section{Transforming communities}

The task of bringing about the required paradigm shift is challenged by the deep-rooted social and cultural beliefs that frame the community's perceptions of disability as a tragedy for the individual and for their family. It is a common belief that persons with disabilities are not capable of contributing but instead so as to live they require lifelong 'care' that must be provided by the family. That the family does not expecting any reciprocation from the disabled family member makes the person with disability seem like a burden to the family lowering the self-esteem of the disabled family member. The awareness that providing enabling 'support' and environments can transform them into contributing members is absent 
amongst all stakeholders including the persons with disabilities themselves. Finally, the community does not see itself as having a role to play in offering support, especially in daily living activities that are considered 'dirty tasks'. These beliefs, coupled with the general poverty and scarce public services that exist in rural areas, create a self-reinforcing cycle that denies any rights or even a basic standard of living to the disabled person. Breaking this circle is difficult unless perceptions are changed.

Bringing about change in deep-rooted perceptions is not easy and may require a multifaceted approach. To begin with, the education of persons with disabilities can influence community perceptions, something that was also identified in this research. However, education policies need to be pro-disability, in terms of providing equal access and reasonable accommodation for disabled students, especially girls with disabilities. There is scant research available into the education of persons with disabilities in rural areas, and even less on the support and environmental aspects required for their inclusion in rural areas and how that support and environment can be provided.

In terms of practice, presently there are meagre health and rehabilitation services available in rural areas. Government institutional structures presently operate at no lower than district level. Since districts are often large with the government facility being impossible to reach by the disabled person, persons with disabilities in rural areas are left with no government health or rehabilitation options close to them. That which is available is provided through the scantly located community-based rehabilitation programmes run by nongovernmental organisations. While these non-governmental organisations do important work, their reach is limited and their projects are often driven by the funds available rather than the requirements of people. Therefore, there is a need for the government to intervene and proactively develop and support the running of community-based rehabilitation services. Furthermore, these community-based interventions need to be as much focused on changing 
community perceptions as on working with persons with disabilities and their families. This is particularly important, as the support systems, especially in rural India, have to evolve from within the community and with community involvement, and in so doing counter the negative perceptions of the community. Without a transformation of these perceptions the development of support structures for disabled persons may well remain a challenge.

Finally, the goal is to make persons with disabilities more independent in different activities according to their choices. Achieving this requires a more integrated approach that looks at different aspects of independent living in a more holistic manner. For instance, this goal requires not only developing better support options but also looking at the environments of persons with disabilities and how they are able to operate their assistive devices in those environments. Unfortunately, in India environmental accessibility is considered only with respect to public spaces, completely ignoring the home environment both in legislation and in practice. Moreover, assistive devices are also considered in a similar charitable light, as being only for poor persons with disabilities. Further research is required to contextualise the integrated approach to independent living in the context of rural India; the results of this research should then guide any future strategy to implement the UN CRPD that presently remains far from being accomplished.

\section{References}

Burchardt, T. 2004. "Capabilities and Disability: The Capabilities Framework and the Social Model of Disability". Disability \& Society 19(7): 735-751. DOI. $10.1080 / 0968759042000284213$

Ghai, A. 2002. "Disability in the Indian context: Post-colonial perspectives.” In Disability/ postmodernity: Embodying disability theory, edited by M. Corker and T. Shakespeare, 88-100. London: Continuum.

Ghai. A. 2015. Rethinking Disability in India. New Delhi: Routledge.

Ghosh, N. \& Banerjee, S. (2017). Too Much or Too Little? Paradoxes of Disability and Care Work in India. Review of Disability Studies Journal, 13 No.4. 
Grech, S. 2015. Disability and Poverty in the Global South: Renegotiating Development in Guatemala. London: Palgrave Macmillan.

Green, J. \& Thorogood, N. (2004). Qualitative Method for Health Research. London: Sage Publications Limited.

Gupta, R., Rowe, N., Pillai, V.K. (2009). Perceived caregiver burden in India. Journal of Women and Social work. Vol. 24:1, Page 69-79.

Kelly, S.E. 2010. “Qualitative Interviewing Techniques and Styles.” In The Sage Handbook of Qualitative Methods in Health Research, edited by I, Bourgeault, R. Dingwall, and R. De Vries, 307 - 325. London: Sage Publications Ltd

Giacomini, M.(2010). Theory matters in qualitative health research. In The Sage Handbook Qualitative Methods in the health research, eds. I. Bourgeault, R. Dingwall, R. De Vries, 125 -156. London: Sage Publications Ltd.

Miles, M. (2002). Community and individual responses to disablement in South Asian histories: Old traditions, new myths?. Retrieved March 2018, from https://www.independentliving.org/docs3/miles2002a.html

Mitra, S. 2006. “Capability approach and disability." Journal of Disability Policy Studies. 16(4), 236 - 247. DOI: 10442073060160040501

Nussbaum, M. (2006). Frontiers of Justice: Disability, Nationality, Species Membership. Cambridge, UK: Belknap Press.

Nussbaum, M. (2013). Creating Capabilities - The Human Development Approach. Ranikhet, India: Permanent Black.

Planning Commission of India. 2013. Evaluation Study on The Scheme of Assistance to Differently Abled Persons for Purchase/Fitting of Aids/Appliances (ADIP). December 2013. Accessed 10 January 2018.

http://planningcommission.gov.in/reports/peoreport/peo/eva_adip1501.pdf

Robyens, I. 2005. Assessing Global Poverty and Inequality: Income Resources and Capabilities. METAPHILOSOPHY. Vol. 36, Nos. 1/2. DOI:10.1111/j.14679973.2005.00355.x

Robyens, I. 2005b. The Capability Approach: a Theoretical Survey. Journal of Human Development, 6:1, 93-117.

Sen, A. K. 1999. Development as Freedom. Oxford: Oxford University Press.

Sen, A. K. 2009. The idea of justice. Cambridge: Harvard University Press. 
Terzi, L. (2009). Vagaries of the Natural Lottery? Human Diversity, Disability and Justice: A Capability Perspective. In Brownlee, K. \& Cureton, A. (eds.), Disability and Disadvantage. Oxford University Press. pp. 86--111 (2009)

Trani, J. F., Bahkshi, P., Bellanca, N., Biggeri, M., Marchetta, M. 2011. “Disabilities through the Capability Approach Lens: Implications for Public Policies.” ALTER - European Journal of Disability Research. 5(3), 143-157. DOI: 10.1016/j.alter.2011.04.001

Ugargol, A. P. \& Bailey, A. (2018) Family caregiving for older adults: gendered roles and caregiver burden in emigrant households of Kerala, India. Asian Population Studies, 14:2, 194-210, DOI: 10.1080/17441730.2017.1412593

UN Committee on the Rights of persons with disabilities. General comment No. 5 (2017) on living independently and being included in the community. 27 October 2017. $\mathrm{CRPD} / \mathrm{C} / \mathrm{GC} / 5$

United Nations Office of High Commisioner of Human Rights (UN OHCHR) (2017). Report of the special rapporteur on the rights of persons with disabilities, $\mathrm{A} / \mathrm{HRC} / 34 / 58,24$ February 2017. Retrieved May 2017, from http://ap.ohchr.org/documents/dpage_e.aspx?si=A/HRC/34/58

World Health Organisation (2002). Current and Future Long-Term Care Needs. WHO/NMH/CCL/02.2. Retrieved online: http://www.who.int/chp/knowledge/publications/ltc_needs.pdf

Yeo, R., \& Moore, K. (2003). Including disabled people in poverty reduction work: nothing about us. without us. World Development, 31, 571-590. 


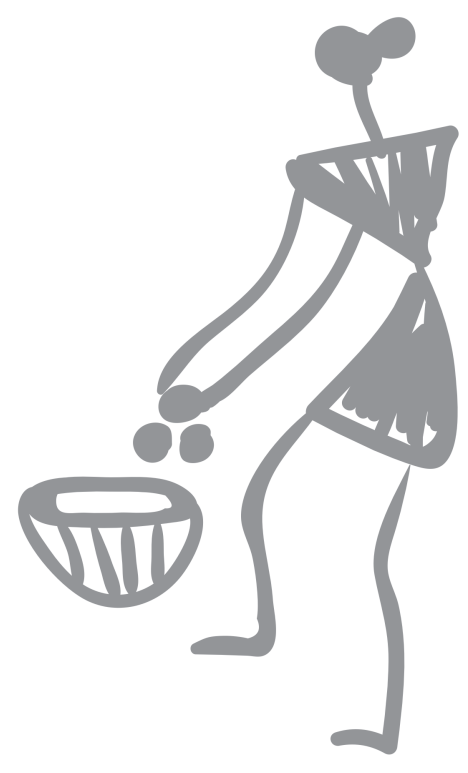


Appendices 



\section{Valorisation}

This research concludes by highlighting the continued isolation and segregation experienced by persons with disabilities in rural India who live in a survival mode. They have no choice or control over their lives as a consequence of the complex interaction between different factors that may be either internal to their personality or external to their social, political, infrastructural environment. Therefore, improving their situation is not easy and it requires action in different domains by different actors. In this chapter, I provide some thoughts about the direction that could be taken by the government, non-governmental organisations and organisations of persons with disabilities, private businesses and rehabilitation professionals to improve the situation. These recommendations are based on the Indian perspective but also may be useful for other low and middle-income countries in Asia who face challenges in realising the rights of persons with disabilities.

The focus of this research is on the support services that are available to persons with disabilities to have autonomy in undertaking their daily living activities, which, according to the United Nations Convention on the Rights of Persons with Disabilities (UN CRPD), is a right of persons with disabilities. This means that countries who have ratified the UN CRPD are obliged to promote and provide support services to all its citizens with disabilities. An evaluation of the legislative frameworks relating to support services of four countries in Asia including India (chapter 2) reflected on some good examples that countries have taken in the direction of operationalising the UN CRPD. For instance:

- All the countries reviewed use a broad definition to define persons with disabilities. Such definitions are based on the UN CRPD and conceptualise disability as a social construct and focus on the barriers faced by a person with disabilities that result in their unequal participation. Such a focus requires looking at solutions for removing barriers and 
providing the preconditions for the participation of persons with disabilities such as support services and accessibility.

- In Nepal, the classification of disabilities defines the eligibility to receive government aid for support services. This classification is based on the functioning of the person to undertake daily activities and participate in social activities. Therefore, eligibility to receive government-aided support services looks at wider aspects of the life of a person with disabilities and not just focus on the severity of impairment. However, the presence of additional eligibility criteria including poverty and the having a family limits access.

- According to the South Korean legislation all persons with disabilities are eligible to receive support services. They are means-tested to decide on the amount of aid they will receive from the government. Aid is in the form of vouchers that persons with disabilities can use to buy services from the provider of their choice. Such a model promotes the development of support services in the community and also offers choice and control to the service users. However, eligibility criteria to receive government aid focus on the severity of impairment and not on functioning.

- Indian legislation has introduced caregivers allowance as a social protection measure. While the allowance is poverty targeted and therefore few persons with disabilities can benefit from it, such an allowance recognises the time and effort spent in caregiving and is useful to compensate for it. However, legislation that looks at the family as the main caregiver can be restrictive to both the families and the persons with disabilities.

- The Philippines legislation has a provision of providing training to families to support and care for the disabled family member. Such training can equip the families to perform these responsibilities more efficiently and also have better outcomes of care and support for persons with disabilities. However, here again, it is presumed that only the family would provide care and support. 
These are some concrete directions for support service provision that countries have adopted, but there is yet a lot to achieve. Support services in low and middle-income countries like India remain under-developed and inadequate. Therefore, legislative amendments are important to be undertaken that address support services as a 'right' that makes it a state's obligation to create a formal support services system in the country that gives persons with disabilities access to paid support.

\section{Legislative amendments recommended}

Legislation relating to support services may have two critical but interrelated directions. First, ensuring that all persons with disabilities are eligible to access support services. Second, creating a demand for formal support services in the country. Presently, the poverty targeted approach that the government has towards providing support services not only restricts the number of persons who have access to these services but also shrinks the demand for them dampening the chances for developing formal support services systems. The perceived role of the family as the main caregivers also reduces the chances of developing formal support services.

One way of tackling this situation is by reviewing the eligibility mechanism that the country follows. Restricting eligibility to poverty or those without a family not only restricts the number of persons with disabilities who can access support services but also weakens the possibilities of creating a robust support services system in the country. As a result persons with disabilities who are not eligible not only do not get any government aid for support services but also are unable to get services through self-payment. In such a situation the right of persons with disabilities to have access to support services is denied. 
Therefore, it is suggested that India may consider means testing as a way of deciding eligibility to receive government aid for support services, similar to the system in South Korea. In this way, the legislation recognises not only the right of all persons with disabilities, which is in line with the UN CRPD, but such a process can also create a large demand for support services that are required to boost service providers and create a market of support services where persons with disability not eligible for government aid can at least pay and get good quality support services.

Equally important is how the legislation describes support providers and caregivers. Presently, it is the family who is seen as being responsible for providing care and support to the disabled family member. Such provisions in the law reinforce the existing social norms towards disability and prevent the idea of formal support services from thriving in the community. Therefore, the legislation must not restrict care and support as a family responsibility but recognise that persons other than the family can provide care and support to disabled persons.

A change in the legislative framework would warrant the involvement of different actors to ensure a smooth and adequate supply of formal support services that address the variety of support persons with disabilities require. There are three main directions recommended with a role for different actors to achieve these directions.

\section{Aligning the legislation, policies and schemes with the UN CRPD}

According to the UN CRPD, the government has the primary responsibility of ensuring access to a range of support services that allow persons with disabilities to live. To enable this the first step they need to undertake is bringing legislative provisions in the directions suggested above, in consultation with persons with disabilities and their organisations and other actors engaged in service provision. With a formal support services system in place, 
they would be required to set standards for support services, regulate and monitor the services.

Since bringing such change in a large country like India is not easy, it may be important to maximise the resources available by becoming disability-inclusive. For instance, while the primary legislation needs amendments, equally the existing schemes and programmes must be more disability-inclusive. In this regards, schemes like the National Rural Employment Guarantee Act, 2005 may be reviewed to see whether it is possible to include formal support providers, such as personal assistants, as one of the employment options under the scheme. The scheme for assistive devices (ADIP) may ensure that the assistive and mobility devices provided to persons with disabilities support them to undertake daily living activities independently and enable them to use mobility devices inside their homes as well. The rural housing schemes run by the government to ensure homes built under the scheme are universally designed, and the scheme budget allocates funds towards adapting the house to individual requirement.

\section{Raising awareness and training}

In this frame, several actions are recommended for the government. First, increasing community sensitivity and awareness towards disability and disability support. For this, organisations of persons with disabilities already working in the grassroots may take a leading role. Existing community-based programs are already involved in awareness-raising. However, efforts by these programs may be in the frame of independent living for which adequate and appropriate support is a pre-requisite.

Training of rehabilitation professionals in a rights-based perspective is equally important. There is a need for rehabilitation and habilitation service providers to have the 
training and develop skills to evaluate environmental accessibility of homes, workspaces and neighbourhoods of persons with disabilities to enable them to have better mobility and functioning. Awareness-raising is as much required of community members as it is for the disabled persons and their families. Therefore, besides awareness-raising of the rights of persons with disabilities, content relating to the role of support services and enabling environments may be included in school curriculums and the curriculums of all professional training.

An existing challenge, however, is that rehabilitation services are available only till the district level, thus there is a big gap in the existing rehabilitation services. Since community-based programs are few in the country, to have an all country effect there is a need for the government to strengthen these community-based programs by increasing their geographical reach to be uniformly available across the country. One key action that may be taken to enable this is by expanding the rehabilitation services that presently are restricted to the district level to the village level.

\section{Involving private businesses}

Considering that India is a large and a high population country, the support services to fulfil the demand may not be adequate if only offered by the public sector. Therefore, engaging with the private sector to ensure the availability of support services in all parts of the country may be required. To enable this the government needs to encourage the private sector to create support services options by increasing the demand that makes it attractive for the private businesses to invest and by supporting the development of formal support services by having enabling policies.

Private businesses can benefit from capitalising on the demand for support services by creating market support services options that persons with disabilities can use. Persons with 
disabilities may pay for these services either from government aid or self-fund. To do this the private businesses may work in collaboration with the government, rehabilitation institutes and organisations of persons with disabilities. For instance, consultation with the organisations of persons with disabilities can help them provide businesses developing support services to understand and respond to the range of support services required by different persons with disabilities. Such organisations can also support them in training the workforce who would provide this support.

Finally, the private businesses can play a leading role in collaboration with other actors to undertake a bottom of the pyramid approach in the innovation of independent living and mobility devices that are culturally and environmentally appropriate for use by persons with disabilities living in rural India. 



\section{Summary}

Introduction - 'Invisible lives - Tales of persons with severe disabilities living in rural India' focuses on looking at the choice and control persons with severe disabilities have in undertaking daily living activities. This is achieved by investigating the daily lives of persons with disabilities and the support that they have to undertake daily living activities. The research also looks at the legislative framework in India about support services, which is important considering that having adequate support is seen as a basic right for persons with disabilities according to the united nations convention on the rights of persons with disabilities (UN CRPD) that India has ratified. The research ends by looking at creating a more enabling environment that reduces the level of dependence that persons with disabilities experience as one way of increasing the choice and control they have over their lives. The research uses the capability approach (CA) as the theoretical framework because it focuses on the equality of opportunities that people have to lead a life they value, which is closely aligned with the UN CRPD. With equality of opportunities being of main importance makes support services a pre-requisite for persons with disabilities to access equal opportunities. Furthermore, having the agency to decide how one lives their own life or influences another person's life is at the heart of the CA, that provided a frame to articulate 'choice' and 'control'. These are the key underlying concepts of this research.

Chapter 2 analyses the primary legislation for support services for persons with disabilities in four Asian countries including India, Philippines, Nepal and South Korea. The purpose of the investigation was to recognise from the different country legislations the common trends of addressing and providing support services according to the UN CRPD. A framework developed using the capability approach considered three aspects of support services provision: first, the eligibility for receiving support services; second, the agency of persons with disabilities in the way services are offered; third, the role of the family in the support 
services provision according to the law. The results show that the eligibility criteria were linked to poverty and did not consider the other personal, social and environmental factors that enhance the barriers faced by persons with disabilities. The results also show that the agency of persons with disabilities was not considered in the way support services provided and thus neither did the support services increase their participation nor did it give them a say in deciding the kind of service they wanted. Finally, the legislation considered the family as being responsible for providing support without considering the additional efforts they put in for supporting the disabled family member. The findings suggest that there some efforts made to harmonise the legislations with the UN CRPD but much more needs to be achieved. The findings also suggest that support services are not seen as a right in most countries and are restricted to being a poverty targeted social security mechanism that expects the family to support the disabled family member.

Chapter 3 shifts the focus from the legislative documents to looking at the perspectives of persons with disabilities living in rural India towards the challenges they face in their daily lives. The chapter uses the capability approach to look into the factors both internal and external that can limit or increase the agency of an individual. The research shows that for persons with severe disabilities in rural areas these factors prevent them from influence the choice and control they have to live a self-determined life. The research presented in this chapter highlight internal factors such as low self-esteem and low level of education of the individual and external factors such as negative societal perception towards disability and inaccessible environments that result in their extreme dependency on the family in the absence of support options in the community. This pushes persons with disabilities into a circle of 'self-worthlessness' making them have low self-esteem, internalising the community perception of disability and not expecting any change in the situation. The chapter concludes by suggesting reducing the dependency they face by working towards changing community 
perceptions towards disability and creating better support structures and environmental accessibility as the way forward.

Chapter 4 looks more closely at the existing support structures that are available to persons with disabilities in rural India. Support presently is provided mostly by the women of the family who are the primary caregivers. The chapter focuses on the experiences and challenges of these caregivers of providing care to the disabled family member. The chapter aims to understand the well-being and agency of the caregivers. The research suggests that the lack of agency amongst women caregivers left them with no options or choice in terms of taking the responsibility of providing care to the disabled family member in addition to all other activities. This left them overworked with little time at hand for caregiving apart from impacting their physical and mental health and social participation. Most often they had to forego daily wages for this, putting them at an economic disadvantage and also reducing their worth within the family. As a result of lack of agency of the women caregivers, the lives of persons with disabilities is impacted and has poor outcomes for both the persons with disabilities who have no control on when they undertake their daily living activities, are dependent on the availability of their primary caregiver and live in a survival mode. The research suggests that the negative perception towards disability and caregiving devalued the women caregivers further. Aspects of care provision by women must be addressed in the policy framework and taken on in feminist debates.

Chapter 5 looks at the physical home environments of persons with disabilities in relation to the mobility device they have to design a tool that can be used by non-technical community workers to assess the barriers in the physical infrastructural of homes and the mobility devices that the persons with disabilities. The chapter has this focus as the earlier chapters highlighted on the need for persons with disabilities to be more mobile and less dependent on 
their caregiver for daily activities. The tool in the form of a checklist enables identification of barriers and provides suggestions of ways of attuning the different aspects of the homes of persons with disabilities with their mobility device to allow them indoor home mobility. There is a dearth of literature in this area and the tool contributes to little literature available. The chapter discusses that presently the mobility devices provided by the government to persons with disabilities are not suitable for use within rural homes. Therefore, newer designs of mobility devices may be developed, produced and distributed through the assistive devices scheme and additionally homes built in rural areas with government aid must ensure indoor accessibility for persons with disabilities.

Chapter 6 provides discussion and conclusions based on the final synthesis of the findings from the different chapters. The book concludes by suggesting that as a result of the negative social perceptions towards disability, support services in rural India are seen from a a charitable approach to be provided by the family. This is often reinforced by the legislation in different ways. As a result, persons with disabilities are fully dependent on their families for daily living activities and feel worthless. Their dependency is compounded by the absence of enabling environments and mobility devices. This underlines the need to address support services as a right by shifting the focus from that of providing 'care' to survive to one that provides 'support' to enable persons with disabilities to lead a more autonomous life. Finally, the chapter provides implications for further research, practice, policy and education, in three aspects. It does so in three areas. First, it highlights the need to include persons with disabilities from rural India in to the debates and planning. Second, it emphasis the need to adopt a rights-based perspective in all areas of work and lastly it suggests the need of looking at ways of transforming the communities to become more inclusive and accessible to persons with disabilities. 


\section{Acknowledgements}

Having a Doctoral degree is a dream come true for me! Many people have supported me in fulfilling this dream, to whom I am most grateful.

To begin with, I would like to thank Dr. Agnes Meershoek and Prof. dr. Luc de Witte without whom this would not have been possible. I couldn't have asked for better mentors, as not only did they give me the freedom to design my research, but they also helped me to comprehend different routes to reach my aim. The marked improvement I see today in my comprehension, analytical skills, research design and planning is all attributed to their capable guidance.

I am very thankful to all the respondents who allowed me to record their experiences for this research. I acknowledge the support of Mr Dasarath and his team from the Rural Development Trust, India for helping me to connect with the respondents and in coordinating interviews.

I am most indebted to Hellen Heutz, Angelique Heijnen and Kyra Kramer from the Department who supported and addressed several of my academic and even non-academic requirements during the past four years. They handled all of my extraordinary requests like getting a standby wheelchair when mine broke, organising an accessible taxi on days when public transport was not available, and so on. The comfort of being able to approach them for the smallest of requirements made my stay in Maastricht most comfortable.

I am grateful to Lori Mees, Scholarship and Alumni Coordinator, who was very receptive to my disability-related reasonable accommodation requirements. She located an accessible hotel close to the Department during my first visit to Maastricht when student accommodation for international students was not accessible. She was also most supportive in coordinating the extra cost for my personal assistant from the NUFFIC. 
Related to accommodation, I also acknowledge the efforts of Maurice

Evers, Managing Director - Student \& Staff housing, Studenten Service Centrum (SSC), who responded to the gap for International students and organized the reconstruction of an accessible room at the students accommodation at Annadal.

Finally, I would like to thank my friends, family and colleagues who have been instrumental in my being able to tread this path. Most importantly, I would like to acknowledge the support of my personal assistant, Amarmani aka Ritu who has silently stood behind me at each step of this journey. 


\section{Author Details}

Shivani Gupta was born on December 23, 1969, in Delhi, India. Upon completion of highschool in 1988 from Welham Girls School Dehra Dun India she went to the Institute of Hotel Management, Delhi India and got a Diploma in Hotel Management in 1991. She started working at the ITC Maurya Hotel soon after, however, a road traffic accident that made her a tetraplegic, propelled her to change her area of work.

Attending a Training of Trainers on Non-Handicapping Environments for Persons with disabilities and older persons organised by the United Nations in 2000 in Bangkok, opened a new area of interest for her. She quit her job as a peer counsellor at the Indian Spinal Injuries Centre, where she worked after her rehabilitation from 1996 to 2002 and joined the Rai University, Delhi NCR, India for a Diploma in Architecture Technology to gain more knowledge in the area of accessibility in built environments. Soon after in 2004 she moved to the United Kingdom to pursue a Masters in Inclusive Environments Design and Management from the University of Reading, UK. Upon completion, she started a consultancy called AccessAbility for enabling the inclusion of persons with disabilities especially through creating environments that are universally designed. She has worked as a consultant since 2006 with various agencies including the government, non-government and $\mathrm{UN}$ agencies in India and other countries.

An urge to develop better research skills and to gain better insights into the lives of persons living in rural India drew her to the University of Maastricht, Netherlands for a doctoral programme for which she secured a NUFFIC fellowship.

Shivani presently lives in India. 



\section{(1.}
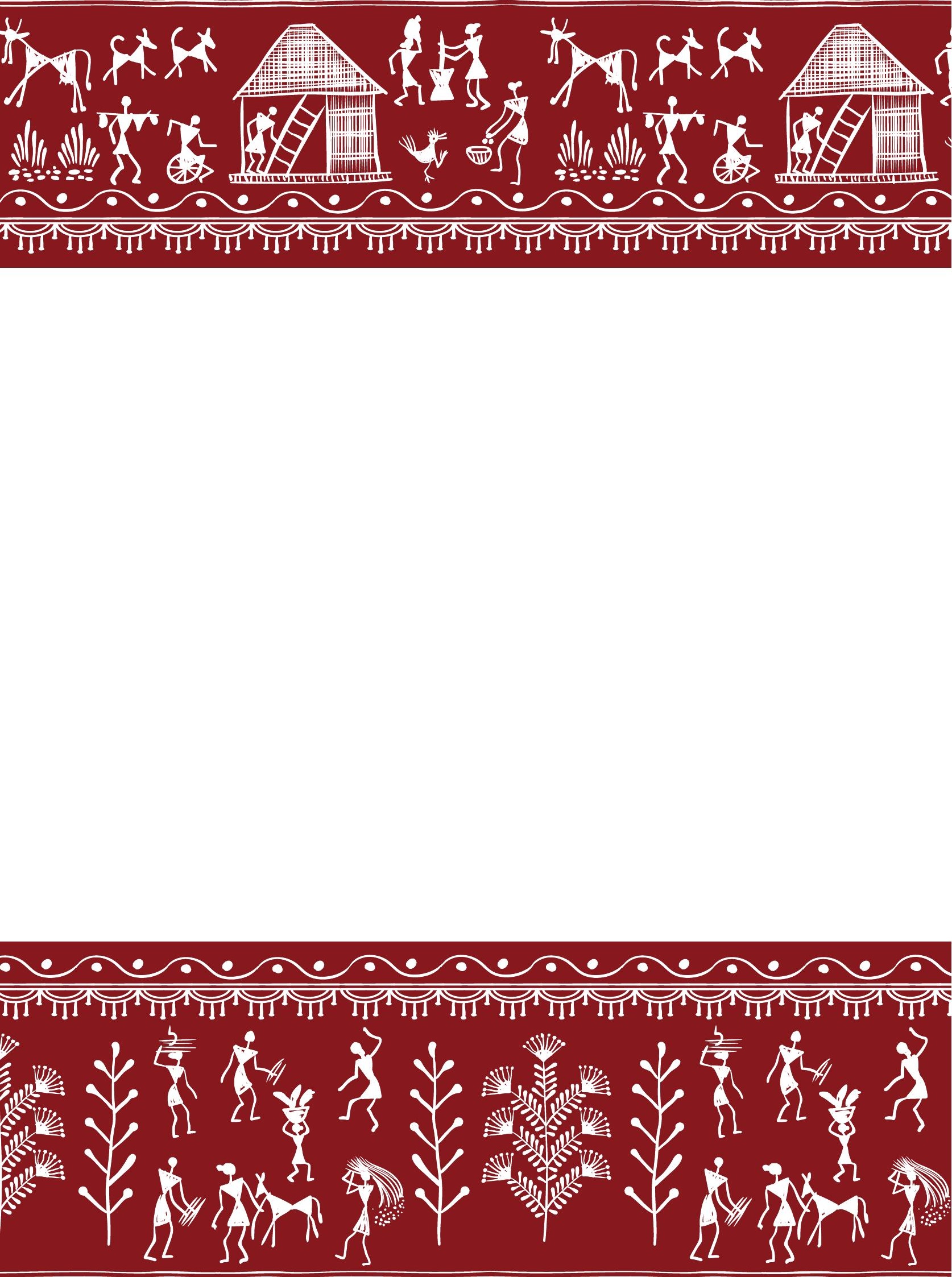

6. 